\title{
INHERITANCE OF COTYLEDON, SEED-COAT, HILUM AND PUBESCENCE COLORS IN SOY-BEANS ${ }^{1}$
}

\author{
C. M. WOODWORTH \\ University of Illinois, Urbana, Illinois \\ Received May 9, 1921 \\ TABLE OF CONTENTS
}

InTRODUCTION $\ldots \ldots \ldots \ldots \ldots \ldots \ldots \ldots \ldots \ldots \ldots \ldots \ldots \ldots \ldots \ldots \ldots \ldots \ldots \ldots \ldots$

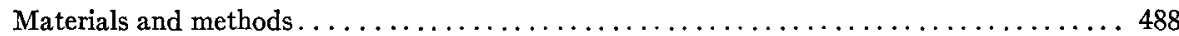

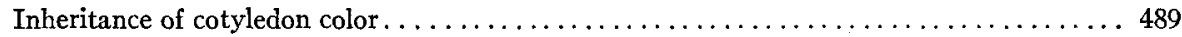

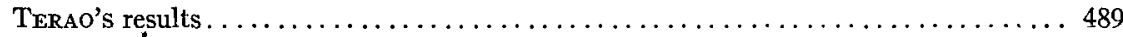

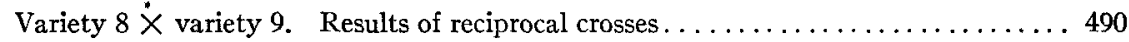

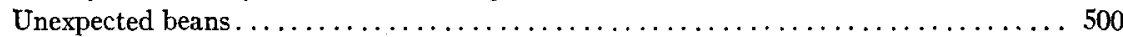

A soy-bean chimera . . . . . . . . . . . . . . . . . . . . . . . . . 503

Interpretation of inheritance of cotyledon color $\ldots \ldots \ldots \ldots \ldots \ldots \ldots \ldots \ldots \ldots \ldots \ldots, 504$

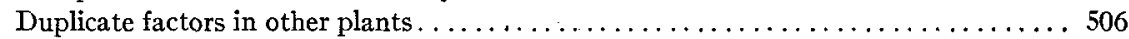

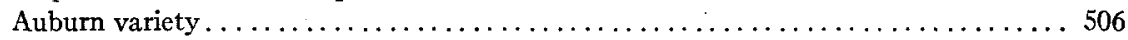

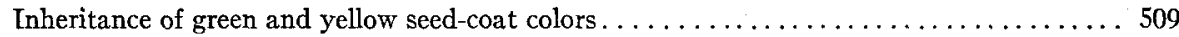

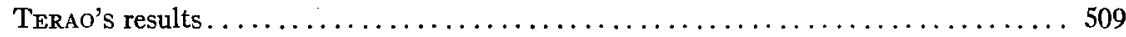

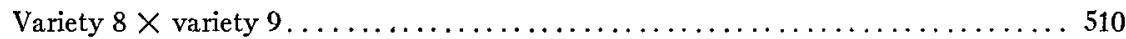

Relation between cotyledon and seed-coat colors . . . . . . . . . . . . . . . . 510

Inheritance of hilum color $\ldots \ldots \ldots \ldots \ldots \ldots \ldots \ldots \ldots \ldots \ldots \ldots \ldots \ldots \ldots \ldots \ldots \ldots \ldots \ldots$

Inheritance of pubescence color $\ldots \ldots \ldots \ldots \ldots \ldots \ldots \ldots \ldots \ldots \ldots \ldots \ldots \ldots \ldots \ldots \ldots \ldots \ldots 517$

Linkage between hilum and pubescence colors $\ldots \ldots \ldots \ldots \ldots \ldots \ldots \ldots \ldots \ldots \ldots \ldots \ldots \ldots 518$

Characters inherited independently $\ldots \ldots \ldots \ldots \ldots \ldots \ldots \ldots \ldots \ldots \ldots \ldots \ldots \ldots \ldots \ldots \ldots .522$

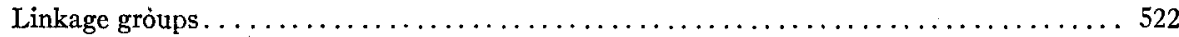

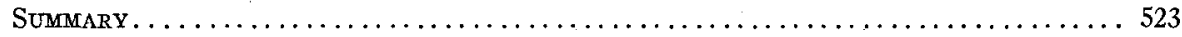

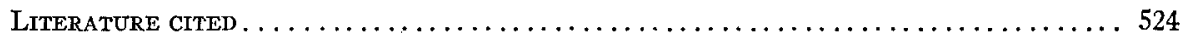

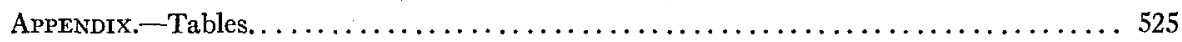

\section{INTRODUCTION}

All genetic studies thus far made on the soy-bean (Soja max) have been concerned with color characters. PIPER and MORSE (1910) noted segregation in some progenies in pubescence and seed-coat colors, though no definite hybridization experiments were conducted. TERAo (1918) reported the results of studies on the inheritance of cotyledon color and the relation of green and yellow seed-coat colors.

The soy-bean is especially favorable in some respects for genetic studies. There is a large number of differential characters exhibited by the many

1 Papers from the Department of Genetics, Agricultural Experiment Station, UNIVERSITY OF Wisconsin, No. 28. Published with the approval of the Drrector of the Station. 
now well-established varieties; and the plant sets seed abundantly, is self-fertile, and nearly always self-fertilized. The only difficulty encountered in conducting such studies on this plant is in making crosses, due to the small size of the flower; but after some practice, a fair degree of success is attained.

\section{MATERIALS AND METHODS}

In 1912 the Department of Genetics of the UNIVERsITY OF WIScONsIN started an experiment to determine the effect of selection within pure lines of soy-beans on the content and drying quality of the oil. When the writer entered the Department in 1914, this experiment was placed under his direction as well as certain genetic studies then in progress on varietal crosses in soy-beans. To Prof. L. J. Cole the writer is indebted for helpful criticism and inspiration which it is a pleasure to acknowledge.

Most of the varieties used in the pure-line selection experiment were obtained from the Agronomy Department of the WISCONSIN AGRICULTURAL Experment Station. Two of these bore the U. S. Seed and Plant Introduction numbers 20406 and 20854, and were given in our records numbers 8 and 9 , respectively. Variety 8 has white or gray pubescence on the stems, leaves and pods, and the hilum, seed coat, and cotyledons are yellow. Variety 9 has brown or tawny pubescence, the hilum is black, and the seed coat and cotyledons are green. The hybrid generations $F_{1}$ to $\mathrm{F}_{3}$ of reciprocal crosses (also $\mathrm{F}_{4}$ of cross variety $8 \quad \% \times$ variety $9 \sigma^{7}$ ) between these two varieties supply nearly all of the data presented in this paper.

Some additional data also are presented on the segregation of cotyledon color within the Auburn variety, S. P. I. No. 21079A, a sample of which was originally obtained from the U. S. DEPARTMENT OF AGRIculture. In the original sample as received, both types of cotyledons were found, though no differences were apparent in other seed characters, such as shape, color of coat, etc. Certain of these seeds, when tested, proved to be heterozygous for yellow cotyledon, and further study of their progenies furnished the data presented elsewhere in this paper.

The difficulty of making artificial crosses in the soy-bean is a real hindrance to the progress of genetic studies in this plant. In making crosses, it is necessary to remove the sepals and petals first, and then to remove the anthers with the point of a needle. In many cases the pistil is severely injured in this operation, and never recovers. Pollination is attended with difficulty, also, (1) because of the scanty supply of pollen in just the right stage of development, and (2) because of the difficulty of applying 
pollen to the stigmatic surface, which, instead of being upright on a straight style, is directed downward on a curved style. Artificial crossing in the greenhouse is even less successful than in the field because the flowers are usually smaller, and because of the greater scarcity of pollen.

As stated in the beginning, the soy-bean is nearly always self-fertilized. Natural hybrids are rare, but they do occur, as will be shown later in this paper. However, under ordinary field conditions and methods of plánting, the number of such hybrids is ordinarily negligible; and this number would likely be still more insignificant when the plants stand farther apart in the row, as was the case in the plantings for these studies. For this reason it was not deemed necessary to bag flowers of hybrid plants. All data, therefore, in the following pages, with the exception of crosses, are from plants grown from seeds which were not protected by bags from possible natural cross-pollination.

A word of explanation is necessary regarding the methods employed in calculating the biometrical constants given in this paper.

The probable errors of Mendelian ratios were calculated according to the formula $\pm .6745 \sqrt{p \times q \times n}$, where $n$ is the total number of individuals in the experiment, $p$ is the percent of one member of the ratio, and $q$ is the percent of the other member of that ratio. Thus, in a 3:1 ratio, $p=75$ percent (.75) and $q=25$ percent (.25); and in a $15: 1$ ratio, $p=93.75$ percent (.9375) and $q=6.25$ percent (.0625). The probable errors thus obtained were compared with the deviations of the actual numbers from those expected on the basis of the given ratio.

For tests of goodness of fit in cases where the number of classes was more than two, use was made of the method suggested by HARRIS (1912).

\section{INHERITANCE OF COTYLEDON COLOR}

\section{TERAO'S results}

TERAo (1918) described the types of cotyledon color, yellow and green, found in soy-beans. In his crosses, the cotyledon color of the hybrid progeny was the same as the female parent in every case, and there was no evidence of segregation in succeeding generations. This character was therefore stated to be maternal in inheritance.

To explain these results TERAo suggested that there were two kinds of chlorophyll represented by the two cotyledon colors; one which always remains green, and the other which changes to yellow on the ripening of the beans. The former was designated as $(G)$ and the latter as $(Y)$. If the female parent possessed $(G)$ or $(Y)$, the hybrid progeny, down at least 
to the $F_{3}$ generation, ${ }^{2}$ would have green or yellow cotyledons, respectively. As the inheritance thus appeared to be strictly maternal, and the male parent consequently could bring neither $(Y)$ nor $(G)$ into the hybrid, no form could be produced having both types of chlorophyll, and the probable relationship of $(Y)$ and $(G)$ in inheritance could not, therefore, be determined.

In the crossing experiments with soy-beans here reported cotyedon color was found to segregate regularly just as does seed-coat color or any other Mendelian character.

\section{Variety $8 \times$ variety 9. Results of reciprocal crosses}

Crosses between varieties 8 and 9 were made reciprocally in the summer of 1916 . Two hybrid seeds resulted from variety $9(q) \times$ variety $8\left(\sigma^{7}\right)$ and 8 from the reciprocal cross. All 10 beans had yellow cotyledons, thus indicating that, in this case at least, cotyledon color was not maternal in its inheritance. Rather it indicated that the same condition exists in soy-beans as in the garden pea; namely, that yellow cotyledon is dominant to green.

The two hybrid plants resulting from variety $9(9) \times$ variety $8\left(0^{7}\right)$ were given the progeny No. (471), and were numbered (471)-80 and (471)-81. They were grown in the field in the summer of 1917. The 8 hybrid plants resulting from variety $8(\%) \times$ variety $9\left(\sigma^{7}\right)$ were grown in the greenhouse in the early spring of 1917 , and were given the progeny No. (399). These plants were small and branchless, and bore few seeds. They were not harvested separately as were the $F_{1}$ 's of the reciprocal; hence the data are given as if from one plant only.

Beans produced by these $F_{1}$ plants showed segregation in cotyledon color. The data are given in table 1.

Plants B82a, (1235)-1, and 1234-1, data for which are included in table 1 , were natural hybrids between varieties 8 and 9 . These varieties were planted in 1918 in a plot by themselves and in such a way that the plants of one variety alternated in the row with those of the other. Such close planting gave opportunity for the branches of adjacent plants to intermingle and to be in contact, thus favoring natural crossing. Among the thousands of beans produced by plants of variety 9 (green cotyledons), 5 were found with yellow cotyledons. These were obviously the result of crossing with variety 8 . Three of these beans produced the hybrid plants mentioned above.

The aberrant ratios given by plants (471)-80 and (471)-81 (see table 1) were possibly due to the fact that many of the beans were not well matured.

2 Terao did not carry the investigation beyond the $F_{3}$ generation. 
The fall of 1917 was very unfavorable for the proper ripening of the seeds. Rainfall was excessive, and there was very little sunshine during the whole ripening period. Moreover, frost killed the plants before many of the last-formed pods were fully developed, and, in consequence, the seeds contained in them dried up and retained the green color of the cotyledons shown by all soy-beans prior to the ripening period.

The small number of beans produced by B82a and plants of (399) (see table 1) was due to their being grown in the greenhouse. B82a showed no segregation at all, but this is not surprising considering the small number of seeds produced. That this plant did not breed true will be shown later when the $F_{3}$ generation is considered.

TABLE 1

Cotyledon color in the $F_{2}$ generation. Data from all crosses, both natural and artificial.

\begin{tabular}{|c|c|c|c|c|c|c|}
\hline \multirow{2}{*}{ PEANT NUMBBER } & \multicolumn{2}{|c|}{ NUMEER SEED OBSERVED WITH } & \multirow{2}{*}{$\begin{array}{c}\text { DEviatron * } \\
\text { (Dev.) }\end{array}$} & \multirow{2}{*}{$\begin{array}{c}\text { PROBABLE } \\
\text { ERROR } \\
\text { (P.E.) }\end{array}$} & \multirow{2}{*}{$\frac{\text { Dev. }}{\text { P. E. }}$} & \multirow{2}{*}{ ACTUAE RATKO } \\
\hline & $\begin{array}{l}\text { Yellow } \\
\text { cotyledo: }\end{array}$ & $\begin{array}{l}\text { Green } \\
\text { cotyledon }\end{array}$ & & & & \\
\hline$(471)-80$ & $115 t$ & $28 t$ & 19 & 1.95 & 9.75 & $4.1: 1$ \\
\hline$(471)-81$ & $119^{\circ}$ & 16 & 8 & 1.89 & 4.23 & $7.4: 1$ \\
\hline (399) & 21 & 1 & 0 & 0.78 & $\longrightarrow$ & $21.0: 1$ \\
\hline $\mathrm{B} 82 \mathrm{~A}$ & 4 & 0 & 0 & 0.33 & - & - \\
\hline$(1235)-1$ & 51 & 7 & 29 & 1.24 & 23.39 & $7.3: 1$ \\
\hline$(1234)-1$ & 153 & 7 & 3 & 2.06 & 1.46 & $22.0: 1$ \\
\hline Total.... & 463 & 59 & 26 & 3.73 & 6.98 & $7.85: 1$ \\
\hline
\end{tabular}

* These deviations are figured on basis of a 15:1 ratio.

$\dagger$ These are corrected fgures. Original figures were 109 beans with yellow and 34 with green cotyledons. For explanation see text.

The peculiar and wide ratios shown by (1234)-1 and (1235)-1 (table 1) may also be due to difficulties and errors in classification, as the fall of 1919 was quite similar to that of 1917 , there being excessive rainfall and little sunshine. Such errors in judging phenotypes can only be checked up by the breeding test, which for these plants has not yet been made.

It must be admitted that the true nature of the inheritance of cotyledon color in the artificial crosses was not discerned from the $F_{2}$ ratios obtained in 1917. Nor, as will be seen later, did an $F_{3}$ generation grown in the same year aid at all in interpreting these ratios. It was not until data on progenies grown in $1918\left(F_{3}\right.$ of one cross, $F_{4}$ of the other) were secured, that it was possible to see the true state of affairs.

The importance of making back-crosses with the recessive type to separate phenotypically similar genotypes was fully appreciated, but crosses 
in soy-beans are very difficult to make, and if a successful cross is made after many trials and failures, only one, two, three, or at most four seeds are obtained. For these reasons, such test matings were not attempted, and resort was had to growing progenies from different plants separately and in as large numbers as possible.

In view of the above considerations, a large $F_{3}$ generation, particularly of one cross (variety 9 , green $o \times$ variety 8 , yellow $\sigma^{7}$ ) was grown in order to determine the meaning of the peculiar $F_{2}$ ratios. The number of plants grown and their parentage are given in table 2. More seeds of each cross were planted but many failed to germinate. The seeds with green coty-

TABLE 2

Showing the number, parentage, etc., of $F_{2}$ plants grown to produce the $F_{3}$ generation in cotyledon color.

\begin{tabular}{|c|c|c|c|c|c|}
\hline \multirow{2}{*}{ cross } & \multirow{2}{*}{ PARENT } & \multirow{2}{*}{$\begin{array}{l}\text { PROGENY } \\
\text { NROMBERS }\end{array}$} & \multicolumn{2}{|c|}{$\begin{array}{l}\text { NUMBER OF PLANTS } \\
\text { GROWN FROM }\end{array}$} & \multirow{2}{*}{ YEAR } \\
\hline & & & $\begin{array}{l}\text { Yellow- } \\
\text { cotyledon } \\
\text { seeds }\end{array}$ & $\begin{array}{l}\text { Green- } \\
\text { cotyledon } \\
\text { seeds }\end{array}$ & \\
\hline $\begin{array}{c}\text { Variety } 8 \text { (yellow) } 9 \\
\times \\
\text { Variety } 9 \text { (green) }{ }^{7}\end{array}$ & (399) & $(470)$ & 18 & 1 & 1917 \\
\hline $\begin{array}{c}\text { Variety } 9 \text { (green) } q \\
\times \\
\text { Variety } 8 \text { (yellow) } 0^{7}\end{array}$ & $\begin{array}{l}(471)-80 \\
(471)-81\end{array}$ & $\begin{array}{l}(801) \\
(803)\end{array}$ & $\begin{array}{c}(60) 61^{*} \\
56\end{array}$ & $\begin{array}{c}\text { (6) } 5^{*} \\
3\end{array}$ & $\begin{array}{l}1918 \\
1918\end{array}$ \\
\hline $\begin{array}{c}\text { Natural cross } \\
\text { Variety } 9 \text { (green) } \% \\
\times \\
\text { Variety } 8 \text { (yellow) } 0^{3}\end{array}$ & B82a & $(1233)$ & 4 & - & 1919 \\
\hline
\end{tabular}

* Corrected figures. For explanation see text.

ledons were especially poor in this respect, only 9 plants being raised from 32 seeds of this type planted, or 28 percent, as compared with a corresponding percentage of 83.0 for the yellow-cotyledon seeds. It was unfortunate that so few of the green-cotyledon plants could be tested by their progeny in this way, as such a test would have furnished a good check on the color classification of the beans of each parent plant.

The $F_{3}$-generation results were interesting for several reasons. In the first place, all plants but one from seeds with green cotyledons bred true for green (table 11). ${ }^{3}$ The exception was a plant which bred true for yellow. The bean from which this plant was grown was produced by plant

${ }^{3}$ Tables 11-53, inclusive, are given in the appendix. 
(471)-80, in 1917 , when, as previously stated, the conditions for properly maturing soy-beans were very poor. All the reliable data from breeding tests show that in soy-beans, green cotyledons are recessive to yellow. Hence, it is believed that the exception above mentioned was caused by an error in the classification, the cotyledons of the parent bean appearing green, but proving themselves to be yellow genetically. Had all the other green-cotyledon seeds of this plant been tested, and had this error been consistent throughout, as may be assumed, then approximately one-sixth, or 6 , of the beans classed as having green cotyledons would have behaved in the breeding test as yellows, and therefore, may be added to the yellow class and subtracted from the green. If this is done, the figures are 115 seeds with yellow and 28 with green cotyledons, or an actual ratio $\left(\mathrm{F}_{2}\right)$ of 4.1:1. These are the corrected figures for this plant given in table 1 .

TABLE 3

Showing relative proportion of the three types of $F_{3}$ yellow-cotyledon seed as indicated by the $F_{3}$ generation.

\begin{tabular}{|c|c|c|c|c|c|c|}
\hline \multirow{2}{*}{ TYPE OR F $F_{2}$ YEXLOW } & \multicolumn{4}{|c|}{ RATIOS IN SINCLE PROGENIES } & \multirow{2}{*}{ TOTAI. } & \multirow{2}{*}{$\begin{array}{l}\text { THEORETI- } \\
\text { CAL NUM- } \\
\text { BERS ON } \\
\text { BASIS } \\
\text { OF } 7: 4: 4 \\
\text { RATIO }\end{array}$} \\
\hline & $(470)$ & (801) & (803) & $(1233)^{*}$ & & \\
\hline Bred true $\ldots \ldots \ldots \ldots \ldots \ldots \ldots \ldots \ldots$ & 10 & 33 & 33 & 2 & 78 & 65 \\
\hline Segregated $15: 1 \ldots \ldots \ldots \ldots \ldots \ldots \ldots$ & 5 & 13 & 12 & 2 & 32 & 37 \\
\hline Segregated $3: 1 \ldots \ldots \ldots \ldots \ldots \ldots$ & 3 & 15 & 11 & - & 29 & 37 \\
\hline Total ............... & 18 & 61 & 56 & 4 & 139 & 139 \\
\hline
\end{tabular}

* Data from natural cross. Parent was B82A (table 1).

In the second place, the plants from $F_{2}$ yellow-cotyledon beans were of three types based on their breeding behavior; namely, a type breeding true for yellow, a type segregating in the approximate ratio of 3 yellow to 1 green, and still another type segregating in the approximate ratio of 15 yellow : 1 green, and there were about as many plants belonging to the first type as to both of the others. These results were such as one would expect on the theory of duplicate factors for cotyledon color. The full data from the cross and its reciprocal are presented in detail in tables 12,13, and 14, but are summarized in table 3.

The $F_{3}$ generation from the natural crosses (progeny 1233) consisted of only 4 plants, 2 of which bred true for yellow cotyledon and the other 2 showed segregation in an approximate 15:1 ratio. Individual counts on this progeny are given in table 15 (see appendix). These data conform closely to those secured from the artificial crosses. That no plants in this prog- 
eny gave 3:1 ratios is believed to be due to the small number grown, and not to an irregularity in genetic behavior.

Cotyledon color in the $\mathrm{F}_{4}$ generation, data for which are given in tables 16-34, was obtained only for the cross variety 8 , yellow, $+\times$ variety 9 , green, $\sigma^{7}$. Neither the reciprocal nor the natural crosses have as yet been carried beyond the $F_{3}$ generation.

Of the nineteen $F_{2}$ plants of this cross grown, ten bred true for yellow cotyledon. Only two of these ten plants produced any green-cotyledon seeds at all (table 14), and in each of these plants, (470)-78 and (470)-79, three seeds were found whose cotyledons appeared green, though it was doubtful whether they could be so called. Unfortunately, they could not be tested out, but many seeds with yellow cotyledons were tested and all were found to breed true for yellow. Similarly, many seeds of the other

TABLE 4

Cotyledon color in the $F_{4}$ generation. Progeny of yellow-cotyledon beans from plants giving $F_{3}$ ratio of 3 yellow: 1 green.

\begin{tabular}{|c|c|c|c|c|c|}
\hline PARENT & $|(470)-63|$ & $\frac{(470)-65}{(909)}$ & $\frac{(470)-72}{(913)}$ & TOTAL & $\begin{array}{l}\text { THEORETI- } \\
\text { CAL NUM- } \\
\text { BERS ON } \\
\text { BASIS } \\
\text { OF } 1: 2 \\
\text { RATIO }\end{array}$ \\
\hline $\begin{array}{l}\text { Bred true } \ldots \ldots \ldots \ldots \ldots \ldots \ldots \ldots \ldots \ldots \ldots \ldots \ldots \\
\text { Segregated, } 3: 1 \ldots \ldots \ldots \ldots \ldots \ldots \ldots \ldots \ldots \ldots\end{array}$ & $\begin{array}{l}3 \\
5\end{array}$ & $\begin{array}{r}6 \\
11\end{array}$ & $\begin{array}{l}6 \\
8\end{array}$ & $\begin{array}{l}15 \\
24\end{array}$ & $\begin{array}{l}13 \\
26\end{array}$ \\
\hline 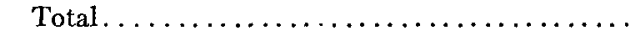 & 8 & 17 & 14 & 39 & 39 \\
\hline
\end{tabular}

eight plants were tested, and they also bred true for yellow cotyledon. Individual counts on these $\mathrm{F}_{3}$ plants are given in tables 24-33, inclusive.

Three $F_{2}$ plants, (470)-63, (470)-65, and (470)-72, as seen from table 14, gave approximate $3: 1$ ratios. Table 4 summarizes the results which are given in detail in tables 21, 22 and 23.

Actual results obtained and expected results are thus shown to be in close agreement.

Plants (470)-60, (470)-70, (470)-71, (470)-75 and (470)-77 gave very diverse and abnormal ratios (see table 14), but it is permissible to place them in the class segregating in a 15:1 ratio because of the progeny tests which are given in detail in tables 16-20. A summary of these results is given in table 5 .

The above progenies are comparable to those given in table 3 , as they are produced from yellow-cotyledon seeds borne by plants giving 15:1 ratios. Hence, the totals may be added together. When this is done, the grand totals are: 
Bred true for yellow cotyledon........................115; expected, 101

Segregated in $15: 1$ ratio $\ldots \ldots \ldots \ldots \ldots \ldots \ldots \ldots \ldots \ldots \ldots$;

Segregated in $3: 1$ ratio $\ldots \ldots \ldots \ldots \ldots \ldots \ldots \ldots \ldots \ldots \ldots, \ldots \ldots \ldots \ldots \ldots+$ expected, 57

$$
x^{2}=3.66 \quad P=.16185
$$

Figure 1 presents these totals graphically.

As might be expected, there was considerable variation in actual ratios among plants showing segregation into the two cotyledon colors. These ratios ranged from 1.73:1 to $24.0: 1$ but in general they grouped themselves about equally on either side of 3 and 15 , respectively. With few exceptions there was no trouble in placing a plant in the former or the latter class. There was one instance of overlapping of these two classes. Plant (470)-77 showed an actual ratio of $4.0: 1$, though the progeny test (table 17) proved it to belong to the $15: 1$ ratio class. This low ratio was slightly

TABLE 5

Cotyledon color in the $F_{4}$ generation. Progeny of yellow-coiyledon beans from plants giving $F_{3}$ ratio of 15 yellow: 1 green.

\begin{tabular}{|c|c|c|c|c|c|c|c|}
\hline PARENT... & $(470)-60$ & $(470)-70$ & $(470)-71$ & $(470)-75$ & $(470)-77$ & \multirow{2}{*}{ TOTAI } & \multirow{2}{*}{$\begin{array}{c}\text { THEORETS } \\
\text { CAL NUM- } \\
\text { BERS ON } \\
\text { BASIS } \\
\text { OE 7:4:4 } \\
\text { RATIO }\end{array}$} \\
\hline PROGENY NUMBERS ..... & (906) & (920) & (903) & (912) & (907) & & \\
\hline Bred true........ & 7 & 11 & 9 & 4 & 6 & 37 & 36 \\
\hline Segregated, $15: 1 \ldots$ & 4 & 3 & 2 & 6 & 3 & 18 & 20 \\
\hline Segregated, $3: 1 \ldots$ & 6 & 5 & 1 & 7 & 2 & 21 & 20 \\
\hline Total $\ldots \ldots \ldots \ldots \ldots$ & 17 & 19 & 12 & 17 & 11 & 76 & 76 \\
\hline
\end{tabular}

exceeded by plants (920)-54 and (915)-98 which belong to the $3: 1$ group but both of which showed an actual ratio of $4.08: 1$. That these plants belonged to the $3: 1$ ratio class is more than probable, particularly plant (915)-98, as its parent was a 3:1-ratio plant and as it was one of a progeny showing only two types (table 23), namely, plants breeding true for yellow, and plants segregating in a $3: 1$ ratio.

It is significant that the widest 15:1 ratios found were those given by plants grown in 1917. For example, plant (470)-60 gave a ratio of 24 yellow: 1 green; plant (470)-71, 5.3:1; plant (471)-80, 4.1:1, and plant (470)77 (above mentioned), 4.0:1. In the case of the first plant, there were only 3 green-cotyledon seeds out of a total of 75 , and it might be suspected that these were accidental mixtures and that the plant really bred true for yellow, were it not for the fact that the yellows, in the next generation, gave results (see table 16) which proved them to behave as the yellows of a 15:1 ratio. Similarly with regard to the other plants mentioned above, 
the actual ratio for each was "wide," but on the other side of 15 , being closer to a $3: 1$ than a $15: 1$; but, in the next generation, they gave results (tables 12, 17, 20) like those given by the yellows of plant (470)-60.

The variation in actual ratio shown by segregating plants of the $15: 1$ class is represented by the frequency table (table 6). The frequency polygon

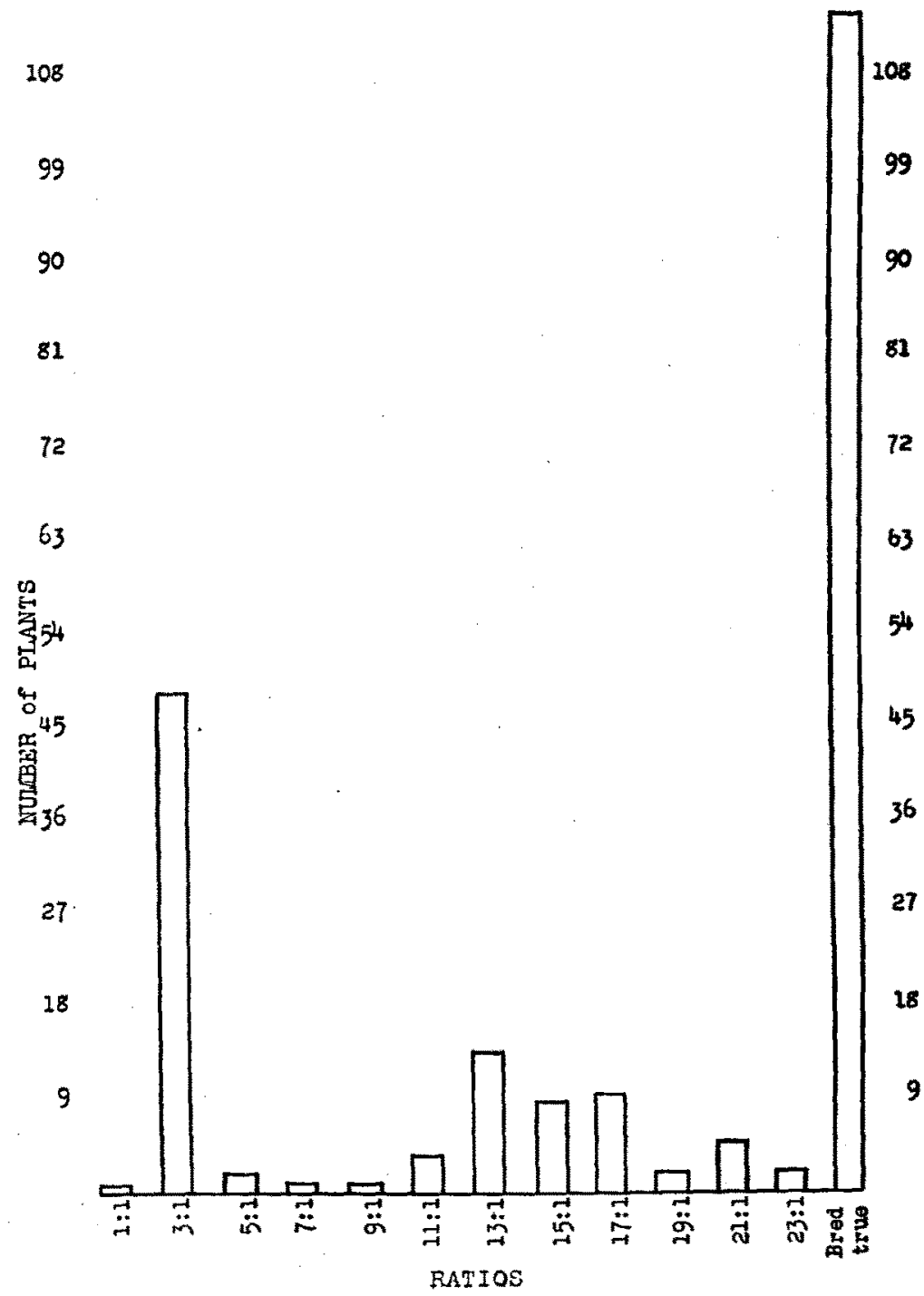

FrgURE 1.-Graphic representation of actual ratios obtained, showing tendency to fall into three groups; namely, (a) those breeding true for yellow; (b) those segregating in 15:1 ratio, and (c) those segregating in 3:1 ratio. Based on tables 3 and 5 combined. 
shown in figure 2 is based on the data given in this table. About two-thirds of the total number of plants are included in the three classes, the mid-values of which are the ratios $13: 1,15: 1$, and $17: 1$.

The actual ratios for the $3: 1$ class of segregating plants were much less variable than those for the 15:1 class. The range was from 1.73:1 to 4.08:1. The lowest ratio (1.73:1) was given by plant (470)-65, also grown in 1917. That this is only an aberrant 3:1 ratio is proved by progeny which the seeds with yellow cotyledons produced (table 22). Plants giving the highest ratio, 4.08:1, have been discussed above.

To show the variation of segregating plants (3:1 class) with respect to actual ratio, the following frequency table (table 7) has been prepared.

TABLE 6

Frequency distribution of segregating plants (15:1 class) with respect to actual ratio of yellow-to greencotyledon seeds.

\begin{tabular}{|c|c|c|c|}
\hline CLASS RANGE & MID-VALUE OF CLASS & $\begin{array}{c}\text { FREQUENCY } \\
\text { (NUMBER OP PLANTS) }\end{array}$ & PERCENT OF TOTAL \\
\hline $2.1: 1$ to $4.0: 1$ & $3: 1$ & 1 & 1.818 \\
\hline $4.1: 1$ to $6.0: 1$ & $5: 1$ & 2 & 3.637 \\
\hline $6.1: 1$ to $8.0: 1$ & $7: 1$ & 3 & 5.454 \\
\hline $8.1: 1$ to $10.0: 1$ & $9: 1$ & 1 & 1.818 \\
\hline $10.1: 1$ to $12.0: 1$ & $11: 1$ & 4 & 7.273 \\
\hline $12.1: 1$ to $14.0: 1$ & $13: 1$ & 14 & 25.455 \\
\hline $14.1: 1$ to $16.0: 1$ & $15: 1$ & 9 & 16.364 \\
\hline $16.1: 1$ to $18.0: 1$ & $17: 1$ & 10 & 18.180 \\
\hline $18.1: 1$ to $20.0: 1$ & $19: 1$ & 2 & 3.637 \\
\hline $20.1: 1$ to $22.0: 1$ & $21: 1$ & 7 & 12.727 \\
\hline $22.1: 1$ to $24.0: 1$ & $23: 1$ & 2 & 3,637 \\
\hline \multicolumn{2}{|c|}{ Total $\ldots \ldots \ldots \ldots \ldots \ldots \ldots \ldots \ldots$} & 55 & 100.000 \\
\hline
\end{tabular}

Fully two-thirds of the total number of plants are contained in the three classes the mid-values of which are the ratios 2.75:1, 3.0:1, and 3.25:1. The frequency polygon shown in figure 3 is based on data given in this table.

The $\mathrm{F}_{4}$ generation brought out two other instances of error in classification. In the first case, plant (470)-77, (see table 14), was noted as having produced 18 yellow- and 12 green-cotyledon beans. The progeny of this plant consisted of 12 plants, 10 of which were from seeds with yellow cotyledons, and 2 from seeds supposedly with green cotyledons. One of these 2 plants (907)-74, (table 17), segregated in cotyledon color, thus proving that the cotyledons of the parent seed were genetically yellow, though they appeared green. If, as may be assumed, one-half of the seeds of (470)-77 classed as having green cotyledons are considered as really 


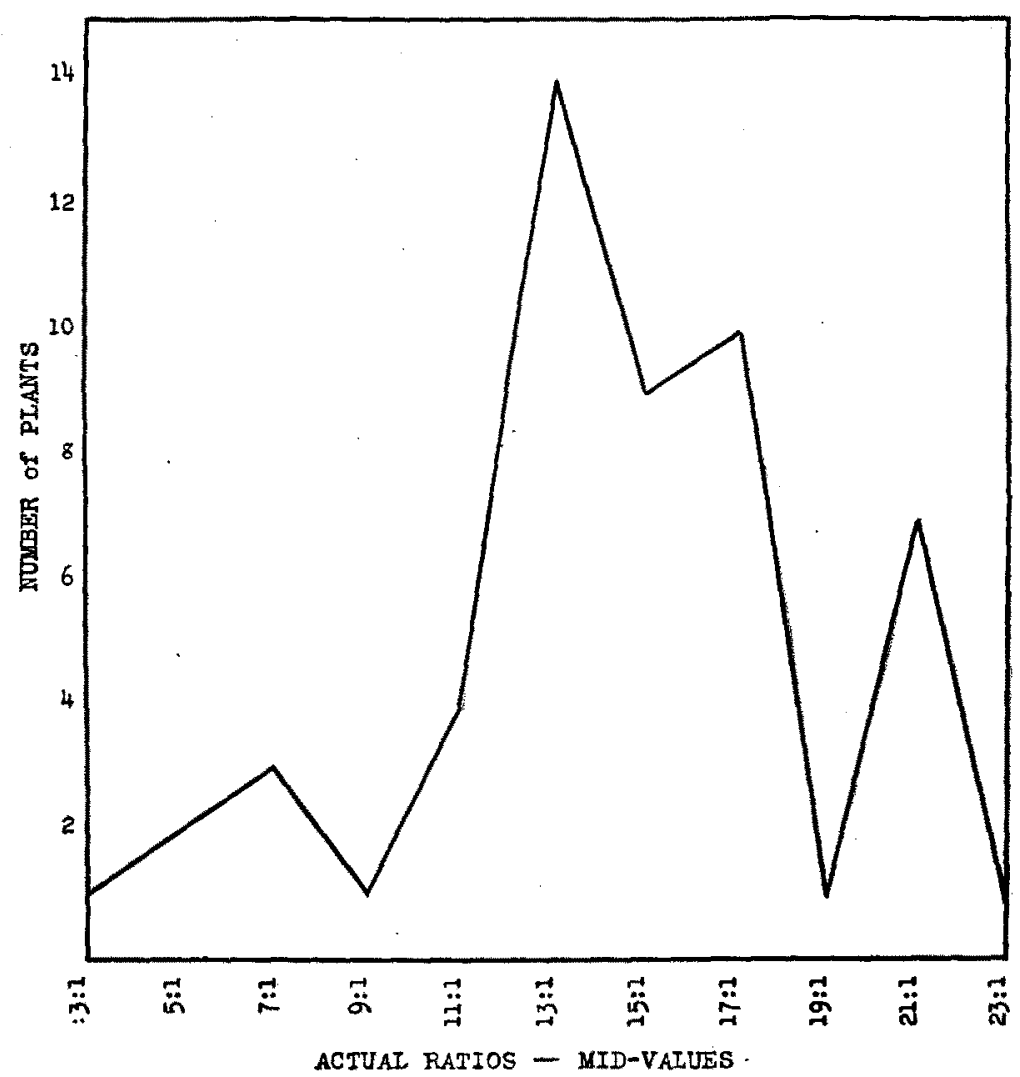

FIGURE 2.-Frequency polygon showing variation of segregating plants (15:1 class) with respect to actual ratio of yellow- to green-cotyledon beans.

TABLE 7

Frequency distribution of segregaling plants (3:1 class) showing variation in actual ratio of yellowto green-cotyledon seeds.

\begin{tabular}{c|c|c|c}
\hline ClLASS RANGE & MID-VALUE OF CLASS & $\begin{array}{c}\text { FREQUENCY } \\
\text { (NIJMBER OF PLANTS) }\end{array}$ & PERCENT OF Totar \\
\hline $1.63: 1$ to $1.87: 1$ & $1.75: 1$ & 1 & 1.351 \\
$1.88: 1$ to $2.12: 1$ & $2.00: 1$ & 0 & - \\
$2.13: 1$ to $2.37: 1$ & $2.25: 1$ & 2 & 2.703 \\
$2.38: 1$ to $2.62: 1$ & $2.50: 1$ & 8 & 10.811 \\
$2.63: 1$ to $2.87: 1$ & $2.75: 1$ & 13 & 17.568 \\
$2.88: 1$ to $3.12: 1$ & $3.00: 1$ & 19 & 25.675 \\
$3.13: 1$ to $3.37: 1$ & $3.25: 1$ & 22 & 29.730 \\
$3.38: 1$ to $3.62: 1$ & $3.50: 1$ & 5 & 6.756 \\
$3.63: 1$ to $3.87: 1$ & $3.75: 1$ & 2 & 2.703 \\
$3.88: 1$ to $4.12: 1$ & $4.00: 1$ & 2 & 2.703 \\
\hline Total................................. & 74 & 100.000 \\
\hline
\end{tabular}


genetically yellows, then the figures would be 24 yellow and 6 green instead of 18 and 12 , respectively.

Similarly, plant (470)-65 was noted as having produced 20 seeds with yellow and 22 with green cotyledons. The progeny of this plant consisted of 15 plants, 7 of which were from seeds with yellow cotyledons and 8 from seeds supposedly with green cotyledons. One of these 8 plants (909)-150, (table 22), segregated, however, instead of breeding true for

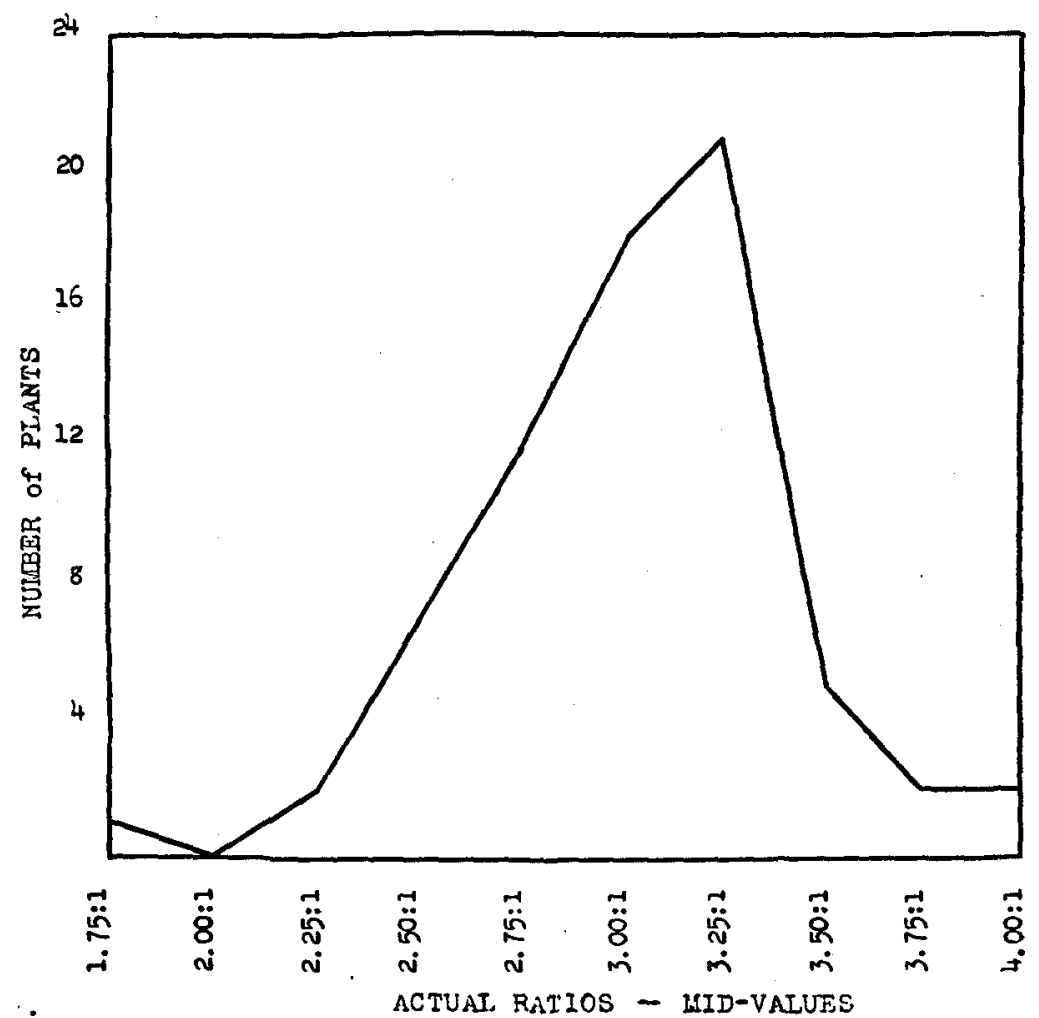

FIGURE 3.-Frequency polygon showing variation of segregating plants (3:1 class) in actual ratio of yellow- to green-cotyledon seeds.

green, thus proving the cotyledons of the parent seed to have been yellow, genetically. A re-examination of the seeds not planted showed there were 12 seeds with yellow and 7 with green cotyledons. These added to the number tested and the number which were planted but failed to germinate, gives a total of 25 yellow- and 16 green-cotyledon seeds. If it be assumed that one of the 7 green-cotyledon seeds not planted should, on being tested, prove to behave genetically as a yellow, then the final figures would be 26 
yellow and 15 green, the "corrected" figures for this plant given in table 14. One seed of unknown cotyledon color was lost; hence the total number is one less than as originally given.

In figure 4 a diagrammatic representation is given of the inheritance of cotyledon color in the cross variety 9 \% (green cotyledons) $\times$ variety $8 \sigma^{x}$ (yellow cotyledons). Figure 5 is a similar diagram for the reciprocal of this cross. A comparison of these two diagrams shows at a glance

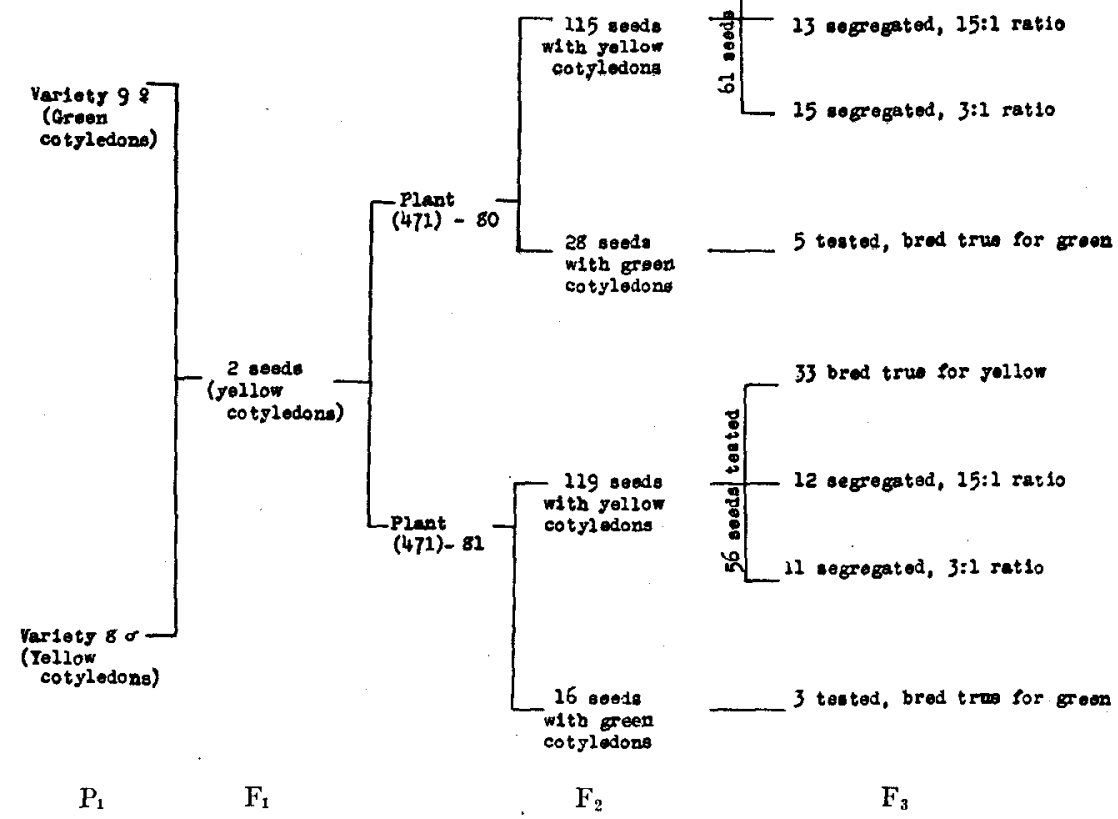

FIGURE 4.-Diagrammatic representation of inheritance of cotyledon color in cross variety 9 을 (green) $\times$ variety $8 \sigma^{7}$ (yellow).

that the mode of inheritance of cotyledon color is the same irrespective of which variety is used as the female parent.

\section{Unexpected beans}

Reference to tables $11,13,14,17,20,22,23,24,26,29,30,33$, and 34 shows that in plants classed as breeding true for yellow or green cotyledons a few beans with the unexpected cotyledon color were found. The question arises as to how these may be accounted for.

In number, they are few compared with the total number of "expected" beans. All plants classed as breeding true for yellow or green cotyledon 
produced a total of 123,624 beans. Of these, 110 , or one bean in 1123, had the unexpected cotyledon color, -57 yellow and 53 green.

Of the 347 plants here considered, 298, or 86 percent, produced yellowor green-cotyledon seeds exclusively. In each of 19 plants, or 5 percent of the total, 1 bean was found with the unexpected cotyledon color; in 15 plants, 2 such beans; in 9 plants, 3 ; in 1 plant, 4 ; in 4 plants, 5 ; and in 1 plant, 10.

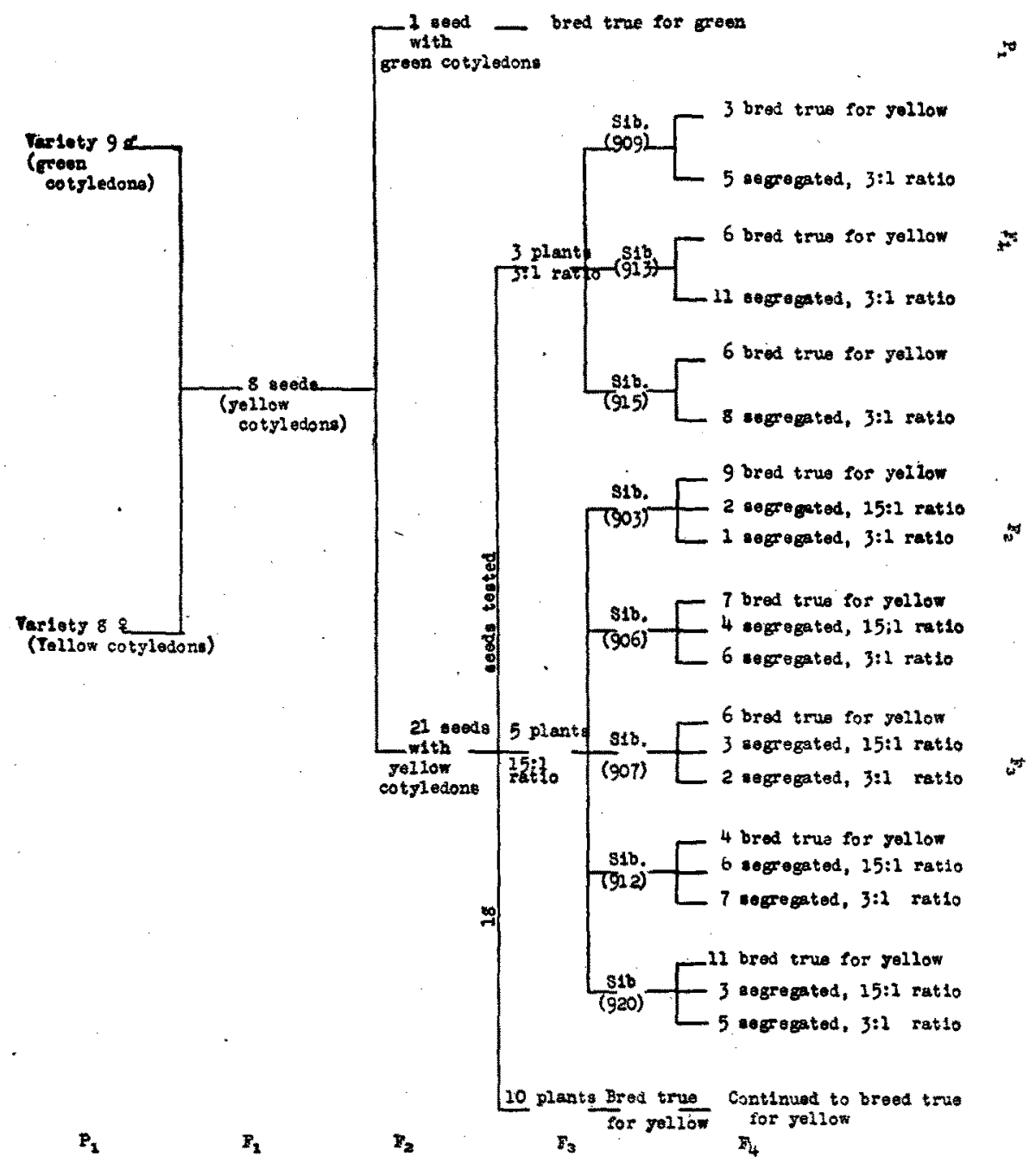

FIGURE 5.-Diagrammatic representation of inheritance of cotyledon color in cross variety $8 \%$ (yellow) $\times$ variety $9 \sigma^{3}$ (green). 
The occurrence of yellow-cotyledon beans in plants classed as breeding true for green will be considered first. There are at least three ways in which these may be accounted for: (1) crossing; (2) mutation; and (3) seed mixture. The first is the most probable since (a) yellow is dominant, (b) cotyledon color is a seed character, permitting the effect of the cross to become apparent the same season it is made, and (c) it has already been shown (page 490) that crosses do occur occasionally. The occurrence of a dominant mutation, as from green to yellow cotyledon, is a possibility. As to (3), it is very probable that some of these unexpected beans are seed mixtures. It would not be surprising if, in harvesting and threshing so many plants and in cleaning such a large number of seed, a few mixtures should occur in spite of the greatest pains taken to prevent it. Seed mixtures are easily and quickly detected if other seed characters, such as seed-coat color, are also different, but where there are no differences except in color of cotyledon, one cannot be certain whether the unexpected seeds are really mixtures or whether they may not as likely be accounted for by crossing or by mutation. Furthermore, the breeding test would seldom aid in settling this question. Heterozygosity would not serve as a criterion since yellow-cotyledon seeds resulting from crossing or from mutation would probably be heterozygous, as would also the majority of mixed yellow-cotyledon seeds from segregating plants.

Of the 53 green-cotyledon seeds found on plants classed as being homozygous for yellow, 18 were small, shrivelled and immature, and the cotyledons appeared green even though genetically they may have been yellow. In such immature seeds it appears that that stage of ripening is never reached where the green pigment fades out, and so the yellow always remains hidden. If, however, these 18 beans be disregarded because of their immaturity and the consequent doubt as to the color of their cotyledons, there will still remain 35 unexpected seeds to be accounted for.

It is clear that certain considerations involved in the occurrence of unexpected yellow-cotyledon beans do not apply to the unexpected greens. Thus, cross-pollination with the green-cotyledon type would not account for them since yellow is dominant. Nor would "loss" mutations give rise to green-cotyledon seeds unless they occurred in both gametes at once, which, while not impossible, is at least extremely unlikely.

It is believed that, occasionally, genetically yellow-cotyledon beans fail to turn yellow on ripening, but always remain green, though showing a fair degree of maturity in other ways. Such beans may be due to an unfavorable environment for bringing out the proper cotyledon color. The location on the parent plant is of prime importance in this connection. Seeds borne on the lower branches often do not have sufficient sunlight 
and air; they may even be lying on the ground and often be almost completely covered with soil, and of course they cannot ripen properly. This belief is supported by two or three instances (cited earlier in this paper) of beans, classed as having green cotyledons, breeding like genetic yellows.

Of course, such unexpected seeds cannot be discerned in plants segregating for cotyledon color; they affect the ratios, but so slightly as to be of no significance. As indicated above, in every 1123 beans there was 1 bean with the unexpected cotyledon color. The average number of beans per plant for the plants classed as being homozygous for green or yellow cotyledon was 356 . On the average, then, in every 3 plants examined, 1 unexpected bean would be found. If these figures be assumed to apply to segregating plants as well, it is clear that in two-thirds of the plants, the ratio would not be affected at all, and in one-third, it would be affected too slightly to be significant.

It appears likely then that a considerable number of the beans with unexpected cotyledon color are the result of cross-pollination. The rest are due to such factors as unfavorable weather conditions, mutations, and mechanical mixtures. In numbers they are very small in proportion to the total number of beans counted (upwards of a hundred thousand); and therefore, it is felt that they do not affect the validity of the results.

\section{A soy-bean chimera}

During the course of these studies, a single bean was found having one yellow and one green cotyledon. The color of each cotyledon was quite normal and distinct, making a striking contrast. A view of the back of the bean opposite the hilum showed a distinct line of demarcation. The seed coat being green and slightly transparent, the difference in color of the cotyledons produced a chromium green effect on one side and a yellowish green on the other.

This bean was borne by plant (909)-160, which produced, in addition, 272 beans with yellow and 91 beans with green cotyledons. The parent plant was, therefore, heterozygous for one factor only.

The plant grown the following year from the chimera proved to be heterozygous, bearing 85 seeds with yellow and 23 seeds with green cotyledons. These two types were distributed over the plant according to chance, just as on any normal segregating plant; hence, the embryo proper of the bean was not affected genetically by whatever caused the abnormal condition of the cotyledons.

The most plausible explanation appears to be that a somatic mutation occurred at a very early stage in the development of the embryo. As all the cells were heterozygous for but one of the factors for cotyledon color, 
such a mutation would involve a change in only one factor, and would therefore be within the limits of probability. Many other cases of somatic mutation are known, particularly in corn (Coldins 1919).

\section{Interpretation of inheritance of cotyledon color}

BunYard (see DARBISHIRE 1911, page 131) has shown that the cotyledons of both yellow- and green-cotyledon varieties of the garden pea ( $P i$ sum sativum) have both yellow and green pigments while the seeds are still immature. As the peas ripen, the green pigment fades out in yellow: varieties, but persists in green varieties. Yellow-cotyledon varieties, therefore, are first green, later turning yellow, and they differ from the greens only in having a factor which causes the green pigment to fade out as the beans mature.

It is probable that in the soy-bean the same situation exists in regard to the green and yellow pigments in the cotyledons. This is indicated by the fact that in immature beans the cotyledons are green irrespective of the variety. Furthermore, on exposing mature beans with green cotyledons to the light for a time, the green color gradually fades out, and the cotyledons become yellow, thus proving that both pigments were originally present, at least potentially. It is probable, therefore, that, as the beans ripen, the green pigment disappears in yellow-cotyledon varieties, but remains in varieties with green cotyledons; and that, as in peas, the yellow-cotyledon varieties differ from the greens only in having a factor which causes the green pigment to fade out at the time of maturity.

In the garden pea WHITE (1916) has assumed that three factors are concerned with the production of cotyledon color; namely, $Y, G$, and $I$. $Y$ and $G$ are factors for yellow and green pigments, respectively, both being present in all but one of the varieties with which he experimented; and $I$ is a factor causing the green pigment to disappear at maturity, present only in yellow-cotyledon varieties. Thus, the two cotyledon colors in peas ordinarily differ by a single factor, $I$, and in crosses the yellow proves dominant, the ratio of 3 yellow to 1 green being obtained in $F_{2}$.

WHITE found one yellow-cotyledon variety, "Goldkönig," which evidently lacked both factors $G$ and $I$; for in crosses with green-cotyledon varieties, green was dominant, and an $\mathrm{F}_{2}$ ratio of 3 green to 1 yellow was obtained; while in crosses with other varieties with yellow cotyledons, the $F_{2}$ ratio of 13 yellow to 3 green was obtained.

Inasmuch as the relation between the two cotyledon colors in soy-beans is probably the same as that in peas, the same factors may be used. So far as known, however, $Y$ and $G$ are present in all varieties of soy-beans; no recessive yellow has been found such as WHITE reports in the Goldkönig 
pea, though numerous crosses have been made between different yellowcotyledon varieties. On the contrary, in the cross and its reciprocal reported in this paper, green is recessive to yellow, as also is the case in the Auburn, brief mention of which has been made earlier in this paper, and which will be discussed more fully later. All the data available therefore, have shown that yellow cotyledon in soy-beans is dominant to green.

With regard, however, to factors, such as $I$, that cause the green pigment to disappear at maturity, varieties of soy-beans with yellow cotyledons differ among themselves, as shown uy the data which have been presented. Some, perhaps most varieties, as for example, Auburn, possess only one factor of this nature, while others typified by variety 8 , possess two such factors. These are duplicates of each other and produce the same effect, as far as cotyledon color is concerned, whether one or both are present.

If $D$ be used to symbolize the factor which is the duplicate of $I$, then the factorial composition of variety 8 (yellow cotyledons) is YYGGIIDD, and of variety 9 (green cotyledons), YYGGiidd. The hybrid between these two varieties would therefore be YYGGIiDd. The factorial composition of the $F_{2}$ generation and their breeding behavior in $F_{3}$ are as follows:

\begin{tabular}{|c|c|c|c|}
\hline \multirow[t]{4}{*}{$F_{2}$ ratio } & Genotypes & & Types and proportions in $F_{3}$ \\
\hline & (1) $Y Y G G I I D D$ & 1) & \\
\hline & (2) $Y Y G G I I D d$ & 2 & \\
\hline & (3) YYGGIiDD & $2\}-7$ & Breed true for yellow cotyledon \\
\hline \multirow{4}{*}{15 yellow } & (4) YYGGiiDD & 1). & \\
\hline & (5) YYGGIIdd & 1) & \\
\hline & (6) YYGGIiDd & $4-4$ & Segregate in $15: 1$ ratio \\
\hline & $\begin{array}{ll}\text { (7) } & \text { YYGGIidd } \\
\text { (8) } & \text { YYGGiiDDd }\end{array}$ & $\left.\begin{array}{l}2 \\
2\end{array}\right\}-4$ & Segregate in $3: 1$ ratio \\
\hline 1 green & (9) YYGGiidd & $1-1$ & Breeds true for green cotyledon \\
\hline
\end{tabular}

Lines segregating in a 3:1 ratio carry only one of these factors, $I$ or $D$. Whether one or the other is present in a particular line may be determined by making crosses between it and other lines also giving this simple ratio. If, as a result of such crosses, types are obtained which breed true or which again segregate in a 3:1 ratio, the same factor is present in both lines; but if segregation occurs in a 15:1 ratio, different factors are present in the two lines, and $D$ can be arbitrarily assigned to one line and $I$ to the other. These lines can then be used in crosses with other yellow-cotyledon varieties to determine whether, in the latter, $I$ or $D$, or even a different factor is responsible for the yellow cotyledon color.

Another method of determining which factor is carried by a particular line is by means of linkage which exists between one of the factors for yellow cotyledon and the factor, $V$, for green seed coat. This will be considered more in detail in a succeeding section. 
As far as could be determined dominance was complete in the case of both $I$ and $D$. Furthermore, one factor appears not only as efficient as the other in causing the green pigment to fade on maturity, but either one appears to be as efficient as both together in bringing about this change. Hence, factors, $D$ and $I$ are considered to be real duplicates of each other, like SHulL's $C$ and $D$ for obcordate seed capsules in Bursa.

\section{Duplicate factors in other plants}

Duplicate factors have been reported by NILsson-EHLe (1908)for red grains in wheat and (1909) for the presence of a ligule in oats; for endosperm color in corn by EAST (1910), EAST and HAYES (1911), and BuRTT-DAVY (1914); for capsule form, leaf lobes and leaf texture in Bursa bursa-pastoris by Shull $(1914,1918,1920)$; and for variegation in Plantago major by IkENo (1917). In respect to grain color in wheat and endosperm color in corn there is an apparent lack of dominance and a cumulative effect resulting in a greater intensity of color when either factor is homozygous or when both are present in the same zygote. In the other cases mentioned above, dominance is apparently complete, and the several genotypes in $F_{2}$ cannot be distinguished except by the progeny test. The factors in all these cases, however, show independence in inheritance (i.e., no linkage).

\section{Auburn variety}

It will be recalled that both cotyledon colors were found in a bulk sample of Auburn, a black-seeded variety.

In 1915, a number of plants were grown from both green- and yellowcotyledon seeds as found in the original sample, but no detailed records were made concerning cotyledon color. Only one plant (115)-184, grown from a seed with yellow cotyledons, was harvested. Of 628 seeds produced by this plant, 480 had yellow and 148 had green cotyledons. This proportion suggests a 3:1 ratio of yellow to green. On the basis of such a ratio the expected numbers would be 471 and 157 , respectively.

The following year, 52 plants were grown from the yellow-cotyledon beans and 17 from the green, and counts were made on 50 and 17 plants, respectively. Tables 35 and 36 give the data for each plant.

Of the 50 plants from yellow-cotyledon seeds (see table 36 ), 38 proved to be heterozygous, and 12 bred true for yellow. On the basis of a $2: 1$ ratio these numbers should be 33 and 17, respectively.

In 1917, fifteen plants were grown from yellow-cotyledon seeds of plant (211)-390. All but one of these proved to be heterozygous. The ratio, therefore, of heterozygous to homozygous plants was 14:1. No reason is 
apparent for such a wide divergence from expectation. It may be only a chance deviation, but it may be significant, especially as it falls in line with the case above given in which the homozygous plants were also deficient. There were also five plants grown from green-cotyledon seeds of (211)390 , and they all bred true for green.

As green is recessive all beans with this cotyledon color should breed true. It will be noted from table 35 that in addition to the green some yellow-cotyledon seeds were found in each plant, and that they ranged in number from 3 in plant (210)-310 to 27 in plant (210)-308. In a total of 12,085 beans produced by all plants from green-cotyledon seeds, $11,893 \mathrm{had}$ green cotyledons, and 192, yellow, or a ratio of 62:1.

Among the 12 plants (table 36) classed as breeding true for yellow cotyledons only 4 unexpected seeds were found out of 9864 seeds produced. This is a ratio of 1 to 2466 . The disparity in the ratios given by the two types of plants is very striking.

In a preceding section, a discussion was given of ways in which the occurrence of such unexpected beans may be accounted for. Points there brought out apply equally well here. Cross-pollination, for example, would account for many of the yellow-cotyledon seeds found in plants otherwise breeding true for green. Direct proof that natural crossing did occur is at hand. Plant (210)-330 (see table 35), is noted as having 14 seeds with yellow cotyledons and 987 with green. In 1917, twelve plants were grown from the green-cotyledon seeds, and all bred true. From the seeds with yellow cotyledons seven plants were grown, one of which bore seeds with the black seed coat characteristic of the Auburn variety, while the seeds borne by the other six plants had a mottled black and yellow seed coat. All but one of these seven plants showed segregation incotyledon color in an approximate 15:1 ratio (see table 37), and that plant produced only 23 seeds, most of which were small and immature. Probably all had yellow cotyledons, though this could not be determined with certainty. Plant (210)-330 was growing in the row in close proximity toplant (211)-332 which segregated in a 3:1 ratio in cotyledon color; and in the rows on either side of (210)-330 were types with yellow seed coats, yellow cotyledons, brown hilums and gray pubescence. It is more than probable that the results shown in table 37 can be explained by natural crosses with these adjacent types.

Plant (469)-54 was tested further, and the resulting progeny showed segregation in several plant characters, such as color of seed coat, pubescence and hilum, while with respect to cotyledon color, three types were produced in approximately the expected proportions; namely, a type breeding true for yellow, a type segregating in a 3:1 ratio, and a type seg- 
regating in a 15:1 ratio. Among the segregates, moreover, a plant was occasionally found with the self-black seed coat typical of the Auburn variety. It is fairly certain, therefore, that most of the original beans with yellow cotyledons, at first supposed to be mixtures, were the result of crosses with a yellow-cotyledon variety having two factors for cotyledon color.

Plant (469)-53 with its self-black seed coat cannot be explained in this way. If it is the result of a cross with a yellow-coated variety, the seed coat would likely be mottled instead of self-black. The ratio of yellow to green cotyledons shown by this plant is also peculiar; the deviation on a $15: 1$ basis being nearly 6 times the probable error. It may represent only a 3:1 ratio, and hence be simply the result of a cross with plant (211)-332, or a mixture from a segregating plant of this variety. Further speculation, however, is out of place till this plant has been tested.

A number of seeds of plant (211)-340 (see table 36) were also tested to compare the progenies of certain apparently "intermediate"-cotyledoncolored seeds with those whose cotyledons were a full rich yellow. From the latter type of seeds, 12 plants were grown, all of which bred true for yellow cotyledon. One of these, however, showed the same peculiar seedcoat color as was described above, indicating that the original bean was the result of a cross. From the intermediate seeds, 39 plants were grown, 37 of which bred true for yellow, one segregated in a ratio of 3 yellow: 1 green, and one bred true for green. A mechanical mixture was probably responsible for the last-named plant, while natural crossing would account for the one which segregated, particularly as plant (211)-340 grew in the row adjacent to and in contact with a plant, (211)-338, which segregated in cotyledon color.

In view of the above evidences for the occurrence of natural hybrids in the Auburn variety, it is believed that natural crossing will account for a considerable number of the unexpected beans. A mutative change from green to yellow might also account for some. There are a few beans, it is true, whose occurrence can only be explained, perhaps, by stating that they are the result of mechanical mixtures; but they are thought to be much less numerous than the hybrid beans, and therefore, that they are too few in number to cast any doubt on the ratios herein reported or the conclusions drawn therefrom.

The three green-cotyledon seeds found among plants otherwise breeding true for yellow are very probably not the result of cross-pollination or of mutation. They may be genetic yellows in which the green pigment has not faded out for some reason or other; or they may simply be mixtures from some other plant. The latter is the more probable. If these are 
considered to be mixtures, then it would be expected that as many more beans with yellow cotyledons should be classed as such. This would mean that 1 in 1233 beans was a mixture, not far from the proportion which was found in plants breeding true for yellow in progenies of the cross variety $8 \times$ variety 9 , discussed earlier in this paper.

There is no reason to believe that the proportion of mixed seeds is any greater in the plants breeding true for green. Hence, only a few of the 192 unexpected seeds found in these plants can be accounted for in this way. The evidence points to the conclusion that nearly all of them are the result of cross-pollination, which, for some reason not yet evident, appears to occur much more frequently in the Auburn variety than in varieties 8 and 9 .

The data presented above show that the inheritance of cotyledon color in the Auburn variety can be explained by a simple allelomorphic relationship between the two cotyledon colors. Whether $I$ or $D$ is the factor responsible for yellow cotyledon in this variety is not yet known; but if it be $I$, then the yellow types have the composition $Y Y G G I I$ or $Y Y G G I i$, and the greens, $Y Y G G i i$; but if it be $D$, then this factor should be substituted for $I$ in the above formulae. Which factor is involved may be determined by following the same procedure as outlined for this purpose in types arising from the cross variety $8 \times$ variety 9 .

INHERITANCE OF GREEN AND YELLOW SEED-COAT COLORS

\section{TERAO's results}

TERAo (1918) has already shown that green and yellow seed coats in soy-beans behave as a single allelomorphic pair, green being dominant to yellow and both types recurring in $\mathrm{F}_{2}$ in a simple $3: 1$ ratio. This he found to be true no matter which way the cross was made when the female parent had yellow cotyledons, but when the cotyledons and seed coats of the female parent were green, there was no segregation at all, the $F_{1}$ 's and $F_{2}$ 's breeding true to the characters of the female parent.

These peculiar inheritance phenomena were interpreted as follows: The two kinds of chlorophyll, "(Y)" and " $(\mathrm{G})$ " are present in the seed coats as well as in the cotyledons. In the inheritance of the seed coats, however, there is a pair of Mendelian factors $(H h)$ concerned.

"The factor ' $H$ ' inhibits the chlorophyll ' $(Y)$ ' in the seed-coat of the beans with yellow cotyledons from changing to yellow, producing beans with yellow cotyledons and green seed-coat; the absence of the factor ' $H$ ', expressed by ' $h$ ' allows the seed-coat of the bean with yellow cotyledons to remain yellow. The seed-coat of the bean with green cotyledons remains green no matter whether the factor ' $H$ ' is present or absent, because the beans of this kind have the chlorophyll '(G)' which is incapable of changing the color." 
However, in the $F_{2}$ of the cross green cotyledons, green seed coat $q \times$ yellow cotyledons, yellow seed coat $\sigma^{7}$, two types were observed, namely, a dark green, and a light green seed coat; and these occurred in a 3:1 ratio. But no plants were produced with yellow seed coats.

\section{Variety $8 \times$ variety 9}

The cross variety 9 (green coat) $\times$ variety 8 (yellow coat) gave results which in part seemed to confirm those of TERAO. But seeds produced by $F_{1}$ plants had green seed coats irrespective of the way the cross was made, and without regard, also, to whether the cotyledon color of the female parent was green or yellow. The $F_{2}$ generation consisted of both types in an approximate ratio of 3 green to 1 yellow (see table 38 ).

$\mathrm{F}_{2}$ plants with yellow seed coats bred true for this character, as shown by three progenies totaling 58 plants. Of 16 progenies from $F_{2}$ plants with green seed coats, 5 bred true for green and 11 segregated again, giving approximately 3 green to 1 yellow. The data for each progeny are given in table 39.

If the $F_{2}$ progenies and those of the $F_{3}$ which show segregation are added together, the total is 236 green to 87 yellow, a deviation of 6 from expectation.

From the data above presented it appears clear that green and yellow seed coats in soy-beans behave in inheritance as if determined by a single pair of factors $(V, v) .^{4}$

\section{RELATION BETWEEN COTYLEDON AND SEED-COAT COLORS}

When seed-coat and cotyledon colors are considered together, it is obvious that the two characters are not absolutely independent of each other in inheritance. TERAO (1918) observed this fact, stating that "beans with green cotyledons have always green seed coats." The present author has not observed any variety with green cotyledons beneath yellow coats, and PIPER and MORSE (1910) in their descriptions of nearly 300 varieties, mention no such type. Many varieties exist with black seed coats and green cotyledons and a type with green cotyledons and brown coats has recently been isolated in connection with the present investigation. This type also does not seem to occur among established varieties.

Among hybrids of the cross between varieties 8 and 9, a few plants have appeared bearing seeds with green cotyledons and yellow seed coats. When plants of this type appear, they breed true because recessive for both characters. 
It is well to repeat here that variety 8 had yellow cotyledons beneath yellow seed coats, and variety 9 had green cotyledons beneath green seed coats. Hence one parent brought into the hybrid one dominant character, and the other parent, the other dominant character. It may not be out of place, also, to mention the well-known fact that the cotyledon color appears a generation ahead of a plant character, such as seed-coat color. In the above cross and its reciprocal, then, the hybrid seeds obtained showed the dominant cotyledon color, yellow, but the coat color of these seeds was yellow or green depending on which parent bore them.

Seeds produced by $F_{1}$ plants had green coats, the dominant color, but they were in the proportion of 15 yellow to 1 green, in respect to cotyledon, as pointed out earlier in this paper. From the yellow-cotyledon seeds

TABLE 8

Relation of cotyledon color and seed coat color in inheritance. Observed and corrected figures compared with expected on basis of independence.

\begin{tabular}{|c|c|c|c|c|c|}
\hline COTYLEDON COLOR & COAT COLOR & $\begin{array}{l}\text { EXPECTED } \\
\text { PROPORTIONS }\end{array}$ & OBSERVED & CORRECTED & CAICULATED \\
\hline 15 yellow. & $\begin{array}{l}3 \text { green } \\
1 \text { yellow }\end{array}$ & $\begin{array}{l}45 \\
15\end{array}$ & $\begin{array}{r}147 \\
63\end{array}$ & $\begin{array}{r}150 \\
64\end{array}$ & $\begin{array}{r}160 \\
53\end{array}$ \\
\hline 1 green... & $\begin{array}{l}3 \text { green } \\
1 \text { yellow }\end{array}$ & $\begin{array}{l}3 \\
1\end{array}$ & $\begin{array}{r}18 \\
0\end{array}$ & $\begin{array}{r}14 \\
0\end{array}$ & $\begin{array}{r}11 \\
4\end{array}$ \\
\hline \multicolumn{3}{|l|}{ Total. } & 228 & 228 & 228 \\
\hline
\end{tabular}

210 plants were grown, and from the green-cotyledon seeds, $18 .{ }^{5}$ Table 8 shows how these plants were distributed among the various classes, and how this distribution compares with that expected on the basis of independence of the characters in inheritance.

A correction is made of the observed figures in table 8 for the reason that cotyledon color segregates on the $F_{1}$ plants, and in planting for the $\mathrm{F}_{2}$ generation, no attempt was made to grow just one-fifteenth as many plants from green- as from yellow-cotyledon beans. Furthermore, if this had been done, the failure of some seeds to germinate would have resulted perhaps in wide departures from the theoretical ratio,--deviation for which segregation and recombination of genetic factors would not have been responsible. The use of such corrected figures is justified, as Lindstrom (1917) has pointed out, provided (1) that the ratio to which the correction is made has been proved, and (2) that the actual proportions shown by

\footnotetext{
${ }^{5}$ Included in these figures are $\mathrm{F}_{2}$ and $\mathrm{F}_{3}$ plants of like parentage. The individual progenies on which these totals are based are given in table 40.
} 
the observed figures for the other segregating character are maintained in the corrected figures.

The low value of $\mathrm{P}$ (table 8), calculated from deviations of the corrected from the expected numbers, points to a strong probability that the deviations were not due to random sampling. Some factor besides chance, therefore, was evidently involved in producing these results. In this connection two points appear significant; (1) not a single plant from greencotyledon seeds bore yellow-coated seeds, though 4 such plants in 18 were expected; and (2) of the plants from yellow-cotyledon seeds, those bearing yellow-coated beans were in excess and those bearing green-coated seeds were deficient.

These facts become significant when it is remembered that the two types in excess, (a) yellow cotyledon, yellow seed coat, (b) green cotyledons, green seed coat, were the two parental types; and it appeared that a possible explanation for these results is that of linkage between one of the factors for cotyledon color, as $D$, and the factor, $V$, for green seedcoat color.

As stated earlier in this paper, $D$ and $I$, the factors for yellow cotyledon color, give every evidence of being absolutely independent in inheritance. If so, then they are located on different pairs of chromosomes; and if $V$ is linked, say, with $D$, it is independent of $I$; or if linked with $I$, it is independent of $D$. Obviously, so far as the results are concerned, it makes no difference whether $V$ is linked with one or the other cotyledon factor. The linkage is considered arbitrarily, therefore, to exist between $V$ and $D$.

The first question which naturally arises is whether the linkage is complete or only partial. If it be assumed for the moment that the linkage is complete, then the expected numbers for the types given in table 8 would be $157,57,14$, and 0 as compared with the corrected numbers $150, .64$, 14 , and 0 , respectively. In this particular case, then $\chi^{2}=1.172$, and $\mathrm{P}=$ .565483. Obviously, this is the closest fit that can be obtained for these data; for, any amount of partial linkage that might be assumed would bring the results nearer those calculated for the independent inheritance of $V$ and $D$. Complete linkage, therefore, appears to give a satisfactory explanation as far as these data are concerned.

It has been shown earlier in this paper that the $F_{2}$ seeds were of three types as indicated by the $\mathrm{F}_{3}$ generation in cotyledon color; namely, (1) those which bred true for yellow cotyledon; (2) those which segregated in a 15:1 ratio; and (3) those which segregated in a 3:1 ratio; and further, that these types appeared in the proportions of $7: 4: 4$, respectively. If 
the cotyledon and seed-coat colors are independent in inheritance, each of these three types of $F_{2}$ yellow-cotyledon seeds should produce plants that show the coat colors in the ratio of 3 green to 1 yellow. In table 9 , below, are shown the types and their expected proportions together with the actual data obtained. ${ }^{6}$

With the exception of the two types which segregated in cotyledon color, and which had green coats, there is obviously a wide divergence between observed and expected numbers. The deviations are so large that $\mathbf{P}$ has no value at all to 5 decimal places, and hence the data strongly sup-

TABLE 9

Relation of colyledon color and seed-coat color in inheritance. Observed figures compared with expected on basis of independence.

\begin{tabular}{|c|c|c|c|c|}
\hline COTYLEDON COLOR & SEED-COAT COLOR & $\begin{array}{c}\text { EXPECTED } \\
\text { PROPORTIONS }\end{array}$ & OBSERVED & EXPECTED \\
\hline 7 Bred true for yellow & $\begin{array}{l}3 \text { green } \\
1 \text { yellow }\end{array}$ & $\begin{array}{r}21 \\
7\end{array}$ & $\begin{array}{l}57 \\
55\end{array}$ & $\begin{array}{l}73.5 \\
24.5\end{array}$ \\
\hline 4 Segregated 15:1 & $\begin{array}{l}3 \text { green } \\
1 \text { yellow }\end{array}$ & $\begin{array}{r}12 \\
4\end{array}$ & $\begin{array}{r}45 \\
3\end{array}$ & $\begin{array}{l}42.0 \\
14.0\end{array}$ \\
\hline 4 Segregated 3:1 & $\begin{array}{l}3 \text { green } \\
1 \text { yellow }\end{array}$ & $\begin{array}{r}12 \\
4\end{array}$ & $\begin{array}{r}45 \\
5\end{array}$ & $\begin{array}{l}42.0 \\
14.0\end{array}$ \\
\hline \multicolumn{2}{|c|}{ Total $\ldots \ldots \ldots \ldots \ldots \ldots \ldots \ldots \ldots \ldots$} & 60 & 210 & 210.0 \\
\hline
\end{tabular}

port the idea of a linkage relation existing between the two characters concerned.

On the assumption of complete linkage between $V$ and $D$, no $F_{2}$ plants could occur which segregated in cotyledon color and had yellow seed coats. However, there were 8 such plants as shown in table 9,3 segregating in a 15:1 ratio and 5 in a $3: 1$ ratio. Hence, the linkage cannot be complete.

It is next in order, therefore, to test out the theory of partial linkage. No direct way of doing this for these data was available. Tables were at hand (Bateson and Punnetr 1911, Castle 1916) giving expected proportions of zygotic types in $\mathrm{F}_{2}$ for any assumed linkage values in cases where only 2 factor pairs were involved; but these tables obviously could not be used for cases involving 3 factor pairs, 2 of which were duplicate.

- Individual progenies which furnish these data are given in table 40 . 
Hence, for such special cases the following formula ${ }^{7}$ was developed from Emerson's (1916) general formula:

$$
\frac{\mathrm{a}}{12 r^{2}+11\left(s^{2}+2 r s\right)}: \frac{\mathrm{b}}{4\left(s^{2}+2 r s\right)+3 r^{2}}: \frac{\mathrm{c}}{s^{2}+2 r s}: \stackrel{\mathrm{d}}{r^{2}}
$$

where and

type a $=$ yellow cotyledon, green seed coat, type $b=$ yellow cotyledon, yellow seed coat, type $\mathrm{c}=$ green cotyledon, green seed coat, type $\mathrm{d}=$ green cotyledon, yellow seed coat,

$r: s=$ any assumed gametic ratio.

The following formulae for $r$ and $s$ in terms of types $a, b, c$, and $d$, were deduced from the above general formula:

$$
\begin{gathered}
r=.25 \sqrt{\mathrm{a}+\mathrm{b}+\mathrm{d}+15 \mathrm{c}} \\
s=.25 \sqrt{\mathrm{a}+\mathrm{b}+\mathrm{c}+\mathrm{d}}-r
\end{gathered}
$$

The values of $r$ and $s$ having thus been found, the percentage of crossing over was calculated by the following formula:

$$
\frac{r}{r+s} \times 100=\text { percent crossing over, repulsion phase. }
$$

The application of formulae 2 and 3 to the corrected figures in table 8 gives the value .5 for $r$ and 3.275 for $s$; in other words, in approximately every 8 gametes formed, 1 is a crossover. Applying formula 4, the percentage of crossing over is found to be 13.25. If, however, the exact corrected figures, $149.625,64.125,14.25$ and 0 be used in these calculations instead of the whole numbers, $150,64,14$ and 0 , respectively, $r=0$, and $s=3.775$. Thus, no crossover gametes are formed, and the linkage is complete. Obviously, no conclusion can be drawn from these data as to the exact amount of linkage.

Fortunately, the data in table 9 throw some light on this problem. For any assumed gametic ratio, the expected zygotic series was determined by substituting for $r$ and $s$ in the following formula:

$$
\begin{aligned}
& \frac{\mathrm{a}}{6 r^{2}+3\left(4 r s+s^{2}\right)}: \frac{\mathrm{b}}{r^{2}+2\left(r s+2 s^{2}\right)}: \frac{\mathrm{c}}{4 r^{2}+2\left(2 r s+2 s^{2}\right)}: \\
& \stackrel{\mathrm{d}}{4 r s}: \frac{\mathrm{e}}{2 r^{2}+2\left(3 r s+2 s^{2}\right)}: \frac{\mathrm{f}}{2 r^{2}+3 r s}: \frac{\mathrm{g}}{2 r s+s^{2}}: \frac{\mathrm{h}}{r^{2}}
\end{aligned}
$$

'The development of this and the following formulae will be presented in a separate paper. 
where seed coats;

type $a=$ number of plants with all yellow-cotyledon seeds, green seed coats;

type $b=$ number of plants with all yellow-cotyledon seeds, yellow

type $\mathrm{c}=$ number of plants with 15 yellow- : 1 green-cotyledon seeds, green seed coats;

type $d=$ number of plants with 15 yellow- : 1 green-cotyledon seeds, yellow seed coats;

type e $=$ number of plants with 3 yellow-: 1 green-cotyledon seeds, green seed coats;

type $\mathrm{f}=$ number of plants with 3 yellow- : 1 green-cotyledon seeds, yellow seed coats; seed coats;

type $\mathrm{g}=$ number of plants with all green-cotyledon seeds, green seed coats;

type $\mathrm{h}=$ number of plants with all green-cotyledon seeds, yellow

By comparing the expected zygotic series thus obtained with the corresponding observed numbers, the calculated series giving the closest correspondence was chosen by inspection, and the approximate percentage of crossing over determined from the corresponding gametic ratio. In table 41 are shown the deviations of the observed from the expected proportions based on the given gametic ratios, together with the values of $\chi^{2}$ and $\mathrm{P}$ for each. The gametic ratio of $2: 13$ appears to give the closest fit. This is a crossover percentage of 13.33, which is quite close to that calculated on the basis of the corrected numbers in table 8 . It is very probable, therefore, that a ratio of 1 crossover gamete to 7 non-crossover gametes is not far from the correct ratio. More data are required, however, to determine the correct linkage value.

\section{INHERITANCE OF HIIUM COLOR}

The two varieties which furnished the foregoing data on cotyledon and seed-coat colors also differed in color of hilum or "eye." In seeds of variety 8 , the original hilum color was yellow, the same color as the seed coat, while in seeds of variety 9 , the hilum was black, and the color was confined exclusively to the "eye."

Selfed seed borne by the parent plants of both varieties had hilums typical of their respective variety as above described. However, plants grown from these beans produced seed which were not altogether typical. Thus, seeds of variety 9 showed a pattern extending partially over the seed, due, 
apparently, to the spreading of the black pigment from the hilum as a center. In the case of variety 8 , there was a change also, the hilum being brown in later generations, instead of the typical yellow. The seeds, furthermore, showed a similar pattern, except that the superimposed pigment was brown instead of black. The pattern in both cases consisted of blotches, patches, splashes or bands irregular in outline and variable in extent and location even on seeds from the same plant. ${ }^{8}$

The $F_{1}$ plants resulting from reciprocal crosses between these two varieties bore seeds with black hilum like that in seeds of variety 9 , thus showing this to be the dominant character. These $F_{1}$ beans showed the pattern development, as did also those produced by the $F_{2}$ and $F_{3}$ plants. The pattern color was in every case the same as the hilum color, and there was, in the hybrids, the same variation in extent and location on the seed coats as in the pure-line progeny of the two parents described above.

The two types, black and brown hilums (which is equivalent to saying black and brown patterns), were obtained in the $F_{2}$ generation in a 9:7 ratio. The data are given in table 42. As there shown, of 144 plants, 85 had black hilum and 59 had brown. These numbers thus showed a deviation of 4 from expectation.

The 9:7 ratio obtained in the $F_{2}$ generation suggests two complementary factors, as $B$ and $H$, for the production of black hilum. In the absence of either one or the other factor, the hilum is brown, and in the absence of both, the hilum is yellow like that shown by typical seeds of variety 8 . On this interpretation, the expected ratio is $9: 6: 1$. It was impossible in this material, however, to distinguish the double recessive and it is consequently included with the browns; hence the ratio, 9:7.9

$\mathrm{F}_{2}$ plants bearing seeds with brown hilum, bred true for this character in $F_{3}$. There were in all 19 progenies containing 544 plants, the seeds

${ }^{8}$ The cause of development of the pattern in pure lines of self-colored beans is not at present known. It is a phenomenon of wide occurrence, appearing in a number of yellow and green varieties in many sections where soy-beans are grown. Seeds with such a pattern show no segregation on being tested and hence are not the result of hybridization. There are indications that the causal factors are, in part, physiological rather than genetic in nature, for the following reasons: (1) the wide variation in the extent of the pattern (from self-yellow or self-green to self-brown or self-black) on seeds from the same plant; and (2) the striking similarity in some material in the pattern shown by seeds in the same pod, and the dissimilarity of seeds in different pods though borne by the same plant. The study of the factors involved in the development of the pattern is of great practical importance from the standpoint of the uniformity of soy-bean varieties. It is hoped that investigations now in progress will throw some light on this problem.

${ }^{9}$ Whatever factors were responsible for the encroachment of the pattern in the pure-line progeny of variety 8 also caused its development in the double recessives obtained as segregates in this cross. In this discussion, therefore, the double recessive type is considered a bean with a brown pattern and brown hilum indistinguishable from $B B h h$ or $b b H H$. 
of which all had brown hilums. Had it been possible to distinguish the double recessive, many of these progenies would no doubt have shown segregation.

The $F_{2}$ plants bearing seeds with black hilum bred differently, as was expected. On the theory of complementary factors, $1 \mathrm{~F}_{2}$ plant out of 9 should breed true in $\mathrm{F}_{3} ; 4$ should produce blacks and browns in an approximate $3: 1$ ratio; and the remaining 4 out of 9 should behave like the $F_{I}$ plants, giving again an approximate 9:7 ratio. Of 17 progenies, 2 bred true, 7 gave blacks and browns in a ratio of $3: 1$, and 8 gave these types in a ratio of $9: 7$, as close an approximation to the theoretical proportions as is possible in 17 progenies. The actual data obtained are presented in table 43.

Data on the $F_{4}$ generation were obtained from progenies of single plants of progeny (917). Ofthe 14 plants with black hilum, 11 were tested and gave the results shown in table 44 . It will be seen from this table that 4 progenies bred true, 3 gave a 3:1 ratio, and 4, a 9:7 ratio. In 11 progenies, the expected proportions for the three types are 1:5:5. For the actual data, $x^{2}=10.00$, and $P=.006738$. The fit is therefore poor, but the numbers are small. Some significance can be attached to the fact that all the types expected were obtained.

In a total of 28 progenies in $F_{3}$ and $F_{4}$, all from plants with black hilum, 6 bred true for this character, 10 segregated in a 3:1 ratio, and 12 segregated in a 9:7 ratio. On the basis of a 1:4:4 ratio, these numbers should be $3,12.5$ and 12.5 , respectively. For these combined data, $\chi^{2}=3.52$, and $\mathrm{P}=.177377$.

\section{INHERITANCE OF PUBESCENCE COLOR}

Tawny and gray pubescence colors have already been mentioned. They are found to behave in inheritance as a simple allelomorphic pair of characters, tawny being dominant to gray, as PIPER and Morse (1910) have shown.

Reciprocal crosses between variety 9 (tawny pubescence) and variety 8 (gray pubescence) gave $10 \mathrm{~F}_{1}$ plants, all of which were tawny. The $\mathrm{F}_{2}$ generation showed segregation in a simple monohybrid ratio and the results were the same no matter which way the cross was made. Table 45 gives the results obtained.

Progenies were grown from $11 \mathrm{~F}_{2}$ plants with gray pubescence, and all bred true, giving a total of 273 plants. From $F_{2}$ plants with tawny pubescence, 19 progenies were grown and they gave the results shown in table 46 . 
From this table, it is seen that 7 progenies bred true while 12 segregated. The expected numbers on the basis of a 1:2 ratio are 6 and 13, respectively. The ratios for the individual progenies show considerable variation, and the deviations from the expected 3:1 are, in some cases, quite marked. For example, (907) gave a ratio of 11 tawny to 1 gray; (908) 1 to 1 ; (917) 17 to 1 ; (1154) 9 to 1 ; and (1159) 7.5 to 1 . The numbers are small, however, and may be, in consequence, only chance deviations from the expected.

Of the 17 plants in progeny (917) with tawny pubescence, 11 were tested. On the assumption that the above ratio shown by (917) is a $3: 1$, it would be expected that one-third, or 4, of the plants tested would breed true, and two-thirds, or 7, would again segregate in a 3:1 ratio. As shown in table 47,6 bred true and 5 segregated. This excess in the number of homozygous tawny plants appears significant though it may not be so. However, the fact that the segregating progenies produced fair 3:1 ratios for such small numbers would seem to indicate mere chance deviation in the case of progeny (917):

Summation of all progenies in $F_{2}, F_{3}$ and $F_{4}$, showing segregation, gives 430 plants with tawny and 130 with gray pubescence, the expected numbers being 420 and 140 , respectively.

Of 30 progenies, in $F_{3}$ and $F_{4}$, all from plants with tawny pubescence, 13 bred true for this character while 17 segregated. Based on a 1:2 ratio, these numbers should be 10 and 20, respectively, thus showing a deviation of three.

Hence, in the inheritance of pubescence color, a single pair of factors, $T t$, is involved.

\section{LINKAGE BETWEEN HILUM AND PUBESCENCE COLORS}

One of the parents of this cross (variety 9) had tawny pubescence and black hilum, $(B B H H T T)$ and the other parent (variety 8 ), gray pubescence and yellow hilum (bbhhtt). ${ }^{10}$ The cross and its reciprocal showed the same results in all hybrid generations.

Plants of the $F_{1}$ generation had tawny pubescence and black hilum, these being the dominant characters. In the $F_{2}$ generation, the following types were obtained: (a) tawny pubescence and black hilum; (b) tawny pubescence and brown hilum; (c) gray pubescence and brown hilum. Not a single plant was observed with gray pubescence and black hilum. The actual data (table 10) conform fairly well to a 9:3:4 ratio for the three types obtained.

${ }^{10}$ In this discussion, as in the section on hilum color, the double recessive type in hilum color is always included with the browns, being indistinguishable from them. 
$F_{2}$ plants which had brown hilum and gray pubescence, bred true for these characters as was shown by 11 progenies totaling 273 plants. $F_{2}$ plants with brown hilum and tawny pubescence bred true for the former character, and either bred true for tawny pubescence or segregated in a ratio of 3 tawny to 1 gray. The data are given in table 46 , which contains $\mathrm{F}_{3}$ results on the inheritance of pubescence color. Progenies in this table from brown tawny plants are (920), (921), and (1153). Of the 3 progenies, therefore, 2 bred true and 1 segregated.

Plants of the $F_{2}$ generation with tawny pubescence and black hilum bred differently in $F_{3}$. Some bred true for both characters, some segregated in hilum color alone, and the rest segregated in both characters, but in different proportions, depending on the factorial composition of the parent plant. The actual results are set forth in table 48 .

TABLE 10

$F_{2}$ generation of black tawny $\times$ brown gray.

\begin{tabular}{|c|c|c|c|c|}
\hline \multirow{2}{*}{ PROGENY NUTRBERS } & \multicolumn{4}{|c|}{ NUMBER OF PLANTS OBSERVED } \\
\hline & $\begin{array}{l}\text { Black } \\
\text { tawny }\end{array}$ & Black gray & $\begin{array}{l}\text { Brown } \\
\text { tawny }\end{array}$ & Brown gray \\
\hline$(470)$ & 10 & - & 2 & 7 \\
\hline (801) & 40 & - & 10 & 16 \\
\hline$(803)$ & 35 & - & 7 & 17 \\
\hline 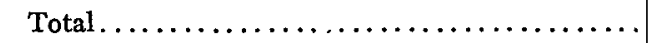 & 85 & - & 19 & 40 \\
\hline Expected numbers on basis of $9: 3: 4$ ratio........ & 81 & - & 27 & 36 \\
\hline
\end{tabular}

Theoretically, the $F_{2}$ plants with black hilum and tawny pubescence should consist of the following types (as shown by the $F_{3}$ ) and in the following proportions:

Of 9 black tawny $\mathrm{F}_{2}$ plants

(a) 1 should breed true.

(b) 2 should segregate into 3 black tawny: 1 brown tawny.

(c) 2 should segregate into 3 black tawny: 1 brown gray.

(d) 4 should segregate into 9 black tawny: 3 brown tawny: 4 brown gray.

As seen from table $48,2 \mathrm{~F}_{2}$ plants belong to class (a), 4 to class (b), 3 to class (c), and 8 to class (d). These numbers are as close to expectation as is possible with 17 progenies. Were one more added to class (c) the actual and expected numbers would correspond exactly. 
The totals for the 9:3:4 class show wide departures from the expected numbers, particularly those for the brown tawny and brown gray classes, the former being as much in excess as the latter is deficient. The actual ratio thus resembles more closely a 9:4:3 than a 9:3:4. All but 2 or 3 individual progenies showed such a reversal of ratio. This is peculiar in view of (1) the close correspondence of the $F_{2}$ data with the theoretical, and (2) the existence of the 4 types of $F_{2}$ plants in expected proportions, as indicated by the $F_{3}$ generation; but in the presence of such proof, it is not believed necessary to call in question the theoretical interpretation suggested.

As stated above under the separate discussions of the inheritance of hilum and pubescence colors, 11 plants of (917) with black hilum and tawny pubescence were tested. Their progenies constituted the $F_{4}$ generation of this cross with respect to these 2 characters. The data are given in table 49.

This table shows that of 11 progenies, 4 bred true, 2 gave a $3: 1$ ratio in hilum color, 1 gave a 3:1 ratio of black tawny to brown gray, and 4 gave a 9:3:4 ratio. Theoretically, these numbers should be 1, 2.5, 2.5 and 5, respectively.

Altogether, 28 progenies are represented in tables 48 and 49 . Of these, 6 bred true, 6 segregated in a ratio of 3 black tawny to 1 brown tawny, 4 segregated in a ratio of 3 black tawny to 1 brown gray, and 12 segregated in a 9:3:4 ratio. These types should be in the proportions 3:6:6:13. The totals would have been in closer accord with expectation, had the $\mathrm{F}_{4}$ results not shown such marked deviations.

Summation of all progenies in $F_{2}, F_{3}$ and $F_{4}$, giving 9:3:4 ratios, gives the following results:

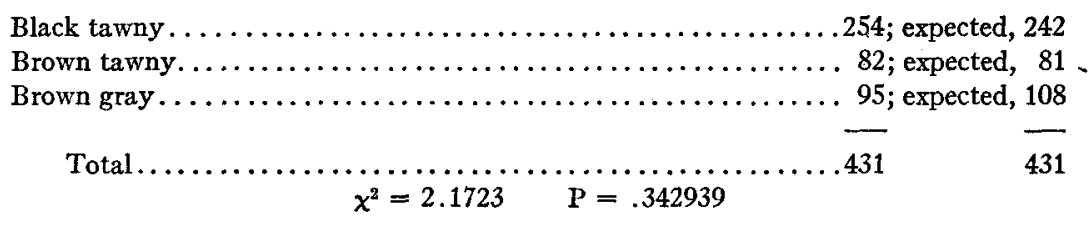

Summation of all progenies in $F_{3}$ and $F_{4}$, giving ratios of 3 black tawny to 1 brown tawny, gives the following totals:

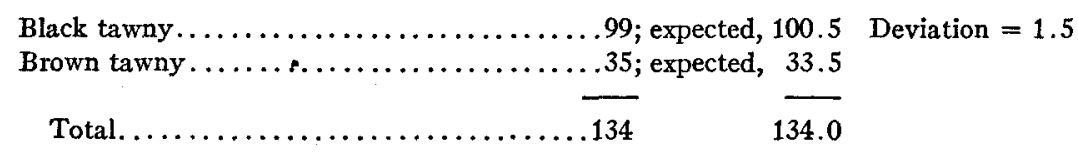


Summation of all progenies in $F_{3}$ and $F_{4}$ giving ratios of 3 black tawny to 1 brown gray, gives the following totals:

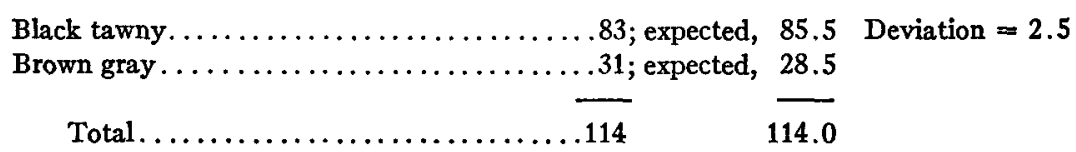

The data above presented are in accord with the interpretation that one of the factors for hilum color, $B$ or $H$, is completely linked with $T$, the factor for tawny pubescence. It is an arbitrary matter whether $B$ and $T$, or $H$ and $T$, are considered thus linked, as far as the interpretation of the results is concerned. The linkage is therefore taken to exist between $H$ and $T$.

On this interpretation, the types obtained in $\mathrm{F}_{2}$ and their behavior in $F_{\mathrm{z}}$ when selfed are as follows:

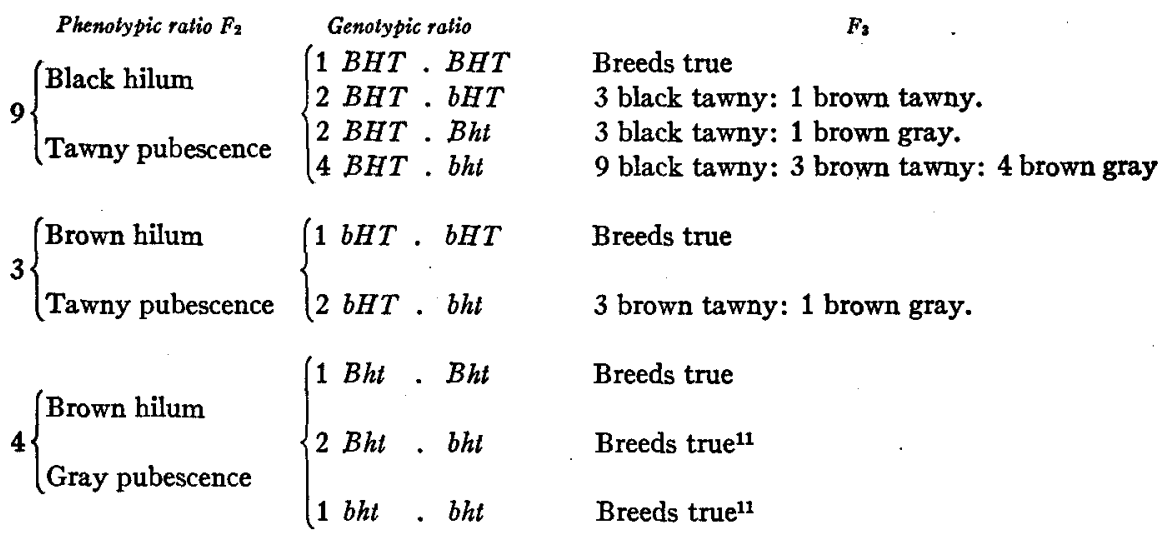

It is clear from the foregoing that all plants with brown hilum and tawny pubescence carry $H$ and $T$ but lack $B$; while plants with gray pubescence may lack all three factors or may carry $B$ only. Owing, then, to this linkage relation it is possible to determine which of the plants with brown hilum carry $B$ and which carry $H$.

As the linkage is complete between $H$ and $T$, the combined effects of these two factors may be thought of as due to a single factor which has more than one effect. Thus, $T$, the factor for tawny pubescence, may be thought of as not only being able to change the pubescence color from gray to tawny, but also as acting with $B$ to change the hilum color from brown to black. This is perhaps the most convenient way of regarding the situation.

11 Theoretically, presence and absence of $B$ should differentiate between brown and yellow hilum. See p. 516. 
Single factors having multiple effects have been established in a number of forms. In Drosophila melanogaster, for example, the factor for morula eye is also responsible for "spineless" (BRIDGEs 1919). In corn, red grain and red cob are inherited together and apparently both are due to the same factor (EMERson 1911). In the soy-bean (unpublished data), a purplish stem always accompanies a purple flower. Very likely the same factor causes both effects. Other examples could be cited, all to the same point. Indeed, so many cases of unbroken correlation have been and are being established that every factor, it is believed, has many more effects than simply the one which happens to be most conspicuous and for which it is named.

\section{CHARACTERS INHERITED INDEPENDENTLY}

The relationship between hilum and pubescence, and between cotyledon and green seed coat have been discussed above. It next remains to discover what relation, if any, exists between (1) cotyledon and pubescence color, (2) cotyledon and hilum color, (3) seed-coat and pubescence color, and (4) seed-coat and hilum color.

The data are given in tables 50-53. The progenies furnishing these data are $F_{2}$ 's and $F_{3}$ 's of like parentage in plant characters, but $F_{3}$ 's and $\mathrm{F}_{4}$ 's of like parentage in cotyledon color. Included in the tables are the expected numbers calculated on the basis of independent inheritance of the factors concerned, and the values of $\chi^{2}$ and $P$.

The lowest value for $P, 0.634195$, was found in table 53 , giving the data on seed-coat and pubescence colors; the highest value for $\mathrm{P}, 0.809799$, was found in table 52, for seed-coat and hilum. The chances, therefore, are better than even in each case that the characters concerned are inherited independently of each other.

\section{LINKAGE GROUPS}

The inheritance of six factors and their linkages have been discussed in this paper. These factors are grouped as follows:

I. $D$, factor for yellow cotyledon. $\{$ About 13 percent $V$, factor for green seed coat. \{ crossing over.

II. I, duplicate factor for yellow cotyledon.

III. $B$, factor for brown hilum. Complementary with $B$ in producing black hilum.

IV. $\underset{T, \text { factor for brown hilum. }}{\text {, factor for tawny pubescence. }}\left\{\begin{array}{c}\text { Completely } \\ \text { linked. }\end{array}\right.$ 
$Y$ and $G$ are factors for yellow and green pigment, respectively, in the cotyledons, but since no soy-beans have yet been found lacking one or the other pigment, except as caused by the action of $I$ or $D$, the mode of inheritance of $Y$ and $G$ cannot be determined.

Studies have been made on the inheritance of other characters in the soy-bean; as, dwarfness, flower color, etc. The data are to be published soon. To date, however, their relations with the characters reported in this paper have not been determined, though some preliminary studies indicate that flower color is independent of both factors $D$ and $I$ for cotyledon color.

\section{SUMMARY}

1. Yellow cotyledon was found to be dominant to green. There was no evidence of maternal inheritance.

2. Cotyledon color in the $F_{2}$ generation of certain crosses showed aberrant ratios which were interpreted as 15:1 ratios only in the light of data on later hybrid generations.

3. The $\mathrm{F}_{\mathbf{3}}$ generation consisted of three types of progenies derived from $\mathrm{F}_{2}$ yellow-cotyledon beans; namely, a type breeding true for yellow; a type segregating according to a 15:1 ratio; and a type segregating according to a 3:1 ratio. The observed numbers of plants belonging to the three types approached closely the expected proportions of $7: 4: 4$.

4. Cotyledon color in the $\mathrm{F}_{4}$ generation confirmed results obtained in $F_{3}$. (a) Progenies from yellow-cotyledon beans which bred true in $F_{3}$ continued to breed true in $F_{4}$. (b) Progenies from lines giving 3:1 ratios in $\mathrm{F}_{3}$ were of two types in $\mathrm{F}_{4}$; namely, a type breeding true, and a type giving 3:1 ratios; and these two types were to each other as 1:2. (c) Progenies from lines giving 15:1 ratios in $F_{3}$ gave again the three types and in the same proportions as were obtained in the $F_{3}$ generation.

5. With three exceptions the green-cotyledon beans bred true for green. These exceptions are believed to be due to errors in classification, the beans appearing green, though proving themselves to be yellow, genetically.

6. Fourteen percent of the plants classed as breeding true for yellow or green cotyledon bore from 1 to 10 seeds of the unexpected cotyledon color. Cross-pollination, unfavorable weather conditions, mutation, and mechanical mixtures are the factors believed to be responsible for their occurrence. It is felt that they do not occur in proportions large enough to affect the validity of the results.

7. In the Auburn, a black-seeded variety, found to be segregating for cotyledon color, all green-cotyledon beans were found to breed true, but 
the yellow-cotyledon beans from segregating plants were of two types in the ratio of $1: 2$, namely, a type breeding true for yellow, and a type giving a 3:1 ratio,-indicating a simple allelomorphic relationship between the two cotyledon colors.

8. Green seed coat proved to be dominant to yellow seed coat, and in $F_{2}$ a ratio of three green to one yellow was obtained.

9. There is an apparent repulsion between green seed coat and yellow cotyledon, and conversely between yellow seed coat and green cotyledon. Evidence available indicated about 13 percent crossing over.

10. Black hilum is dominant to brown hilum, and in $F_{2}$ a ratio of 9 black to 7 brown was obtained. This indicates that there are two factors, complements of each other, which are necessary to produce black hilum. In the absence of either one or both, the hilum is brown.

11. Tawny pubescence is dominant to gray pubescence, and in $F_{2}$ a ratio of 3 tawny to 1 gray was obtained.

12. Complete linkage was found to exist between the factor for tawny pubescence, and one of the complementary factors for black hilum. No plants were produced with black hilum and gray pubescence.

In the light of these facts the following factors were used to explain the inheritance of the above characters in soy-beans:

$Y$, factor for yellow pigment in cotyledon.

$G$, factor for green pigment in cotyledon.

$I$, factor causing green pigment to fade out at maturity; $i$, green cotyledon, in absence of $D$.

$D$, duplicate of $I ; d$, green cotyledon, in absence of $I$.

$V$, factor for green seed coat; $v$, yellow seed coat.

$T$, factor for tawny pubescence; $t$, gray pubescence.

$B$, factor for brown hilum. Complement of $H$.

$H$, factor for brown hilum. Complement of $B$. With both $B$ and $H$ present the hilum is black.

\section{LITERATURE CITED}

Bateson, W., and Punnetr, R. C., 1911 On gametic series involving reduplication of certain terms. Jour. Genetics 1: 293-302. Pl. 40.

BRDges, C. B., and Morgan, T. H., 1919 The second-chromosome group of mutant characters. Carnegie Institution of Washington Publication No. 278, pp. 123-304.

Burtr-Davy, J., 1914 Maize, its history, cultivation, handling, and uses, $x l+831$ pp. Figs. 1-245. London: Longmans, Green \& Co.

Castre, W. E., 1916 'Tables of linkage intensities. Amer. Nat. 60: 575, 576.

ColıIns, J. L., 1919 Chimeras in corn hybrids. Jour. Heredity 10: 3-10.

Darbishire, A. D., 1911 Breeding and the Mendelian discovery. vi +282 pp., 34 figs. 6 pls. New York: Cassell \& Co. 
EAST, E. M., 1910 A Mendelian interpretation of variation that is apparently continuous. Amer. Nat. 44: 65-82.

EAST, E. M., and HaYes, H. K., 1911 Inheritance in maize. Connecticut Agric. Exp. Sta. Bull. No. 167, pp. 1-141, Pls. 1-25.

EMERSon, R. A., 1911 Genetic correlation and spurious allelomorphism in maize. 24th Ann. Rept. Nebraska Agric. Exp. Sta., pp. 1-58.

1916 The calculation of linkage intensities. Amer. Nat. 50: 411-420.

HARRIs, J. A., 1912 A simple test of the goodness of fit of Mendelian ratios. Amer. Nat. 41: 741-745.

IkENo, S., 1917 Variegation in Plantago. Genetics 2: 390-416.

LINDSTROM, E. W., 1917 Linkage in maize; aleurone and chlorophyll factors. Amer. Nat. 46: 225-237.

NILsson-Ehle, H., 1908 Einige Ergebnisse von Kreuzungen bei Hafer und Weizen. Bot. Notiser 1908: 257-294.

1909 Kreuzungsuntersuchungen an Hafer und Weizen. Lunds Univ. Årsskr. N. F. Afd. 2, Bd. 5, Nr. 2, pp. 1-122.

Pearson, Kari, 1914 Tables for statisticians and biometricians. Pp. lxxxiii +143 . London: Cambridge University Press.

PIPER, C. V., and Morse, W. J., 1910 The soy-bean: history, varieties, and field studies. U. S. Dept. Agric., Bur. Plant Industry Bull. No. 197, pp. 1-84. Pls. 1-8.

SHULL, G. H., 1914 Duplicate genes for capsule-form in Bursa bursa-pastoris. Zeitschr. f. ind. Abstamm. u. Vererb. 12 : 97-149.

1918 The duplication of a leaf-lobe factor in the shepherd's purse. Brooklyn Bot. Gard. Mem. 1: 427-445.

1920 A third duplication of genetic factors in shepherd's purse. Science 51: 596. Terao, H., 1918 Maternal inheritance in the soy-bean. Amer. Nat. 62: 51-56.

WHITE, O. E., 1916 Inheritance studies in Pisum. I. Inheritance of cotyledon color. Amer. Nat. 60: 530-547.

\section{APPENDIX}

TABLE 11

Cotyledon color in $F_{3}$ generation. Plants produced from seeds with green cotyledons.

\begin{tabular}{c|r|r|r}
\hline \multirow{2}{*}{ PARENT } & \multirow{2}{*}{ pLANT NOMGER } & \multicolumn{2}{|c}{ NOMBER SEEDS OBSERVED WITH } \\
\cline { 2 - 3 } & & Yellow cotyledon & Green cotyledon \\
\hline$(339)$ & $(470)-73$ & 0 & 39 \\
$(471)-80$ & $(801)-110$ & 3 & 375 \\
$(471)-80$ & -112 & 0 & 311 \\
$(471)-80$ & -118 & 3 & 285 \\
$(471)-80$ & -122 & 3 & 426 \\
$(471)-80$ & -132 & 5 & 264 \\
$(471)-81$ & $(803)-248$ & 2 & 209 \\
$(471)-81$ & -252 & 0 & 468 \\
$(471)-81$ & -254 & 2 & 377 \\
\hline Totals .......................... & & 18 & 2754 \\
\hline
\end{tabular}


TABLE 12

Cotyledon color in $F_{3}$ generation. Plants produced from seeds with yellow cotyledons. Progeny of (471)-80.

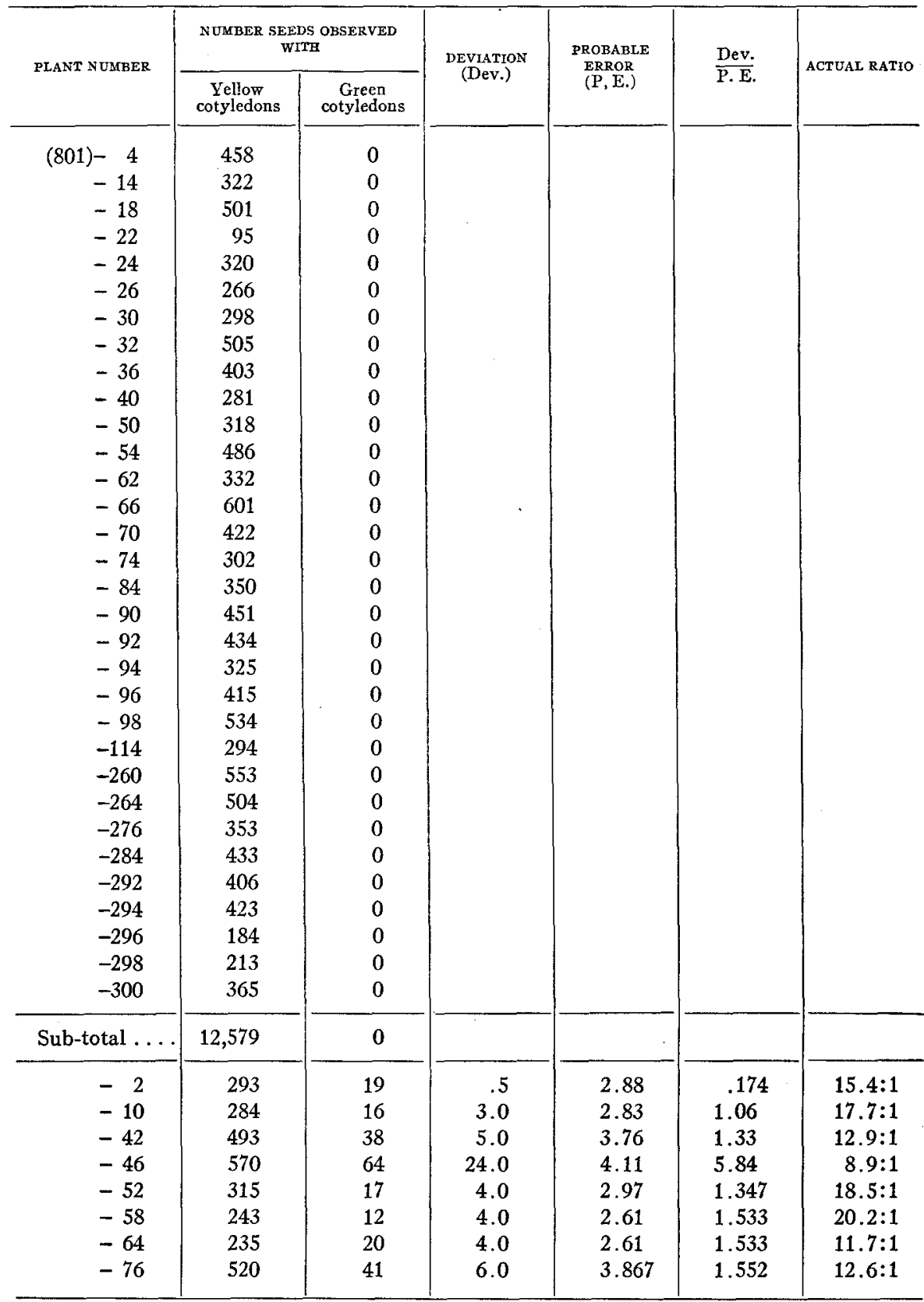


TABLE 12 (continued)

\begin{tabular}{|c|c|c|c|c|c|c|}
\hline \multirow{2}{*}{ PLANT NUMBER } & \multicolumn{2}{|c|}{$\begin{array}{l}\text { NUMBER SEEDS OBSERVED } \\
\text { WITH }\end{array}$} & \multirow{2}{*}{$\begin{array}{l}\text { DEviation } \\
\text { (Dev.) }\end{array}$} & \multirow{2}{*}{$\begin{array}{c}\text { PROBABLEE } \\
\text { FRROR } \\
\text { (P.E. })\end{array}$} & \multirow{2}{*}{$\frac{\text { Dev. }}{\text { P.E. }}$} & \multirow{2}{*}{ ACTUAX RATIO } \\
\hline & $\begin{array}{l}\text { Yellow } \\
\text { cotyledons }\end{array}$ & $\begin{array}{c}\text { Green } \\
\text { cotyledons }\end{array}$ & & & & \\
\hline$(801)-78$ & 160 & 12 & 1.0 & 2.14 & .468 & $13.3: 1$ \\
\hline-82 & 408 & 25 & 2.0 & 3.397 & .589 & $16.3: 1$ \\
\hline-86 & 412 & 19 & 8.0 & 3.39 & 2.057 & $21.7: 1$ \\
\hline-282 & 271 & 13 & 5.0 & 2.75 & 1.819 & $20.8: 1$ \\
\hline-286 & 344 & 24 & 1.0 & 3.13 & .318 & $14.3: 1$ \\
\hline Sub-total ... & 4548 & 320 & 16.0 & 11.39 & 1.405 & $14.2: 1$ \\
\hline-16 & 209 & 64 & 4.0 & 4.83 & .829 & $3.26: 1$ \\
\hline-20 & 242 & 63 & 13.0 & 5.10 & 2.548 & $3.84: 1$ \\
\hline-34 & 229 & 87 & 8.0 & 5.19 & 1.542 & $2.63: 1$ \\
\hline-60 & 354 & 115 & 2.0 & 6.33 & 0.316 & $3.07: 1$ \\
\hline-68 & 294 & 81 & 14.0 & 5.66 & 2.474 & $3.63: 1$ \\
\hline-80 & 282 & 110 & 12.0 & 5.78 & 2.077 & $2.56: 1$ \\
\hline-88 & 262 & 102 & 11.0 & 5.57 & 1.975 & $2.56: 1$ \\
\hline-100 & 203 & 76 & 6.0 & 4.88 & 1.228 & $2.67: 1$ \\
\hline-104 & 291 & 107 & 7.5 & 5.83 & 1.287 & $2.71: 1$ \\
\hline-266 & 357 & 117 & 1.5 & 6.36 & 0.236 & $3.05: 1$ \\
\hline-268 & 395 & 118 & 10.0 & 6.62 & 1.511 & $3.35: 1$ \\
\hline-272 & 247 & 91 & 6.5 & 5.37 & 1.211 & $2.70: 1$ \\
\hline-278 & 208 & 69 & 0.0 & 4.86 & 0.000 & $3.01: 1$ \\
\hline-280 & 226 & 70 & 4.0 & 5.03 & 0.795 & $3.22: 1$ \\
\hline-290 & 402 & 121 & 10.0 & 6.68 & 1.498 & $3.32: 1$ \\
\hline Sub-total . & 4201 & 1391 & 7.0 & 21.84 & .321 & $3.02: 1$ \\
\hline
\end{tabular}


TABLE 13

Cotyledon color in $F_{8}$ generation. Plants produced from seeds with yellow cotyledons. Progeny of $(471)-81$.

\begin{tabular}{|c|c|c|c|c|c|c|}
\hline \multirow{2}{*}{ PLANT NUMBER } & \multicolumn{2}{|c|}{$\begin{array}{l}\text { NCMBER SEEDS OBSERVED } \\
\text { WITH }\end{array}$} & \multirow{2}{*}{$\begin{array}{l}\text { DEVIATroN } \\
\text { (Dev.) }\end{array}$} & \multirow{2}{*}{$\begin{array}{l}\text { PROBABLLE } \\
\text { ERROR } \\
\text { (P.E.) }\end{array}$} & \multirow{2}{*}{$\frac{\text { Dev. }}{\text { P. E. }}$} & \multirow{2}{*}{ ACTUAL RATTO } \\
\hline & $\begin{array}{c}\text { Yellow } \\
\text { cotyledons }\end{array}$ & $\begin{array}{c}\text { Green } \\
\text { cotyledons }\end{array}$ & & & & \\
\hline $\begin{array}{r}(803)-2 \\
-\quad 4 \\
-10 \\
-26 \\
-30 \\
-32 \\
-34 \\
-42 \\
-44 \\
-50 \\
-52 \\
-54 \\
-60 \\
-64 \\
-66 \\
-72 \\
-76 \\
-80 \\
-82 \\
-86 \\
-88 \\
-90 \\
-94 \\
-98 \\
-270 \\
-274 \\
-276 \\
-282 \\
-284 \\
-286 \\
-290 \\
-292 \\
-300\end{array}$ & $\begin{array}{l}303 \\
130 \\
211 \\
430 \\
346 \\
374 \\
333 \\
426 \\
199 \\
227 \\
506 \\
319 \\
586 \\
213 \\
390 \\
359 \\
185 \\
328 \\
513 \\
122 \\
332 \\
417 \\
451 \\
412 \\
309 \\
415 \\
340 \\
376 \\
294 \\
486 \\
541 \\
337 \\
350\end{array}$ & $\begin{array}{l}0 \\
0 \\
2 \\
0 \\
0 \\
0 \\
0 \\
0 \\
0 \\
0 \\
0 \\
0 \\
0 \\
0 \\
0 \\
0 \\
0 \\
0 \\
1 \\
0 \\
0 \\
0 \\
0 \\
0 \\
0 \\
0 \\
0 \\
0 \\
0 \\
0 \\
0 \\
0 \\
0\end{array}$ & & & & \\
\hline Sub-total ... & 11,560 & 3 & & & & \\
\hline $\begin{array}{l}-14 \\
-18 \\
-28 \\
-62 \\
-68 \\
-78 \\
-84\end{array}$ & $\begin{array}{l}276 \\
385 \\
277 \\
336 \\
474 \\
394 \\
309\end{array}$ & $\begin{array}{l}23 \\
34 \\
19 \\
22 \\
39 \\
27 \\
25\end{array}$ & $\begin{array}{l}4.0 \\
8.0 \\
0.5 \\
0.0 \\
7.0 \\
1.0 \\
4.0\end{array}$ & $\begin{array}{l}2.82 \\
3.34 \\
2.81 \\
3.09 \\
3.70 \\
3.35 \\
2.98\end{array}$ & $\begin{array}{l}1.419 \\
2.395 \\
0.178 \\
0.000 \\
1.892 \\
0.299 \\
1.342\end{array}$ & $\begin{array}{l}12.0: 1 \\
11.3: 1 \\
14.6: 1 \\
15.3: 1 \\
12.2: 1 \\
14.6: 1 \\
12.4: 1\end{array}$ \\
\hline
\end{tabular}


TABLE 13 (continued)

\begin{tabular}{|c|c|c|c|c|c|c|}
\hline \multirow{2}{*}{ PLANT NUMBER } & \multicolumn{2}{|c|}{$\begin{array}{l}\text { NOMBEER SEEDS OBSERVED } \\
\text { WITH }\end{array}$} & \multirow{2}{*}{$\begin{array}{l}\text { DEviation } \\
\text { (Dev.) }\end{array}$} & \multirow{2}{*}{$\begin{array}{l}\text { PROBABLE } \\
\text { ERROR } \\
\text { (P.E.) }\end{array}$} & \multirow{2}{*}{$\frac{\text { Dev. }}{\text { P. E. }}$} & \multirow{2}{*}{ ACTUAL RATIO } \\
\hline & $\begin{array}{c}\text { Yellow } \\
\text { cotyledons }\end{array}$ & $\begin{array}{c}\text { Green } \\
\text { cotyledons }\end{array}$ & & & & \\
\hline$(803)-96$ & 311 & 17 & 3.5 & 2.96 & 1.183 & 18.3:1 \\
\hline-100 & 426 & 31 & 2.0 & 3.49 & 0.573 & $13.7: 1$ \\
\hline-278 & 270 & 15 & 3.0 & 2.756 & 1.089 & $18.0: 1$ \\
\hline-288 & 201 & 14 & 2.0 & 2.756 & 0.837 & 13.3:1 \\
\hline-296 & 412 & 27 & 0.0 & 3.42 & 0.000 & $15.2: 1$ \\
\hline Sub-total .. & 4071 & 293 & 20.0 & 10.79 & 1.860 & $13.9: 1$ \\
\hline-6 & 290 & 107 & 8.0 & 5.82 & 1.374 & $2.71: 1$ \\
\hline-8 & 58 & 25 & 5.0 & 2.66 & 1.880 & $2.32: 1$ \\
\hline-16 & 332 & 120 & 7.0 & 6.21 & 1.127 & $2.77: 1$ \\
\hline-36 & 242 & 87 & 5.0 & 5.30 & 0.943 & $2.78: 1$ \\
\hline-40 & 222 & 66 & 6.0 & 4.96 & 1.209 & $3.36: 1$ \\
\hline-48 & 468 & 141 & 11.0 & 7.21 & 1.526 & $3.32: 1$ \\
\hline-56 & 223 & 69 & 4.0 & 4.99 & 0.802 & $3.23: 1$ \\
\hline-74 & 313 & 96 & 6.0 & 5.91 & 1.015 & $3.26: 1$ \\
\hline-92 & 151 & 54 & 3.0 & 4.18 & 0.718 & $2.80: 1$ \\
\hline-272 & 264 & 87 & 1.0 & 5,47 & 0.183 & $3.03: 1$ \\
\hline-294 & 141 & 61 & 10.5 & 4.15 & 2.530 & $2.31: 1$ \\
\hline Sub-total . & 2704 & 913 & 9.0 & 17.56 & 0.513 & $2.96: 1$ \\
\hline
\end{tabular}


TABLE 14

Cotyledon color in $F_{3}$ generation. Plants produced from yellow-cotyledon seeds of $F_{1}$ plants. Variety 8 (yellow) o $\times$ variety $g$ (green) $\sigma^{\top}$.

\begin{tabular}{|c|c|c|c|c|c|c|}
\hline \multirow{2}{*}{ PLANT NUMBERR } & \multicolumn{2}{|c|}{ NCMKBER SEEDS OBSERVED WITE } & \multirow{2}{*}{$\begin{array}{l}\text { DEVIATION } \\
\text { (Dev.) }\end{array}$} & \multirow{2}{*}{$\begin{array}{c}\text { PROBABLE } \\
\text { ERRRR } \\
\text { (P. E.) }\end{array}$} & \multirow{2}{*}{$\frac{\text { Dev. }}{\text { P.E. }}$} & \multirow{2}{*}{$\begin{array}{l}\text { ACTDAL } \\
\text { RAITO }\end{array}$} \\
\hline & $\begin{array}{l}\text { Yellow } \\
\text { cotyledons }\end{array}$ & $\begin{array}{c}\text { Green } \\
\text { cotyledons }\end{array}$ & & & & \\
\hline$(470)-59$ & 94 & 0 & & & & \\
\hline-61 & 51 & 0 & & & & \\
\hline-62 & 97 & 0 & & & & \\
\hline-66 & 73 & 0 & & & & \\
\hline-67 & 100 & 0 & & & & \\
\hline-68 & 73 & 0 & & & & \\
\hline-69 & 59 & 0 & & & & \\
\hline-76 & 64 & 0 & & & & \\
\hline-78 & 53 & $3(?)$ & & & & \\
\hline-79 & 58 & 0 & & & & \\
\hline Sub-total .. & 722 & $3(?)$ & & & & \\
\hline-60 & 72 & 3 & 2 & 1.410 & 1.419 & $24.0: 1$ \\
\hline-70 & 63 & 5 & 1 & 1.346 & 0.743 & $12.6: 1$ \\
\hline-71 & 21 & 4 & 2 & 0.816 & 2.451 & $5.3: 1$ \\
\hline-75 & 42 & 4 & 1 & 1.110 & 0.901 & $10.5: 1$ \\
\hline-77 & $24 \dagger(18)^{*}$ & $6 \dagger(12)^{*}$ & 4 & 0.894 & 4.475 & $4.0: 1$ \\
\hline Sub-total ..... & 242 & 22 & 7 & 2.550 & 2.750 & 10.1:1 \\
\hline-63 & 54 & 15 & 2 & 2.430 & 0.823 & $3.60: 1$ \\
\hline-65 & $26 \dagger(20)^{*}$ & $15 \dagger(22)^{*}$ & 5 & 1.870 & 2.674 & $1.73: 1$ \\
\hline-72 & 27 & 8 & 1 & 1.730 & 0.578 & $3.38: 1$ \\
\hline Sub-total ... & 107 & 38 & 2 & 3.520 & 0.570 & $2.82: 1$ \\
\hline
\end{tabular}

* Original figures.

$\dagger$ Corrected figures. See text.

TABLE 15

Cotyledon color in $F_{3}$ generation. Data from a natural cross. Progeny of plant B82a.

\begin{tabular}{|c|c|c|c|c|c|c|}
\hline \multirow{2}{*}{ PLANT NUMBER } & \multicolumn{2}{|c|}{$\begin{array}{l}\text { NOMBER SEEDS OBSERVED } \\
\text { WITH }\end{array}$} & \multirow{2}{*}{$\begin{array}{l}\text { DEVIATION } \\
\text { (Dev.) }\end{array}$} & \multirow{2}{*}{$\begin{array}{c}\text { PROBABLE } \\
\text { ERROR } \\
\text { (P. E.) }\end{array}$} & \multirow{2}{*}{$\frac{\text { Dev. }}{\text { P. E. }}$} & \multirow{2}{*}{ ACTUAL RAT IO } \\
\hline & $\begin{array}{l}\text { Yellow } \\
\text { cotyledons }\end{array}$ & $\begin{array}{c}\text { Green } \\
\text { cotyledons }\end{array}$ & & & & \\
\hline $\begin{array}{l}(1233)-1 \\
(1233)-4\end{array}$ & $\begin{array}{l}109 \\
146\end{array}$ & $\begin{array}{l}0 \\
0\end{array}$ & & & & \\
\hline Sub-total .. & 255 & 0 & & & & \\
\hline$(1233)-2$ & 175 & 10 & 2 & 2.221 & 0.9005 & $17.5: 1$ \\
\hline$(1233)-3$ & 186 & 9 & 3 & 2.280 & 1. 3160 & $20.7: 1$ \\
\hline Sub-total ... & 361 & 19 & 5 & 3.183 & 1.5710 & 19.0:1 \\
\hline
\end{tabular}


TABLE 16

Colyledon color in $F_{4}$ generation. Planis produced from seeds with yellow colyledons. Progeny of $(470)-60$.

\begin{tabular}{|c|c|c|c|c|c|c|}
\hline \multirow{2}{*}{ PLANT NUMBBER } & \multicolumn{2}{|c|}{$\begin{array}{l}\text { NUMBER SEEDS OBSERVED } \\
\text { WITH }\end{array}$} & \multirow{2}{*}{$\begin{array}{c}\text { DEVIATION } \\
\text { (Dev.) }\end{array}$} & \multirow{2}{*}{$\begin{array}{c}\text { PROBABLE } \\
\text { ERROR } \\
\text { (P. E.) }\end{array}$} & \multirow{2}{*}{$\frac{\text { Dev. }}{\text { P. E. }}$} & \multirow{2}{*}{ ACTOAL RATIO } \\
\hline & $\begin{array}{l}\text { Yellow } \\
\text { cotyledons }\end{array}$ & $\begin{array}{c}\text { Green } \\
\text { cotyledons }\end{array}$ & & & & \\
\hline $\begin{array}{r}(906)-24 \\
-26 \\
-32 \\
-34 \\
-42 \\
-58 \\
-60\end{array}$ & $\begin{array}{l}339 \\
508 \\
284 \\
246 \\
178 \\
559 \\
397\end{array}$ & $\begin{array}{l}0 \\
0 \\
0 \\
0 \\
0 \\
0 \\
0\end{array}$ & & & & \\
\hline Sub-total .... & 2511 & 0 & & & & \\
\hline $\begin{array}{l}-30 \\
-36 \\
-40 \\
-56\end{array}$ & $\begin{array}{l}439 \\
428 \\
359 \\
214\end{array}$ & $\begin{array}{l}27 \\
25 \\
29 \\
17\end{array}$ & $\begin{array}{l}2.0 \\
3.0 \\
5.0 \\
3.0\end{array}$ & $\begin{array}{l}3.52 \\
3.475 \\
3.220 \\
2.480\end{array}$ & $\begin{array}{l}0.570 \\
0.864 \\
1.550 \\
1.210\end{array}$ & $\begin{array}{l}16.30: 1 \\
17.10: 1 \\
12.40: 1 \\
12.60: 1\end{array}$ \\
\hline Sub-total .... & 1440 & 98 & 2,0 & 6.400 & 0.313 & $14.70: 1$ \\
\hline $\begin{array}{l}-44 \\
-46 \\
-50 \\
-52 \\
-54 \\
-62\end{array}$ & $\begin{array}{l}195 \\
474 \\
285 \\
330 \\
592 \\
164\end{array}$ & $\begin{array}{r}62 \\
180 \\
93 \\
126 \\
203 \\
67\end{array}$ & $\begin{array}{r}2.0 \\
16.0 \\
1.5 \\
12.0 \\
4.0 \\
9.0\end{array}$ & $\begin{array}{l}4.680 \\
7.470 \\
5.680 \\
6.240 \\
8.240 \\
4.440\end{array}$ & $\begin{array}{l}0.430 \\
2.140 \\
0.260 \\
1.920 \\
0.486 \\
2.030\end{array}$ & $\begin{array}{l}3.15: 1 \\
2.63: 1 \\
3.06: 1 \\
2.62: 1 \\
2.92: 1 \\
2.45: 1\end{array}$ \\
\hline Sub-total .... & 2040 & 731 & 38.0 & 15.370 & 2.470 & $2.79: 1$ \\
\hline
\end{tabular}


TABLE 17

Cotyledon color in $F_{4}$ generation. Planis produced from seeds with yellow cotyledons. Progeny of $(470)-77$.

\begin{tabular}{|c|c|c|c|c|c|c|}
\hline \multirow{2}{*}{ PLANT NUMBER } & \multicolumn{2}{|c|}{$\begin{array}{l}\text { NUMBERR SEEDS OBSERVED } \\
\text { WITH }\end{array}$} & \multirow{2}{*}{$\begin{array}{l}\text { DEviation } \\
\text { (Dev.) }\end{array}$} & \multirow{2}{*}{$\begin{array}{c}{ }^{*} \\
\text { PROBABLEE } \\
\text { ERROR } \\
\text { (P.E. })\end{array}$} & \multirow{2}{*}{$\begin{array}{l}\text { Dev. } \\
\text { P. E. }\end{array}$} & \multirow{2}{*}{ ACTUAL, RATIO } \\
\hline & $\begin{array}{l}\text { Yellow } \\
\text { cotyledons }\end{array}$ & $\begin{array}{c}\text { Green } \\
\text { cotyledons }\end{array}$ & & & & \\
\hline $\begin{array}{r}(907)-80 \\
-82 \\
-88 \\
-90 \\
-92 \\
-94\end{array}$ & $\begin{array}{l}210 \\
231 \\
437 \\
284 \\
271 \\
328\end{array}$ & $\begin{array}{l}0 \\
0 \\
0 \\
0 \\
2(?) \\
0\end{array}$ & & & & \\
\hline Sub-total ... & 1761 & $2(?)$ & & & & \\
\hline $\begin{array}{l}-76 \\
-84 \\
-86\end{array}$ & $\begin{array}{r}283 \\
7 \\
332\end{array}$ & $\begin{array}{r}21 \\
1 \\
26\end{array}$ & $\begin{array}{l}2.0 \\
0.5 \\
4.0\end{array}$ & $\begin{array}{l}2.850 \\
0.462 \\
3.090\end{array}$ & $\begin{array}{l}0.702 \\
1.083 \\
1.295\end{array}$ & $\begin{array}{r}13.50: 1 \\
7.00: 1 \\
12.80: 1\end{array}$ \\
\hline Sub-total... & 622 & 48 & 6.0 & 4.230 & 1.420 & $13.00: 1$ \\
\hline $\begin{array}{l}-74 \\
-78\end{array}$ & $\begin{array}{l}282 \\
294\end{array}$ & $\begin{array}{r}93 \\
111\end{array}$ & $\begin{array}{r}1.0 \\
10.0\end{array}$ & $\begin{array}{l}5.660 \\
5.880\end{array}$ & $\begin{array}{l}0.177 \\
1.710\end{array}$ & $\begin{array}{l}3.03: 1 \\
2.65: 1\end{array}$ \\
\hline Sub-total .... & 576 & 204 & 9.0 & 8.160 & 1.103 & $2.82: 1$ \\
\hline
\end{tabular}


TABLE 18

Cotyledon color in $F_{4}$ generation. Plants produced from seeds with yellow cotyledons. Progeny of $(470)-75$.

\begin{tabular}{|c|c|c|c|c|c|c|}
\hline \multirow{2}{*}{ PLANT NUMBER } & \multicolumn{2}{|c|}{$\begin{array}{l}\text { NUMRER SERDS OBSERVED } \\
\text { WITH }\end{array}$} & \multirow{2}{*}{$\begin{array}{l}\text { DEVIATION } \\
\text { (Dev.) }\end{array}$} & \multirow{2}{*}{$\begin{array}{c}\text { PROBABLY } \\
\text { ERROR } \\
\text { (P.E.) }\end{array}$} & \multirow{2}{*}{$\frac{\text { Dev. }}{\text { P.E. }}$} & \multirow{2}{*}{ ACTUAL raTro } \\
\hline & $\begin{array}{c}\text { Yellow } \\
\text { cotyledons }\end{array}$ & $\begin{array}{c}\text { Green } \\
\text { cotyledons }\end{array}$ & & & & \\
\hline $\begin{array}{r}(912)-278 \\
-284 \\
-288 \\
-296\end{array}$ & $\begin{array}{l}256 \\
498 \\
474 \\
152\end{array}$ & $\begin{array}{l}0 \\
0 \\
0 \\
0\end{array}$ & . & . & & \\
\hline Sub-total ... & 1380 & 0 & & & & \\
\hline $\begin{array}{l}-262 \\
-266 \\
-276 \\
-292 \\
-294 \\
-298\end{array}$ & $\begin{array}{l}435 \\
382 \\
442 \\
416 \\
395 \\
405\end{array}$ & $\begin{array}{l}26 \\
24 \\
31 \\
30 \\
24 \\
33\end{array}$ & $\begin{array}{l}3 \\
1 \\
1 \\
2 \\
2 \\
6\end{array}$ & $\begin{array}{l}3.51 \\
3.29 \\
3.55 \\
3.45 \\
3.34 \\
3.42\end{array}$ & $\begin{array}{l}0.855 \\
0.304 \\
0.282 \\
0.580 \\
0.599 \\
1.755\end{array}$ & $\begin{array}{l}16.70: 1 \\
15.90: 1 \\
14.30: 1 \\
13.90: 1 \\
16.50: 1 \\
12.30: 1\end{array}$ \\
\hline Sub-total ... & 2070 & 168 & 28 & 7.72 & 3.267 & $12.30: 1$ \\
\hline $\begin{array}{l}-260 \\
-268 \\
-270 \\
-272 \\
-274 \\
-280 \\
-286\end{array}$ & $\begin{array}{l}359 \\
454 \\
334 \\
291 \\
250 \\
453 \\
275\end{array}$ & $\begin{array}{r}124 \\
158 \\
102 \\
121 \\
79 \\
137 \\
85\end{array}$ & $\begin{array}{c}3 \\
5 \\
7 \\
18 \\
3 \\
10.5 \\
5\end{array}$ & $\begin{array}{l}6.42 \\
7.23 \\
6.10 \\
5.93 \\
5.30 \\
7.09 \\
5.54\end{array}$ & $\begin{array}{l}0.468 \\
0.692 \\
1.150 \\
3.036 \\
0.567 \\
1.481 \\
0.903\end{array}$ & $\begin{array}{l}2.90: 1 \\
2.87: 1 \\
3.28: 1 \\
2.41: 1 \\
3.17: 1 \\
3.30: 1 \\
3.20: 1\end{array}$ \\
\hline Sub-total .... & 2416 & 806 & 0.5 & 16.58 & 0.030 & $3.00: 1$ \\
\hline
\end{tabular}


TABLE 19

Cotyledon color in $F_{4}$ generation. Plants produced from seeds with yellow cotyledons. Progeny of $(470)-70$.

\begin{tabular}{|c|c|c|c|c|c|c|}
\hline \multirow{2}{*}{ PLANT NUMBER } & \multicolumn{2}{|c|}{$\begin{array}{l}\text { NUMBER SEEDS OBSERVED } \\
\text { WITH }\end{array}$} & \multirow{2}{*}{$\begin{array}{l}\text { DEviATION } \\
\text { (Dev.) }\end{array}$} & \multirow{2}{*}{$\begin{array}{c}\text { PROBABLE } \\
\text { FRROR } \\
\text { (P.E.) }\end{array}$} & \multirow{2}{*}{$\frac{\text { Dev. }}{\text { P.E. }}$} & \multirow{2}{*}{ ACTUAL RATIO } \\
\hline & $\begin{array}{c}\begin{array}{c}\text { Yellow } \\
\text { cotyledons }\end{array}\end{array}$ & $\begin{array}{c}\text { Green } \\
\text { cotyledons }\end{array}$ & & & & \\
\hline$(920)-20$ & 157 & 0 & & & & \\
\hline-22 & 381 & 0 & & & & \\
\hline-26 & 308 & 0 & & & & \\
\hline-30 & 408 & 0 & & & & \\
\hline-32 & 433 & 0 & & & & \\
\hline-38 & 407 & 0 & & & & \\
\hline-40 & 295 & 0 & & & & \\
\hline-44 & 270 & 0 & & & & \\
\hline-46 & 590 & 0 & & & & \\
\hline-50 & 200 & 0 & & & & \\
\hline-52 & 517 & 0 & & & & \\
\hline Sub-total ... & 3946 & 0 & & & & \\
\hline-34 & 497 & 28 & 5 & 3.74 & 1.337 & $17.70: 1$ \\
\hline-36 & 375 & 17 & 7.5 & 3.23 & 2.322 & $22.10: 1$ \\
\hline-48 & 349 & 20 & 3 & 3.14 & 0.956 & $17.50: 1$ \\
\hline Sub-total . . & 1221 & 65 & 15 & 5.85 & 2.565 & $18.80: 1$ \\
\hline-24 & 291 & 101 & 3 & 5.78 & 0.519 & $2.88: 1$ \\
\hline-28 & 147 & 45 & 3 & 4.05 & 0.741 & $3.27: 1$ \\
\hline-42 & 335 & 98 & 10 & 6.08 & 1.645 & $.3 .42: 1$ \\
\hline-54 & 388 & 95 & 26 & 6.42 & 4.050 & $4.08: 1$ \\
\hline-56 & 413 & 125 & 9.5 & 6.77 & 1.403 & $3.30: 1$ \\
\hline Sub-total . & 1574 & 464 & 45.5 & 13.19 & 3.450 & $3.39: 1$ \\
\hline
\end{tabular}


TABLE 20

Cotyledon color in $F_{4}$ generation. Plants produced from seeds with yellow cotyledons. Progeny of $(470)-71$.

\begin{tabular}{|c|c|c|c|c|c|c|}
\hline \multirow{2}{*}{ PLANT NUMBER } & \multicolumn{2}{|c|}{$\begin{array}{l}\text { NUMBER SEEDS OBSERVED } \\
\text { WITH }\end{array}$} & \multirow{2}{*}{$\begin{array}{l}\text { Deviation } \\
\text { (Dev.) }\end{array}$} & \multirow{2}{*}{$\begin{array}{c}\text { PROBABLIE } \\
\text { ERROR } \\
\text { (P. E.) }\end{array}$} & \multirow{2}{*}{$\frac{\text { Dev. }}{\text { P.E. }}$} & \multirow{2}{*}{ ACTUAL RATIO } \\
\hline & $\begin{array}{l}\text { Yellow } \\
\text { cotyledons }\end{array}$ & $\begin{array}{c}\text { Green } \\
\text { cotyledons }\end{array}$ & & & & \\
\hline (903)-190 & 247 & 0 & & & & \\
\hline-194 & 571 & $1(?)$ & & & & \\
\hline-196 & 399 & 0 & & & & \\
\hline-198 & 515 & 0 & & & & \\
\hline-202 & 459 & 0 & & & & \\
\hline-204 & 335 & 0 & & & & \\
\hline-210 & 418 & 0 & & & & \\
\hline-212 & 605 & 0 & & & & \\
\hline-216 & 512 & 0 & & & & \\
\hline Sub-total . . . & 4061 & 1 (?) & & & & \\
\hline-188 & 274 & 18 & 0 & 2.79 & 0.0 & $15.2: 1$ \\
\hline-192 & 412 & 20 & 7 & 3.39 & 2.065 & $20.6: 1$ \\
\hline Sub-total .... & 686 & 38 & 7 & 4.39 & 1.595 & $18.0: 1$ \\
\hline-208 & 385 & 119 & 7 & 6.56 & 1.068 & $3.2: 1$ \\
\hline
\end{tabular}

TABLE 21

Cotyledon color in $F_{4}$ generation. Plants produced from seeds with yellow cotyledons. Progeny of $(470)-72$.

\begin{tabular}{|c|c|c|c|c|c|c|}
\hline \multirow{2}{*}{ PLANT NUMBER } & \multicolumn{2}{|c|}{$\begin{array}{l}\text { NUMBER SEEDS OBSERVED } \\
\text { WITH }\end{array}$} & \multirow{2}{*}{$\begin{array}{l}\text { DEVIATION } \\
\text { (Dev.) }\end{array}$} & \multirow{2}{*}{$\begin{array}{c}\text { PROBABLE } \\
\text { ERROR } \\
\text { (P. E.) }\end{array}$} & \multirow{2}{*}{$\frac{\text { Dev. }}{\text { P.E. }}$} & \multirow{2}{*}{ ACTUAL RATTO } \\
\hline & $\begin{array}{l}\text { Yellow } \\
\text { cotyledons }\end{array}$ & $\begin{array}{c}\text { Green } \\
\text { cotyledons }\end{array}$ & & & & \\
\hline $\begin{array}{r}(913)-18 \\
-28 \\
-38 \\
-44 \\
-48 \\
-54\end{array}$ & $\begin{array}{l}484 \\
517 \\
388 \\
482 \\
502 \\
486\end{array}$ & $\begin{array}{l}0 \\
0 \\
0 \\
0 \\
0 \\
0\end{array}$ & & & & \\
\hline Sub-total . . & 2859 & 0 & & & & \\
\hline $\begin{array}{l}-22 \\
-24 \\
-26 \\
-30 \\
-32 \\
-34 \\
-40 \\
-46 \\
-50 \\
-52 \\
-56\end{array}$ & $\begin{array}{l}267 \\
322 \\
295 \\
258 \\
273 \\
382 \\
381 \\
408 \\
178 \\
265 \\
403\end{array}$ & $\begin{array}{r}104 \\
117 \\
104 \\
80 \\
92 \\
132 \\
128 \\
135 \\
72 \\
91 \\
125\end{array}$ & $\begin{array}{r}11.0 \\
7.0 \\
4.0 \\
4.5 \\
1.0 \\
3.5 \\
1.0 \\
1.0 \\
9.5 \\
2.0 \\
7.0\end{array}$ & $\begin{array}{l}5.62 \\
6.12 \\
5.83 \\
5.37 \\
5.58 \\
6.62 \\
6.59 \\
6.81 \\
4.62 \\
5.51 \\
6.71\end{array}$ & $\begin{array}{l}1.960 \\
1.144 \\
0.687 \\
0.838 \\
0.179 \\
0.529 \\
0.152 \\
0.147 \\
2.057 \\
0.363 \\
1.044\end{array}$ & $\begin{array}{l}2.57: 1 \\
2.75: 1 \\
2.82: 1 \\
3.23: 1 \\
2.97: 1 \\
2.89: 1 \\
2.98: 1 \\
3.02: 1 \\
2.47: 1 \\
2.91: 1 \\
3.20: 1\end{array}$ \\
\hline Sub-total .... & 3432 & 1180 & 27.0 & 19.83 & 1.362 & $2.91: 1$ \\
\hline
\end{tabular}


TABLE 22

Cotyledon color in $F_{4}$ generation. Plants produced from seeds with yellow cotyledons. Progeny of $(470)-65$.

\begin{tabular}{|c|c|c|c|c|c|c|}
\hline \multirow{2}{*}{ PLANT NUMBER } & \multicolumn{2}{|c|}{$\begin{array}{l}\text { NUARER SEEDS OBSERVED } \\
\text { WITH }\end{array}$} & \multirow{2}{*}{$\begin{array}{l}\text { DEviatron } \\
\text { (Dev.) }\end{array}$} & \multirow{2}{*}{$\begin{array}{c}\text { PROBABLE } \\
\text { ERROR } \\
\text { (P.E.) }\end{array}$} & \multirow{2}{*}{$\frac{\text { Dev. }}{\text { P.E. }}$} & \multirow{2}{*}{ ACTEAL RATKO } \\
\hline & $\begin{array}{l}\text { Yellow } \\
\text { cotyledons }\end{array}$ & $\begin{array}{c}\text { Green } \\
\text { cotyledons }\end{array}$ & & & & \\
\hline$(909)-164$ & 364 & 5 & & & & \\
\hline-166 & 349 & $1(?)$ & & & & \\
\hline-170 & 117 & 2 & & & & \\
\hline Sub-total .... & 830 & $7+(1 ?)$ & & & & \\
\hline-150 & 282 & 80 & 10.5 & 5.56 & 1.89 & $3.53: 1$ \\
\hline-160 & 272 & 91 & 0.0 & 5.57 & 0.00 & $3.00: 1$ \\
\hline-162 & 124 & 43 & 1.0 & 3.77 & 0.266 & $2.88: 1$ \\
\hline-168 & 242 & 97 & 12.0 & 5.38 & 0.230 & $2.49: 1$ \\
\hline-172 & 391 & 127 & 2.5 & 6.65 & 0.376 & $3.08: 1$ \\
\hline Sub-total ... & 1311 & 438 & 1.0 & 12.21 & 0.082 & $3.00: 1$ \\
\hline
\end{tabular}

TABLE 23

Cotyledon color in $F_{4}$ generation. Plants produced from seeds with yellow cotyledons. Progeny of $(470)-63$.

\begin{tabular}{|c|c|c|c|c|c|c|}
\hline \multirow{2}{*}{ PLANT NUMBer } & \multicolumn{2}{|c|}{$\begin{array}{l}\text { NUMBER SEEDS OBSERVED } \\
\text { WITH }\end{array}$} & \multirow{2}{*}{$\begin{array}{l}\text { DEVIAITON } \\
\text { (Dev.) }\end{array}$} & \multirow{2}{*}{$\begin{array}{c}\text { PROBABLE } \\
\text { ERROR } \\
\text { (P.E.) }\end{array}$} & \multirow{2}{*}{$\frac{\text { Dev. }}{\overline{P . E}}$} & \multirow{2}{*}{ ACTDAL RATIO } \\
\hline & $\begin{array}{l}\text { Yellow } \\
\text { cotyletons }\end{array}$ & $\begin{array}{c}\text { Green } \\
\text { cotyledons }\end{array}$ & & & & \\
\hline$(915)-102$ & 424 & 0 & & & & \\
\hline-104 & 493 & 1 & & & & \\
\hline-114 & 188 & 0 & & & & \\
\hline-116 & 235 & 0 & & & & \\
\hline-120 & 104 & 0 & & & & \\
\hline-134 & 419 & 0 & & & & \\
\hline Sub-total ... & 1863 & 1 & & & & \\
\hline-98 & 110 & 27 & 7.0 & 3.42 & 2.047 & 4.08:1 \\
\hline-106 & 265 & 82 & 5.0 & 5.44 & 0.919 & $3.23: 1$ \\
\hline-108 & 299 & 101 & 1.0 & 5.84 & 0.171 & $2.96: 1$ \\
\hline-112 & 233 & 74 & 3.0 & 5.12 & 0.586 & $3.15: 1$ \\
\hline-118 & 252 & 78 & 4.5 & 5.31 & 0.847 & $3.23: 1$ \\
\hline-122 & 206 & 59 & 7.0 & 4.75 & 1.474 & $3.49: 1$ \\
\hline-124 & 216 & 67 & 4.0 & 4.91 & 0.815 & $3.22: 1$ \\
\hline-128 & 284 & 96 & 1.0 & 5.69 & 0.176 & $2.96: 1$ \\
\hline Sub-total & 1865 & 584 & 28.0 & 14.45 & 1.938 & $3.19: 1$ \\
\hline
\end{tabular}


TABLE 24

Cotyledon color in $F_{4}$ generation. Progeny of plant (470)-59.

\begin{tabular}{c|c|c}
\hline PLANT NUMBER & $\begin{array}{c}\text { NUMBER SEEDS WITH YELIOW } \\
\text { COTYLDONS }\end{array}$ & $\begin{array}{c}\text { NOMBER SEEDS WITH GREEN } \\
\text { COTYLED ONS }\end{array}$ \\
\cline { 2 - 3 }$(911)-220$ & 485 & 0 \\
-222 & 487 & 0 \\
-224 & 409 & 0 \\
-228 & 192 & 0 \\
-232 & 320 & 0 \\
-234 & 329 & 0 \\
-236 & 406 & $2(?)$ \\
-238 & 437 & 0 \\
-240 & 310 & 0 \\
-242 & 648 & $2(?)$ \\
-248 & 401 & 0 \\
-252 & 394 & 0 \\
-258 & 423 & 0 \\
\hline
\end{tabular}

TABLE 25

Cotyledon color in $F_{4}$ generation. Progeny of plant (470)-61.

\begin{tabular}{c|c|c}
\hline PLANT NUMBER & $\begin{array}{c}\text { NUMBR SEEDS WITH YELLOW } \\
\text { COTYLEDONS }\end{array}$ & $\begin{array}{c}\text { NUMBER SEEDS WITH GREEN } \\
\text { COTYLEDONS }\end{array}$ \\
\hline (905)- & 366 & 0 \\
-4 & 450 & 0 \\
-6 & 216 & 0 \\
-8 & 239 & 0 \\
-10 & 290 & 0 \\
-12 & 261 & 0 \\
-14 & 180 & 0 \\
-16 & 270 & 0 \\
-270 & 309 & 0 \\
-272 & 390 & 0 \\
-274 & 379 & 0 \\
-276 & 270 & 0 \\
-294 & 411 & 0 \\
-278 & 312 & 0 \\
-280 & 385 & 0 \\
-282 & 307 & 0 \\
-284 & 342 & 0 \\
-288 & 305 & 9 \\
-290 & 406 & 0 \\
-298 & 252 & 0 \\
\hline
\end{tabular}


TABLE 26

Cotyledon color in F generation. Progeny of plant (470)-62.

\begin{tabular}{|c|c|c|}
\hline PLANT NUMBBER & $\begin{array}{l}\text { NUMBER SEEDS WITH YELLOW } \\
\text {, COTYLEDONS }\end{array}$ & $\begin{array}{l}\text { NUMBER OF SEEDS WITH GREEN } \\
\text { COTYLEDONS }\end{array}$ \\
\hline (918)-238 & 284 & 0 \\
\hline-240 & 467 & 1 \\
\hline-242 & 348 & 0 \\
\hline-244 & 328 & 0 \\
\hline-246 & 395 & 5 \\
\hline-248 & 317 & 0 \\
\hline-250 & 280 & 0 \\
\hline-252 & 201 & 0 \\
\hline-254 & 437 & 3 \\
\hline-260 & 628 & 0 \\
\hline-262 & 472 & 0 \\
\hline-264 & 257 & 0 \\
\hline-266 & 511 & 0 \\
\hline-270 & 396 & 1 \\
\hline-272 & 250 & 2 \\
\hline-274 & 343 & 1 \\
\hline-276 & 350 & 0 \\
\hline Total...... & 6264 & 13 \\
\hline
\end{tabular}

TABLE 27

Cotyledon color in $F_{1}$ generation. Progeny of plant (470)-66.

\begin{tabular}{c|c|c}
\hline PLANT NUMBER & $\begin{array}{c}\text { NUMBER SEENS WITH YELLOW } \\
\text { COTYLEDONS }\end{array}$ & $\begin{array}{c}\text { NUMBER SEEDS WITH GREEN } \\
\text { COTYLEDONS }\end{array}$ \\
\hline (914)-58 & 423 & 0 \\
-60 & 348 & 0 \\
-64 & 241 & 0 \\
-66 & 380 & 0 \\
-68 & 413 & 0 \\
-70 & 365 & 0 \\
-72 & 274 & 0 \\
-74 & 208 & 0 \\
-76 & 68 & 0 \\
-78 & 246 & 0 \\
-80 & 406 & 0 \\
-82 & 298 & 0 \\
-84 & 417 & 0 \\
-86 & 323 & 0 \\
-88 & 594 & 0 \\
-90 & 320 & 0 \\
-92 & 387 & 0 \\
\hline Total................. & 5711 & 0 \\
\hline
\end{tabular}


TABLE 28

Cotyledon color in F $F_{4}$ generation. Progeny of plant (470)-67.

\begin{tabular}{c|c|c}
\hline PLANT NUMBER & $\begin{array}{c}\text { NUMBER SEEDS WITH YELLOW } \\
\text { COTYLEDONS }\end{array}$ & $\begin{array}{c}\text { NOMBER SEED WITH GREEN } \\
\text { COTYLEDONS }\end{array}$ \\
\cline { 1 - 3 }$(916)-162$ & 539 & 0 \\
-164 & 350 & 0 \\
-166 & 473 & 0 \\
-168 & 481 & 0 \\
-170 & 185 & 0 \\
-174 & 475 & 0 \\
-176 & 473 & 0 \\
-178 & 575 & 0 \\
-180 & 506 & 0 \\
-182 & 484 & 0 \\
-184 & 490 & 0 \\
-186 & 436 & 0 \\
-188 & 469 & 0 \\
-192 & 415 & 0 \\
-194 & 437 & 0 \\
-196 & 372 & 0 \\
\hline Total ................ & 7160 & 0 \\
\hline
\end{tabular}

TABLE 29

Cotyledon color in F generation. Progeny of plant (470)-68.

\begin{tabular}{c|c|c}
\hline PLANT NOMRER & $\begin{array}{c}\text { NUMER SEEDS WITH YELIOW } \\
\text { COTYLEDONS }\end{array}$ & $\begin{array}{c}\text { NUMBER SEEDS WITH GREEN } \\
\text { COTYLEDONS }\end{array}$ \\
\cline { 1 - 2 }$(904)-218$ & 362 & 0 \\
-220 & 340 & 0 \\
-230 & 485 & 0 \\
-234 & 578 & 0 \\
-236 & 244 & 0 \\
-238 & 321 & 0 \\
-242 & 486 & 0 \\
-244 & 452 & 0 \\
-246 & 386 & 0 \\
-248 & 236 & 0 \\
-250 & 390 & 0 \\
-252 & 427 & 0 \\
-254 & 396 & $3(?)$ \\
-256 & 412 & $2(?)$ \\
-258 & 230 & 0 \\
-260 & 203 & 0 \\
-262 & 388 & 0 \\
-264 & 427 & 0 \\
-266 & 561 & 5 \\
\hline
\end{tabular}

Genetics 6: N 1921 
TABLE 30

Cotyledon color in $F_{4}$ generation. Progeny of plant (470)-69.

\begin{tabular}{c|c|c}
\hline PLANT NUMBER & $\begin{array}{c}\text { NUMBER SEEDS WITR YELIOW } \\
\text { COTYLDONS }\end{array}$ & $\begin{array}{c}\text { NUMBER SEEDS WITH GREEN } \\
\text { COTYLEDONS }\end{array}$ \\
\cline { 1 - 3 }$(908)-96$ & 416 & 1 \\
-98 & 398 & 0 \\
-100 & 699 & 0 \\
-102 & 159 & 0 \\
-104 & 391 & 0 \\
-106 & 538 & 0 \\
-108 & 229 & 0 \\
-110 & 429 & 0 \\
-112 & 446 & 3 \\
-118 & 201 & 1 \\
-122 & 666 & 0 \\
-124 & 348 & 1 (?) \\
-126 & 466 & 0 \\
-128 & 342 & 0 \\
-132 & 472 & 0 \\
-134 & 176 & 0 \\
\hline Total............. & 6376 & $5+(1 ?)$ \\
\hline
\end{tabular}

TABLE 31

Cotyledon color in $F_{4}$ generation. Progeny of plant (470)-76.

\begin{tabular}{c|c|c}
\hline PIANT NOMBER & $\begin{array}{c}\text { NUMER SEEDS WITH YELIOW } \\
\text { COTYIEDON }\end{array}$ & $\begin{array}{c}\text { NUMBER SEEDS WITH GREEN } \\
\text { COTYEDONS }\end{array}$ \\
\hline (921)-70 & 193 & 0 \\
-72 & 373 & 0 \\
-80 & 482 & 0 \\
-82 & 222 & 0 \\
-84 & 477 & 0 \\
-86 & 340 & 0 \\
-88 & 459 & 0 \\
-90 & 431 & 0 \\
-92 & 448 & 0 \\
-96 & 557 & 0 \\
-98 & 706 & 0 \\
-100 & 420 & 0 \\
-104 & 456 & 0 \\
\hline
\end{tabular}


TABLE 32

Cotyledon color in $F_{4}$ generation. Progeny of plant (470)-78.

\begin{tabular}{|c|c|c|}
\hline PLANT NUMBER & $\begin{array}{l}\text { NOMBER SEEDS WITH YELLOW } \\
\text { COTYLEDONS }\end{array}$ & $\begin{array}{l}\text { NUMABER SEEDS WIYH GREEN } \\
\text { COTYLLEDONS }\end{array}$ \\
\hline$(917)-198$ & 362 & 0 \\
\hline-200 & 94 & 0 \\
\hline-202 & 650 & 0 \\
\hline-204 & 79 & 0 \\
\hline-206 & 382 & 0 \\
\hline-208 & 593 & 0 \\
\hline-210 & 228 & 0 \\
\hline-212 & 102 & 0 \\
\hline-214 & 172 & 0 \\
\hline-216 & 350 & 0 \\
\hline-218 & 400 & 0 \\
\hline-220 & 312 & 0 \\
\hline-222 & 237 & 0 \\
\hline-228 & 355 & 0 \\
\hline-230 & 210 & 0 \\
\hline-232 & 350 & 0 \\
\hline-234 & 292 & 0 \\
\hline-236 & 267 & 0 \\
\hline Total...... & 5435 & 0 \\
\hline
\end{tabular}

TABLE 33

Cotyledon color in $F_{4}$ generation. Progeny of plant (470)-79.

\begin{tabular}{c|c|c}
\hline PLANT NUMBER & $\begin{array}{c}\text { NOMRER SEEDS WITH YELLOW } \\
\text { COTYLEDONS }\end{array}$ & $\begin{array}{c}\text { NUMBER SEEDS WTH GREEN } \\
\text { COTYLEDONS }\end{array}$ \\
\hline (910)-180 & 364 & 0 \\
-182 & 394 & 1 (?) \\
-184 & 204 & 0 \\
-186 & 197 & 0 \\
-188 & 292 & 0 \\
-190 & 289 & 0 \\
-192 & 476 & 0 \\
-196 & 300 & 0 \\
-200 & 303 & 0 \\
-202 & 319 & 0 \\
-204 & 501 & 0 \\
-208 & 361 & 0 \\
-212 & 520 & 0 \\
-218 & 353 & 0 \\
\hline Total .................. & 4873 & 1 (?) \\
\hline
\end{tabular}

Genetics 6: N 1921 
TABLE 34

Cotyledon color in $F_{4}$ generation. Plants produced from seeds with green cotyledons.

\begin{tabular}{|c|c|c|c|}
\hline PARENT & PLANT NUMBER & $\begin{array}{l}\text { NOMMBER SEEDS WITH } \\
\text { YELIOW COTYLEDONS }\end{array}$ & $\begin{array}{l}\text { NUMBER SEEDS WITH } \\
\text { GREEN COTYLEDCNS }\end{array}$ \\
\hline \multirow[t]{2}{*}{$(470)-60$} & $\begin{array}{r}(906)-18 \\
-20 \\
-22\end{array}$ & $\begin{array}{l}0 \\
0 \\
0\end{array}$ & $\begin{array}{l}306 \\
427 \\
412\end{array}$ \\
\hline & Sub-total.......... & 0 & 1145 \\
\hline \multirow[t]{2}{*}{$(470)-63$} & $\begin{array}{r}(915)-138 \\
-140 \\
-142 \\
-144 \\
-146 \\
-148 \\
-150 \\
-152 \\
-156\end{array}$ & $\begin{array}{r}2 \\
2 \\
10 \\
1 \\
0 \\
0 \\
1 \\
1 \\
4\end{array}$ & $\begin{array}{r}448 \\
265 \\
366 \\
427 \\
389 \\
56 \\
236 \\
262 \\
392\end{array}$ \\
\hline & Sub-total $\ldots \ldots \ldots$ & 21 & 2841 \\
\hline \multirow[t]{2}{*}{$(470)-65$} & $\begin{array}{r}(909)-136 \\
-138 \\
-140 \\
-142 \\
-148 \\
-152 \\
-154\end{array}$ & $\begin{array}{l}0 \\
0 \\
1 \\
0 \\
0 \\
2 \\
0\end{array}$ & $\begin{array}{l}270 \\
260 \\
437 \\
265 \\
214 \\
494 \\
276\end{array}$ \\
\hline & Sub-total ....... & 3 & 2216 \\
\hline \multirow[t]{2}{*}{$(470)-70$} & $\begin{array}{r}(920)-58 \\
-60 \\
-62 \\
-64\end{array}$ & $\begin{array}{l}0 \\
0 \\
0 \\
0\end{array}$ & $\begin{array}{l}300 \\
319 \\
420 \\
389\end{array}$ \\
\hline & Sub-total .......... & 0 & 1428 \\
\hline \multirow[t]{2}{*}{$(470 z)-71$} & $\begin{array}{r}(903)-184 \\
-186\end{array}$ & $\begin{array}{l}2 \\
2\end{array}$ & $\begin{array}{l}475 \\
456\end{array}$ \\
\hline & Sub-total .......... & 4 & 931 \\
\hline \multirow[t]{2}{*}{$(470)-72$} & $\begin{array}{r}(913)-2 \\
-10 \\
-12 \\
-14 \\
-16\end{array}$ & $\begin{array}{l}0 \\
0 \\
2 \\
0 \\
0\end{array}$ & $\begin{array}{l}305 \\
459 \\
386 \\
478 \\
325\end{array}$ \\
\hline & Sub-total . ......... & 2 & 1953 \\
\hline$(470)-77$ & $(907)-72$ & 3 & 215 \\
\hline
\end{tabular}


TABLE 34 (continued)

\begin{tabular}{c|c|c|c}
\hline PARENT & PLANT NUMRER & $\begin{array}{c}\text { NUMBER SEEDS WITH } \\
\text { YELLOW COTYLEDONS }\end{array}$ & $\begin{array}{c}\text { NUMRER SEEDS WITE } \\
\text { GREEN COTYLEDONS }\end{array}$ \\
\hline$(470)-73$ & $(919)-2$ & 3 & 269 \\
-4 & 0 & 316 \\
-6 & 0 & 455 \\
-12 & 1 & 445 \\
-278 & 0 & 471 \\
-282 & 0 & 448 \\
-284 & 0 & 352 \\
-286 & 1 & 424 \\
-288 & 0 & 543 \\
& -294 & 0 & 462 \\
-296 & 0 & 283 \\
& -298 & 0 & 230 \\
& -300 & 1 & 448 \\
\hline
\end{tabular}

TABLE 35

Inheritance of cotyledon color in Auburn variety. Progeny of beans with green cotyledons.

\begin{tabular}{|c|c|c|}
\hline \multirow{2}{*}{ PLANT NUMBER } & \multicolumn{2}{|c|}{ NUMBER SEEDS OBSERVED WITH } \\
\hline & Yellow cotyledons & Green cotyledons \\
\hline$(210)-292$ & 9 & 446 \\
\hline-298 & 14 & 542 \\
\hline-300 & 14 & 977 \\
\hline-304 & 20 & 986 \\
\hline-306 & 12 & 738 \\
\hline-308 & 27 & 508 \\
\hline-310 & 3 & 590 \\
\hline-312 & 8 & 604 \\
\hline-314 & 6 & 656 \\
\hline-316 & 6 & 324 \\
\hline-318 & 4 & 907 \\
\hline-320 & 13 & 770 \\
\hline-322 & 7 & 753 \\
\hline-324 & 19 & 575 \\
\hline-326 & 8 & 1028 \\
\hline-328 & 8 & 502 \\
\hline-330 & 14 & 987 \\
\hline Total................. & 192 & 11,893 \\
\hline
\end{tabular}


TABLE 36

Inheritance of cotyledon color in the Auburn variety. Progeny of beans with yellow cotyledons.

\begin{tabular}{|c|c|c|c|c|c|c|}
\hline \multirow{2}{*}{ PLANT NUMBER } & \multicolumn{2}{|c|}{$\begin{array}{l}\text { NOMARER SEEDS OBSERVED } \\
\text { WITH }\end{array}$} & \multirow{2}{*}{$\begin{array}{c}\text { DEviAtros } \\
\text { (Dev.) }\end{array}$} & \multirow{2}{*}{$\begin{array}{l}\text { PROBABLE. } \\
\text { ERROR } \\
\text { (P.E.) }\end{array}$} & \multirow{2}{*}{$\frac{\text { Dev. }}{\text { P.E. }}$} & \multirow{2}{*}{ ACTUAL RATIO } \\
\hline & $\begin{array}{l}\text { Yellow } \\
\text { cotyledons }\end{array}$ & $\begin{array}{c}\text { Green } \\
\text { cotyledons }\end{array}$ & & & & \\
\hline$(211)-334$ & 713 & 1 & & & & \\
\hline-340 & 1027 & 1 & & & & \\
\hline-342 & 965 & 0 & & & & \\
\hline-360 & 872 & 0 & & & & \\
\hline-372 & 786 & 0 & & & & \\
\hline-394 & 1008 & 0 & & & & \\
\hline-396 & 859 & 0 & & & & \\
\hline-408 & 740 & 0 & & & & \\
\hline-410 & 905 & 0 & & & & \\
\hline-418 & 750 & 2 & & & & \\
\hline-424 & 491 & 0 & & & & \\
\hline-430 & 744 & 0 & & & & \\
\hline Sub-total ... & 9860 & 4 & & & & \\
\hline$(211)-332$ & 614 & $2: 4$ & 7.0 & 8.40 & 0.83 & $2.869: 1$ \\
\hline-336 & 539 & 176 & 3.0 & 7.81 & .38 & $3.063: 1$ \\
\hline-338 & 646 & 239 & 18.0 & 8.69 & 2.07 & $2.701: 1$ \\
\hline-344 & 611 & 217 & 9.0 & 8.42 & 1.07 & $2.830: 1$ \\
\hline-346 & 554 & 165 & 15.0 & 7.83 & 1.92 & $3.358: 1$ \\
\hline-348 & 597 & 178 & 16.0 & 8.13 & 1.97 & $3.354: 1$ \\
\hline-3.50 & 582 & 197 & 2.0 & 8.15 & 2.45 & $2.950: 1$ \\
\hline-352 & 679 & 214 & 9.0 & 8.73 & 1.03 & $3.173: 1$ \\
\hline-354 & 516 & 158 & 10.5 & 7.58 & 1.39 & $3.266: 1$ \\
\hline-356 & 786 & 248 & 10.5 & 9.39 & 1.12 & $3.169: 1$ \\
\hline-358 & 765 & 207 & 36.0 & 9.11 & 3.95 & $3.696: 1$ \\
\hline-364 & 367 & 106 & 12.0 & 6.35 & 1.89 & $3.460: 1$ \\
\hline-368 & 781 & 254 & 5.0 & 9.39 & .53 & $3.075: 1$ \\
\hline-370 & 827 & 292 & 12.0 & 9.77 & 1.23 & $2.830: 1$ \\
\hline-374 & 528 & 175 & 1.0 & 7.74 & .13 & $3.017: 1$ \\
\hline-376 & 480 & 137 & 16.0 & 7.25 & 2.21 & $3.504: 1$ \\
\hline-378 & 491 & 138 & 19.0 & 7.32 & 2.60 & $3.558: 1$ \\
\hline-380 & 827 & 259 & 4.5 & 9.62 & .47 & $3.190: 1$ \\
\hline-382 & 759 & 276 & 17.0 & 9.39 & 1.81 & $2.750: 1$ \\
\hline-386 & 787 & 276 & 10.0 & 9.52 & 1.05 & $2.850: 1$ \\
\hline-388 & 449 & 143 & 5.0 & 7.11 & .70 & $3.140: 1$ \\
\hline-390 & 452 & 127 & 18.0 & 7.01 & 2.57 & $3.560: 1$ \\
\hline-392 & 613 & 216 & 9.0 & 8.41 & 1.07 & $2.840: 1$ \\
\hline-400 & 1055 & 318 & 25.0 & 10.82 & 2.31 & $3.318: 1$ \\
\hline-402 & 629 & 197 & 9.5 & 8.39 & 1.07 & $3.190: 1$ \\
\hline-404 & 732 & 221 & 17.0 & 9.02 & 1.88 & $3.310: 1$ \\
\hline-406 & 820 & 251 & 17.0 & 9.56 & 1.78 & $3.267: 1$ \\
\hline-412 & 730 & 224 & 14.5 & 9.02 & 1.61 & $3.259: 1$ \\
\hline-414 & 236 & 72 & 5.0 & 5.13 & .97 & $3.278: 1$ \\
\hline-416 & 750 & 237 & 10.0 & 9.18 & 1.09 & $3.165: 1$ \\
\hline
\end{tabular}


TABLE 36 (continued)

\begin{tabular}{|c|c|c|c|c|c|c|}
\hline \multirow{2}{*}{ PLANT NUMBER } & \multicolumn{2}{|c|}{$\begin{array}{l}\text { NUMBER SEEDS OBSERVED } \\
\text { WITH }\end{array}$} & \multirow{2}{*}{$\begin{array}{l}\text { DEVIATION } \\
\text { (Dev.) }\end{array}$} & \multirow{2}{*}{$\begin{array}{c}\text { PROBabLE } \\
\text { ERROR } \\
\text { (P.E.) }\end{array}$} & \multirow{2}{*}{$\frac{\text { Dev. }}{\text { P.E. }}$} & \multirow{2}{*}{ ACTUAL RATIO } \\
\hline & $\begin{array}{l}\text { Yellow } \\
\text { cotyledons }\end{array}$ & $\begin{array}{c}\text { Green } \\
\text { cotyledons }\end{array}$ & & & & \\
\hline$(211)-420$ & 903 & 283 & 13.5 & 10.06 & 1.34 & $3.190: 1$ \\
\hline-426 & 1077 & 335 & 18.0 & 10.97 & 1.64 & $3.215: 1$ \\
\hline-428 & 622 & 181 & 20.0 & 8.28 & 2.42 & $3.440: 1$ \\
\hline-432 & 311 & 106 & 2.0 & 5.96 & .34 & $2.930: 1$ \\
\hline-434 & 712 & 205 & 24.0 & 8.84 & 2.72 & $3.470: 1$ \\
\hline-436 & 784 & 227 & 26.0 & 9.29 & 2.80 & $3.450: 1$ \\
\hline-440 & 843 & 284 & 2.0 & 9.81 & 2.04 & $2.970: 1$ \\
\hline-442 & 754 & 235 & 12.0 & 9.18 & 1.31 & $3.210: 1$ \\
\hline Sub-total .... & 25,211 & 7988 & 312.0 & 53.22 & 5.86 & $3.156: 1$ \\
\hline
\end{tabular}

TABLE 37

Segregation in cotyledon color shown by plants grown from yellow-cotyledon seeds of plant (210)-330.

\begin{tabular}{|c|c|c|c|c|c|c|c|}
\hline \multirow{2}{*}{$\begin{array}{l}\text { PLANT } \\
\text { NUMBER }\end{array}$} & \multirow{2}{*}{ SEED COAT } & \multicolumn{2}{|c|}{ NOMBER SEEDS WITH } & \multirow{2}{*}{ Dev.* } & \multirow{2}{*}{ P. E. } & \multirow{2}{*}{$\frac{\text { Dev. }}{\text { P. E. }}$} & \multirow{2}{*}{$\begin{array}{c}\text { ACTUAL } \\
\text { RATIO }\end{array}$} \\
\hline & & $\begin{array}{l}\text { Yellow } \\
\text { cotyledons }\end{array}$ & $\begin{array}{c}\text { Green } \\
\text { cotyledons }\end{array}$ & & & & \\
\hline $469-50$ & Mottled & 183 & 19 & 6.0 & 2.320 & 2.586 & $9.60: 1$ \\
\hline-51 & Mottled & 182 & 10 & 2.0 & 2.260 & 0.885 & $18.20: 1$ \\
\hline-52 & Mottled & $23 \dagger(?)$ & $0(?)$ & 0.0 & 0.000 & 0.000 & \\
\hline-53 & Self-black & 172 & 25 & 13.0 & 2.290 & 5.677 & $6.88: 1$ \\
\hline-54 & Mottled & 157 & 11 & 0.5 & 2.116 & 0.236 & $14.30: 1$ \\
\hline-56 & Mottled & 286 & 15 & 4.0 & 2.833 & 1.412 & 19.00:1 \\
\hline-57 & Mottled & 228 & 15 & 0.0 & 2.545 & 0.000 & $15.20: 1$ \\
\hline \multicolumn{2}{|l|}{ Total. } & 1208 & 95 & 13.5 & 5.893 & 2.291 & $12.70: 1$ \\
\hline
\end{tabular}

* Calculated on basis of 15:1 ratio.

†Not included in total. See text.

TABLE 38

Seed-coat color in the $F_{2}$ generation.

\begin{tabular}{|c|c|c|c|c|c|c|}
\hline \multirow{2}{*}{ PROGENY NUMCBER } & \multicolumn{2}{|c|}{ NOMBER PLANTS WITH } & \multirow{2}{*}{ Dev. } & \multirow{2}{*}{ P. E. } & \multirow{2}{*}{$\frac{\text { Dev. }}{\text { P. E. }}$} & \multirow{2}{*}{ ACTUAL RATIO } \\
\hline & Green coat & Yellow coat & & & & \\
\hline 470 & 16 & 3 & 2.0 & 1.273 & 1.571 & $5.34: 1$ \\
\hline 801 & 47 & 17 & 1.0 & 2.337 & 0.428 & $2.76: 1$ \\
\hline 803 & 40 & 17 & 3.0 & 2.205 & 1.361 & $2.35: 1$ \\
\hline Total.... & 103 & 37 & 2.0 & 3,456 & 0.579 & $2.78: 1$ \\
\hline
\end{tabular}


TABLE 39

Seed-coat color in $F_{3}$ generation. Progeny of $F_{2}$ plants with green seed coats.

\begin{tabular}{c|c|c|c|c|c|c}
\hline & \multicolumn{2}{|c|}{ NUMMER PLANTS WITH } & Dev. & P. E. & Dev. & ACTUAL RATIO \\
\cline { 2 - 5 } & Green coat & Yellow coat & & & \\
\hline 16 & & & & & \\
908 & 15 & & & & & \\
913 & 24 & & & & & \\
914 & 19 & & & & & \\
919 & 13 & & & & & \\
\hline Sub-total ... & 87 & & & & & \\
\hline 903 & 7 & 7 & 3.5 & 1.093 & 3.203 & $1.00: 1$ \\
904 & 15 & 4 & 1.0 & 1.273 & 0.786 & $3.75: 1$ \\
906 & 15 & 5 & 0.0 & 1.306 & 0.000 & $3.00: 1$ \\
907 & 8 & 4 & 1.0 & 1.012 & 0.988 & $2.00: 1$ \\
910 & 9 & 5 & 1.5 & 1.093 & 1.372 & $1.80: 1$ \\
911 & 9 & 4 & 1.0 & 1.053 & 0.949 & $2.25: 1$ \\
912 & 14 & 3 & 1.0 & 1.204 & 0.831 & $4.67: 1$ \\
916 & 14 & 2 & 2.0 & 1.168 & 1.712 & $7.00: 1$ \\
917 & 13 & 5 & 0.5 & 1.239 & 0.404 & $2.60: 1$ \\
918 & 13 & 4 & 0.0 & 1.204 & 0.000 & $3.25: 1$ \\
920 & 16 & 7 & 1.0 & 1.401 & 0.714 & $2.29: 1$ \\
\hline Sub-total ... & 133 & 50 & 4.0 & 3.951 & 1.012 & $2.66: 1$ \\
\hline
\end{tabular}

TABLE 40

Individual progenies in $F_{2}$ and $F_{3}$ showing distribution with respect to both cotyledon and seed-coat colors.

\begin{tabular}{|c|c|c|c|c|c|c|c|c|c|c|}
\hline \multirow{2}{*}{ COTYLEDON COLOR } & \multirow{2}{*}{$\begin{array}{l}\text { SEED-COAT } \\
\text { COIOR }\end{array}$} & \multicolumn{9}{|c|}{ PROGENY NUMBERS } \\
\hline & & 胥 & $\widehat{\vec{\Xi}}$ & $\widehat{\widehat{3}}$ & $\widehat{\widetilde{o}}$ & 高 & $\widetilde{g}$ & $\frac{\widehat{a}}{d}$ & 芯 & Totals \\
\hline All yellow... & Green & 8 & 18 & 15 & 4 & 2 & 3 & 2 & 5 & 57 \\
\hline All yellow... & Yellow & 2 & 15 & 17 & 5 & 5 & 3 & 2 & 6 & 55 \\
\hline 15 yellow : 1 green. & Green & 5 & 12 & 12 & 1 & 4 & 2 & 6 & 3 & 45 \\
\hline 15 yellow : 1 green. . & Yellow & 0 & 1 & 0 & 1 & $\mathbf{0}$ & 1 & 0 & 0 & 3 \\
\hline 3 yellow : 1 green .... & Green & 2 & 14 & 11 & 0 & 6 & 2 & 6 & 4 & 45 \\
\hline 3 yellow : 1 green .... & Yellow & 1 & 1 & $\mathbf{0}$ & 1 & 0 & 0 & 1 & 1 & 5 \\
\hline All green $\ldots \ldots \ldots, \ldots, \ldots, \ldots$ & Green & 1 & 4 & 3 & 2 & 3 & 1 & 0 & 4 & 18 \\
\hline All green . . . . . . . . . . . & Yellow & 0 & 0 & $\mathbf{0}$ & 0 & $\mathbf{0}$ & 0 & $\mathbf{0}$ & 0 & 0 \\
\hline Totals & & 19 & 65 & 58 & 14 & 20 & 12 & 17 & 23 & 228 \\
\hline
\end{tabular}




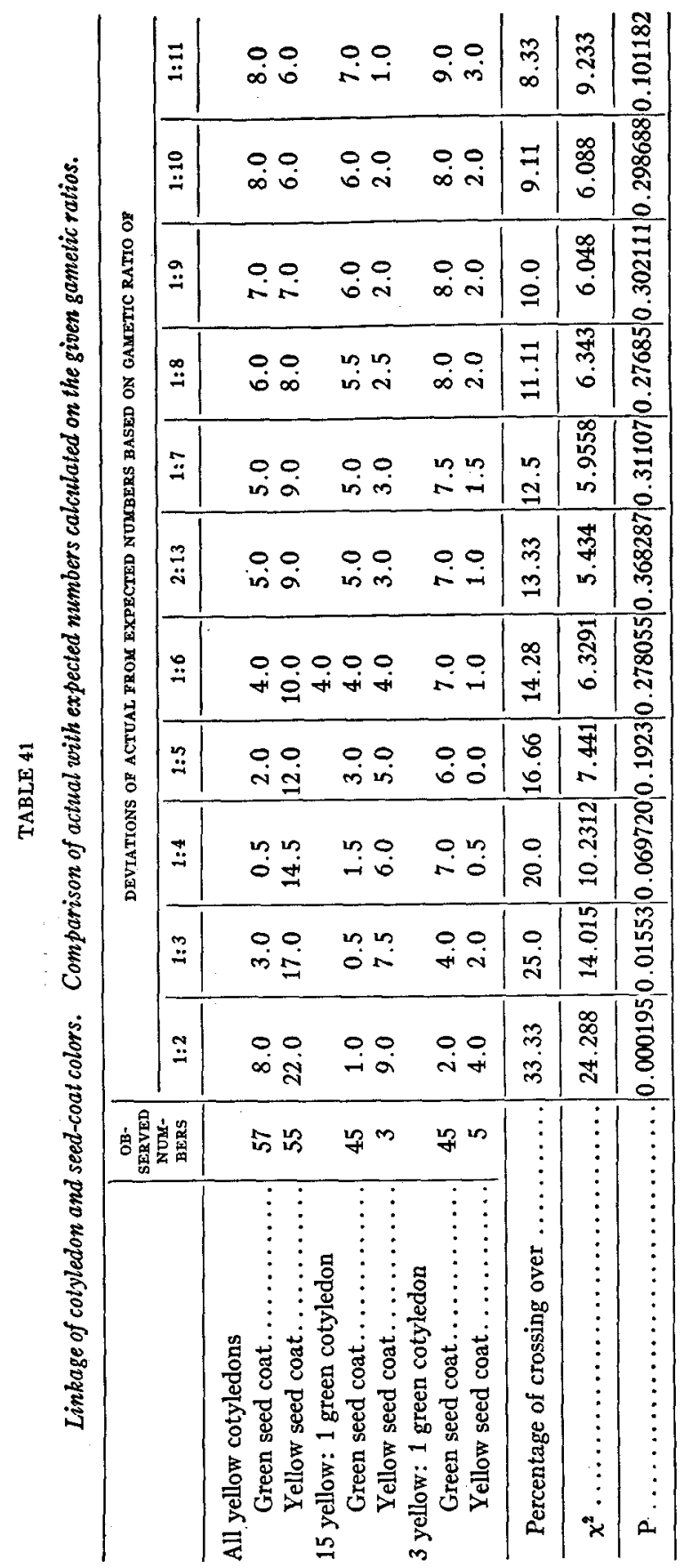


TABLE 42

$F_{2}$ generation with respect to hilum color.

\begin{tabular}{|c|c|c|c|c|c|}
\hline \multirow{2}{*}{ PROGENY NDMBER } & \multicolumn{2}{|c|}{ NUMBER PIANTS OBSERVED WITH } & \multirow{2}{*}{ Dev. } & \multirow{2}{*}{ P.E. } & \multirow{2}{*}{$\frac{\text { Dev. }}{\text { P. E. }}$} \\
\hline & Black hilum & Brown hilum & & & \\
\hline 470 & 10 & 9 & 1 & 1.46 & 0.680 \\
\hline 801 & 40 & 26 & 3 & 2.72 & 1.100 \\
\hline 803 & 35 & 24 & 2 & 2.57 & 0.780 \\
\hline Total. & 85 & 59 & 4 & 4.02 & 0.995 \\
\hline Expected 9:7 & 81 & 63 & & & \\
\hline
\end{tabular}

TABLE 43

$F_{3}$ generation in hilum color. Progenies of $F_{2}$ plants bearing seeds with black hilum.

\begin{tabular}{|c|c|c|c|c|c|c|}
\hline \multirow{2}{*}{ PROGENY NOMAER } & \multicolumn{2}{|c|}{ NUMRBER PLANTS WITH } & \multirow{2}{*}{$\begin{array}{l}\text { DEVIATTON } \\
\text { (Dev.) }\end{array}$} & \multirow{2}{*}{$\begin{array}{l}\text { PROBABLEE } \\
\text { ERROR } \\
\text { (P.E.) }\end{array}$} & \multirow{2}{*}{$\frac{\text { Dev. }}{\text { P.E. }}$} & \multirow{2}{*}{ ACTUAL RATSO } \\
\hline & Black hilum & Brown hilum & & & & \\
\hline $\begin{array}{l}904 \\
910\end{array}$ & $\begin{array}{l}19 \\
14\end{array}$ & ' & & & & \\
\hline Sub-total .... & 33 & & & & & \\
\hline 908 & 8 & 8 & $4^{*}$ & 1.17 & 3.42 & $1.000: 1$ \\
\hline 911 & 7 & 6 & 3 & 1.05 & 2.86 & $1.167: 1$ \\
\hline 916 & 11 & 5 & 1 & 1.17 & 0.94 & $2.200: 1$ \\
\hline 1158 & 28 & 11 & 1 & 1.82 & 0.55 & $2.550: 1$ \\
\hline 1160 & 31 & 4 & 5 & 1.73 & 2.89 & $7.750: 1$ \\
\hline 1161 & 28 & 9 & $\mathbf{0}$ & 1.78 & 0.00 & $3.100: 1$ \\
\hline 1162 & 20 & 9 & 2 & 1.57 & 1.27 & $2.220: 1$ \\
\hline Sub-total ... & 133 & 52 & 6 & 3.97 & 1.51 & $2.560: 1$ \\
\hline 905 & 12 & 8 & $1 \dagger$ & 1.50 & 0.67 & \\
\hline 907 & 7 & 5 & 0 & 1.16 & 0.00 & \\
\hline 912 & 7 & 10 & 3 & 1.38 & 2.17 & \\
\hline 914 & 8 & 11 & 3 & 1.46 & 2.05 & \\
\hline 917 & 14 & 4 & 4 & 1.42 & 2.82 & \\
\hline 1152 & 22 & 15 & 1 & 2.04 & 0.49 & \\
\hline 1154 & 32 & 17 & 4 & 2.34 & 1.28 & \\
\hline 1159 & 19 & 15 & 0 & 1.95 & 0.00 & \\
\hline Sub-total . & 121 & 85 & 6 & 4.80 & 1.25 & \\
\hline
\end{tabular}

* Calculated on basis of 3:1 ratio.

$\uparrow$ Calculated on basis of 9:7 ratio. 
TABLE 44

$F_{4}$ generation in hilum color. Progenies of $F_{3}$ plants bearing seeds with black hilum.

\begin{tabular}{|c|c|c|c|c|c|c|}
\hline \multirow{2}{*}{ PROGENY NUMBER } & \multicolumn{2}{|c|}{$\begin{array}{l}\text { NOMBER PLANTS OBSERVED } \\
\text { WTTH }\end{array}$} & \multirow{2}{*}{$\begin{array}{l}\text { DEVIATION } \\
\text { (Dev.) }\end{array}$} & \multirow{2}{*}{$\begin{array}{c}\text { PROBABLEE } \\
\text { ERROR } \\
\text { (P.E.) }\end{array}$} & \multirow{2}{*}{$\frac{\text { Dev. }}{\text { P.E. }}$} & \multirow{2}{*}{ ACTUAL, RATIO } \\
\hline & Black hilum & Brown hilum & & & & \\
\hline $\begin{array}{l}1244 \\
1247 \\
1248 \\
1251\end{array}$ & $\begin{array}{l}23 \\
24 \\
20 \\
22\end{array}$ & $\begin{array}{l}0 \\
0 \\
0 \\
0\end{array}$ & & & & \\
\hline Sub-total .. & 89 & 0 & & & & \\
\hline $\begin{array}{l}1246 \\
1249 \\
1252\end{array}$ & $\begin{array}{l}18 \\
17 \\
13\end{array}$ & $\begin{array}{l}4 \\
5 \\
6\end{array}$ & $\begin{array}{l}1.5^{*} \\
0.5 \\
1.0\end{array}$ & $\begin{array}{l}1.37 \\
1.37 \\
1.27\end{array}$ & $\begin{array}{l}1.09 \\
3.65 \\
0.79\end{array}$ & $\begin{array}{l}4.50: 1 \\
3.40: 1 \\
2.17: 1\end{array}$ \\
\hline Sub-total ... & 48 & 15 & 1.0 & 2.32 & 0.43 & $3.20: 1$ \\
\hline $\begin{array}{l}1242 \\
1243 \\
1245 \\
1250\end{array}$ & $\begin{array}{r}9 \\
13 \\
10 \\
16\end{array}$ & $\begin{array}{r}12 \\
6 \\
9 \\
6\end{array}$ & $\begin{array}{l}3.0 \dagger \\
2.0 \\
1.0 \\
4.0\end{array}$ & $\begin{array}{l}1.53 \\
1.46 \\
1.46 \\
1.57\end{array}$ & $\begin{array}{l}1.96 \\
1.37 \\
0.68 \\
2.55\end{array}$ & \\
\hline Sub-total .... & 48 & 33 & 2.0 & 3.01 & 0.66 & \\
\hline
\end{tabular}

* Calculated on basis of $3: 1$ ratio.

† Calculated on basis of 9:7 ratio.

TABLE 45

Pubescence color in the $F_{2}$ generation.

\begin{tabular}{|c|c|c|c|c|c|c|}
\hline \multirow{2}{*}{ PROGENY NUMBER } & \multicolumn{2}{|c|}{$\begin{array}{l}\text { NUMBBER PLANTS OBSERVED } \\
\text { WITH }\end{array}$} & \multirow{2}{*}{ Dev. } & \multirow{2}{*}{ P.E. } & \multirow{2}{*}{$\frac{\text { Dev. }}{\text { P.E. }}$} & \multirow{2}{*}{ ACTUAL RATIO } \\
\hline & $\begin{array}{c}\text { Tawny } \\
\text { pubescence }\end{array}$ & $\begin{array}{c}\text { Gray } \\
\text { pubescence }\end{array}$ & & & & \\
\hline 470 & 12 & 7 & 2.0 & 1.27 & 1.58 & $1.710: 1$ \\
\hline 801 & 50 & 16 & 0.5 & 2.37 & 0.21 & $3.130: 1$ \\
\hline 803 & 42 & 17 & 2.0 & 2.24 & 0.89 & $2.470: 1$ \\
\hline Sub-total ... & 104 & 40 & 4.0 & 3.50 & 1.14 & $2.600: 1$ \\
\hline Expected 3:1 & 108 & 36 & & & & \\
\hline
\end{tabular}


TABLE 46

$F_{3}$ generation in pubescence color. Progenies of $F_{2}$ plants with tawny pubescence.

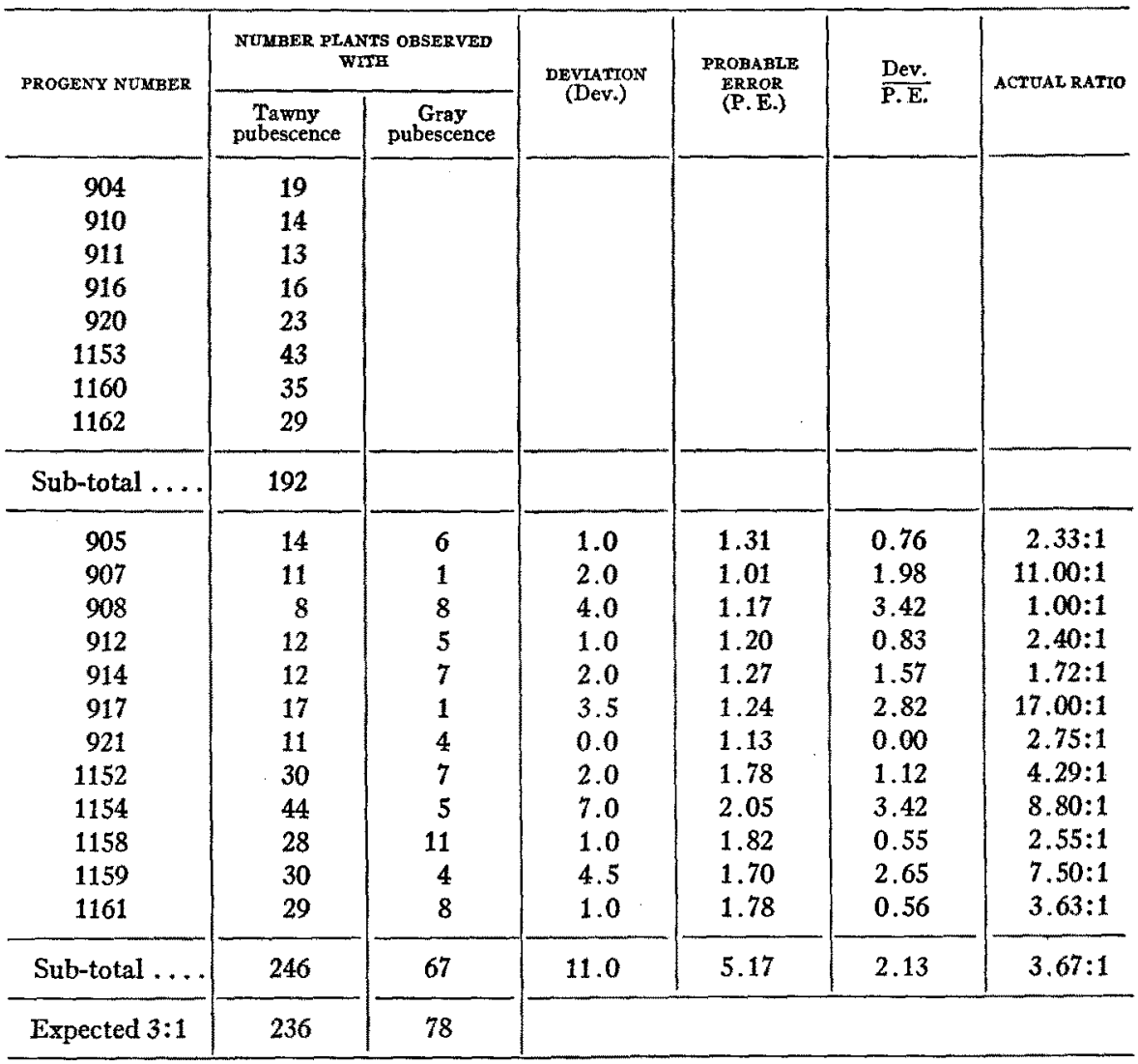

TABLE 47

$F_{4}$ generation in pubescence color. Progenies of tawny plants of (917).

\begin{tabular}{|c|c|c|c|c|c|c|}
\hline \multirow{2}{*}{ PROGENY NUMRER } & \multicolumn{2}{|c|}{$\begin{array}{l}\text { NUMBER PLANTS OBSERVED } \\
\text { WITH }\end{array}$} & \multirow{2}{*}{$\begin{array}{l}\text { DEVIATION } \\
\text { (Dev.) }\end{array}$} & \multirow{2}{*}{$\begin{array}{c}\text { PROBABLE } \\
\text { ERROR } \\
\text { (P.E.) }\end{array}$} & \multirow{2}{*}{$\frac{\text { Dev. }}{\text { P.E. }}$} & \multirow{2}{*}{ ACTUAL RATTO } \\
\hline & Tawny & Gray & & & & \\
\hline 1244 & 23 & 0 & & & & \\
\hline 1247 & 24 & 0 & & & & \\
\hline 1248 & 20 & 0 & & & & \\
\hline 1249 & 22 & 0 & & & & \\
\hline 1251 & 22 & 0 & & & & \\
\hline 1252 & 19 & 0 & & & & \\
\hline Sub-total ... & 130 & 0 & & & & \\
\hline
\end{tabular}


TABLE 47 (Continued)

\begin{tabular}{|c|c|c|c|c|c|c|}
\hline \multirow{2}{*}{ PROGENY NUMB ER } & \multicolumn{2}{|c|}{$\begin{array}{l}\text { NOMBER PLANTS OBSERVED } \\
\text { WITH }\end{array}$} & \multirow{2}{*}{$\begin{array}{l}\text { DEVIATION } \\
\text { (Dev.) }\end{array}$} & \multirow{2}{*}{$\begin{array}{c}\text { PROBABLE } \\
\text { ERROR } \\
\text { (P.E.) }\end{array}$} & \multirow{2}{*}{$\frac{\text { Dev. }}{\text { P. E. }}$} & \multirow{2}{*}{ ACTUAL RATIO } \\
\hline & Tawny & Gray & & & & \\
\hline 1242 & 16 & 5 & 0.0 & 1.34 & 0.00 & $3.20: 1$ \\
\hline 1243 & 15 & 4 & 1.0 & 1.27 & 0.79 & $3.75: 1$ \\
\hline 1245 & 12 & 7 & 2.0 & 1.27 & 1.58 & $1.71: 1$ \\
\hline 1246 & 18 & 4 & 1.5 & 1.37 & 1.09 & $4.50: 1$ \\
\hline 1250 & 19 & 3 & 2.5 & 1.37 & 1.82 & $6.30: 1$ \\
\hline Sub-total .... & 80 & 23 & 3.0 & 2.96 & 1.01 & $3.48: 1$ \\
\hline
\end{tabular}

TABLE 48

$F_{3}$ generation of cross black tawny $\times$ brown gray. Progenies of $F_{2}$ black tawny plants.

\begin{tabular}{|c|c|c|c|c|}
\hline \multirow{2}{*}{ PROGENY NUMBER } & \multicolumn{4}{|c|}{ NUMBER PLANTS OBSERVED } \\
\hline & Black tawny & Black gray. & Brown tawny & Brown gray \\
\hline 904 & 19 & 0 & 0 & 0 \\
\hline 910 & 14 & 0 & 0 & 0 \\
\hline Sub-total ...... & 33 & & & \\
\hline 911 & 7 & 0 & 6 & 0 \\
\hline 916 & 11 & 0 & 5 & 0 \\
\hline 1160 & 31 & 0 & 4 & 0 \\
\hline 1162 & 20 & 0 & 9 & 0 \\
\hline Sub-total...... & 69 & 0 & 24 & 0 \\
\hline Expected 3:1 & 70 & 0 & 23 & 0 \\
\hline 908 & 8 & 0 & 0 & 8 \\
\hline 1158 & 28 & 0 & 0 & 11 \\
\hline 1161 & 29 & 0 & 0 & 8 \\
\hline Sub-total ....... & 65 & 0 & 0 & 27 \\
\hline Expected 3:1 & 69 & 0 & 0 & 23 \\
\hline 905 & 12 & 0 & 2 & 6 \\
\hline 907 & 7 & 0 & 4 & 1 \\
\hline 912 & 7 & 0 & 5 & $\mathbf{5}$ \\
\hline 914 & 8 & 0 & 4 & 7 \\
\hline 917 & 14 & 0 & 3 & 1 \\
\hline 1152 & 22 & 0 & 8 & 7 \\
\hline 1154 & 32 & 0 & 12 & 5 \\
\hline 1159 & 19 & 0 & 11 & 4 \\
\hline Sub-total ...... & 121 & 0 & 49 & 36 \\
\hline Expected 9:3:4 & 116 & 0 & 39 & 51 \\
\hline
\end{tabular}


TABLE 49

$F_{4}$ generation of cross black tawny $\times$ brown gray. Progenies of $F_{3}$ black tawny plants.

\begin{tabular}{|c|c|c|c|c|}
\hline \multirow{2}{*}{ PROGENY NOUMBER } & \multicolumn{4}{|c|}{ NUMBER PLANTS OBSERVED } \\
\hline & Black tawny & Black gray & Brown tawny & Brown gray \\
\hline 1244 & 23 & 0 & 0 & 0 \\
\hline 1247 & 24 & 0 & 0 & 0 \\
\hline 1248 & 20 & 0 & 0 & 0 \\
\hline 1251 & 22 & 0 & 0 & 0 \\
\hline Sub-total ....... & 89 & 0 & 0 & 0 \\
\hline 1249 & 17 & 0 & 5 & 0 \\
\hline 1252 & 13 & 0 & 6 & 0 \\
\hline Sub-total . & 30 & 0 & 11 & 0 \\
\hline 1246 & 18 & 0 & 0 & 4 \\
\hline 1242 & 9 & 0 & 7 & 5 \\
\hline 1243 & 13 & 0 & 2 & 4 \\
\hline 1245 & 10 & 0 & 2 & 7 \\
\hline 1250 & 16 & 0 & 3 & 3 \\
\hline Sub-total ........ & 48 & 0 & 14 & 19 \\
\hline
\end{tabular}

TABLE 50

Showing the independence of cotyledon and pubescence colors in inheritance.

\begin{tabular}{|c|c|c|c|c|c|c|c|c|}
\hline \multirow{2}{*}{ COTYLEON COLOR } & \multirow{2}{*}{$\begin{array}{l}\text { PUBESCENCE } \\
\text { COLOR }\end{array}$} & \multicolumn{5}{|c|}{ PROGENY NUMBERS } & \multirow{2}{*}{ TOTAL } & \multirow{2}{*}{$\begin{array}{c}\text { ExpECTED } \\
\text { ON BASIS } \\
21: 7: 12: 4 \\
12: 4\end{array}$} \\
\hline & & $(470)$ & (801) & $(803)$ & (907) & $(912)$ & & \\
\hline Bred true for yellow & Tawny & 9 & 25 & 22 & 5 & 4 & 65 & 56 \\
\hline Segregated in $15: 1$ ratio & $\begin{array}{l}\text { Tawny } \\
\text { Gray }\end{array}$ & $\begin{array}{l}3 \\
2\end{array}$ & $\begin{array}{r}10 \\
3\end{array}$ & $\begin{array}{l}9 \\
3\end{array}$ & $\begin{array}{l}3 \\
0\end{array}$ & $\begin{array}{l}3 \\
3\end{array}$ & $\begin{array}{l}28 \\
11\end{array}$ & $\begin{array}{l}32 \\
11\end{array}$ \\
\hline Segregated in $3: 1$ ratio & $\begin{array}{l}\text { Tawny } \\
\text { Gray }\end{array}$ & $\begin{array}{l}0 \\
3\end{array}$ & $\begin{array}{r}12 \\
3\end{array}$ & $\begin{array}{l}7 \\
4\end{array}$ & $\begin{array}{l}2 \\
0\end{array}$ & $\begin{array}{l}5 \\
2\end{array}$ & $\begin{array}{l}26 \\
12\end{array}$ & $\begin{array}{l}32 \\
11\end{array}$ \\
\hline \multicolumn{2}{|l|}{ Totals ... } & 18 & 61 & 55 & 11 & 17 & 162 & 162 \\
\hline
\end{tabular}


TABLE 51

Showing the independence of cotyledon and hilum colors in inheritance.

\begin{tabular}{|c|c|c|c|c|c|c|c|c|}
\hline \multirow{2}{*}{ COTYLEDON COLOR } & \multirow{2}{*}{ HILUM COLOR } & \multicolumn{5}{|c|}{ PROGENY NUMBERS } & \multirow{2}{*}{ TOTAL } & \multirow{2}{*}{$\begin{array}{l}\text { EXPECTED } \\
\text { ON BASIS } \\
63: 49: 36: \\
28: 36: 28\end{array}$} \\
\hline & & $(470)$ & (801) & $(803)$ & (907) & (912) & & \\
\hline Bred true for yellow & $\begin{array}{l}\text { Black } \\
\text { Brown }\end{array}$ & $\begin{array}{l}8 \\
2\end{array}$ & $\begin{array}{l}18 \\
15\end{array}$ & $\begin{array}{l}20 \\
12\end{array}$ & $\begin{array}{l}4 \\
2\end{array}$ & $\begin{array}{l}3 \\
1\end{array}$ & $\begin{array}{l}53 \\
32\end{array}$ & $\begin{array}{l}43 \\
33\end{array}$ \\
\hline Segregated in $15: 1$ ratio & $\begin{array}{l}\text { Black } \\
\text { Brown }\end{array}$ & $\begin{array}{l}2 \\
3\end{array}$ & $\begin{array}{r}10 \\
3\end{array}$ & $\begin{array}{l}7 \\
5\end{array}$ & $\begin{array}{l}1 \\
2\end{array}$ & $\begin{array}{l}1 \\
5\end{array}$ & $\begin{array}{l}21 \\
18\end{array}$ & $\begin{array}{l}24 \\
19\end{array}$ \\
\hline Segregated in $3: 1$ ratio & $\begin{array}{l}\text { Black } \\
\text { Brown }\end{array}$ & $\begin{array}{l}0 \\
3\end{array}$ & $\begin{array}{r}10 \\
5\end{array}$ & $\begin{array}{l}6 \\
5\end{array}$ & $\begin{array}{l}2 \\
0\end{array}$ & $\begin{array}{l}3 \\
4\end{array}$ & $\begin{array}{l}21 \\
17\end{array}$ & $\begin{array}{l}24 \\
19\end{array}$ \\
\hline Totals ........... & $\ldots \ldots \ldots$ & 18 & 61 & 55 & 11 & 17 & 162 & 162 \\
\hline
\end{tabular}

TABLE 52

Showing the independence of seed-coat and hilum colors in inheritance.

\begin{tabular}{|c|c|c|c|c|c|c|c|c|c|c|c|}
\hline \multirow{2}{*}{ SEED-COAT COLOR } & \multirow{2}{*}{$\begin{array}{l}\text { HILUM } \\
\text { COLOR }\end{array}$} & \multicolumn{8}{|c|}{ PROGENY NOMBERS } & \multirow{2}{*}{ TOTAL } & \multirow{2}{*}{$\begin{array}{l}\text { EXPECTED } \\
27: 21: 9: 7\end{array}$} \\
\hline & & (470) & (801) & (803) & (907) & (911) & (912) & (916) & $(917)$ & & \\
\hline Green........ & Black & 9 & 28 & 23 & 5 & 6 & 5 & 9 & 11 & 96 & 91 \\
\hline Green........ & Brown & 7 & 19 & 17 & 3 & 3 & 9 & 5 & 2 & 65 & 71 \\
\hline Yellow........ & Black & 1 & 10 . & 12 & 2 & 1 & 2 & 2 & 2 & 32 & 30 \\
\hline Yellow ........ & Brown & 2 & 7 & 5 & 2 & 3 & 1 & 0 & 3 & 23 & 24 \\
\hline \multicolumn{2}{|l|}{ Totals . . . . . } & 19 & 64 & 57 & 12 & 13 & 17 & 16 & 18 & 216 & 216 \\
\hline
\end{tabular}

TABLE 53

Showing the independence of seed-coat and pubescence colors in inheritance.

\begin{tabular}{|c|c|c|c|c|c|c|c|c|c|}
\hline \multirow{2}{*}{ SEED-COAT COLOR } & \multirow{2}{*}{$\mid \begin{array}{c}\text { PUBESCENCE } \\
\text { COLOR }\end{array}$} & \multicolumn{6}{|c|}{ PROGENY NUMBERS } & \multirow{2}{*}{ TOTAL } & \multirow{2}{*}{$\begin{array}{c}\text { EXPECTED } \\
9: 3: 3: 1\end{array}$} \\
\hline & & (470) & (801) & (803) & (907) & (912) & (917) & & \\
\hline Green............ & Tawny & 10 & 34 & 28 & 7 & 9 & 13 & 101 & 105 \\
\hline Green............ & Gray & 6 & 13 & 12 & 1 & 5 & 0 & 37 & 35 \\
\hline Yellow ........... & Tawny & 2 & 14 & 13 & 4 & 3 & 4 & 40 & 35 \\
\hline Yellow........... & Gray & 1 & 3 & 4 & 0 & 0 & 1 & 9 & 12 \\
\hline \multicolumn{2}{|l|}{ Totals } & 19 & 64 & 57 & 12 & 17 & 18 & 187 & 187 \\
\hline
\end{tabular}

